\title{
In the line-up: deleted genes associated with DiGeorge/22q11.2 deletion syndrome: are they all suspects?
}

\author{
Zahra Motahari, Sally Ann Moody, Thomas Michael Maynard and Anthony-Samuel LaMantia*
}

\begin{abstract}
Background: 22q11.2 deletion syndrome (22q11DS), a copy number variation (CNV) disorder, occurs in approximately 1:4000 live births due to a heterozygous microdeletion at position 11.2 (proximal) on the $q$ arm of human chromosome 22 (hChr22) (McDonald-McGinn and Sullivan, Medicine 90:1-18, 2011). This disorder was known as DiGeorge syndrome, Velo-cardio-facial syndrome (VCFS) or conotruncal anomaly face syndrome (CTAF) based upon diagnostic cardiovascular, pharyngeal, and craniofacial anomalies (McDonald-McGinn and Sullivan, Medicine 90:1-18, 2011; Burn et al., J Med Genet 30:822-4, 1993) before this phenotypic spectrum was associated with 22q11.2 CNVs. Subsequently, 22q11.2 deletion emerged as a major genomic lesion associated with vulnerability for several clinically defined behavioral deficits common to a number of neurodevelopmental disorders (Fernandez et al., Principles of Developmental Genetics, 2015; Robin and Shprintzen, J Pediatr 147:90-6, 2005; Schneider et al., Am J Psychiatry 171:627-39, 2014).

Results: The mechanistic relationships between heterozygously deleted 22q11.2 genes and 22q11DS phenotypes are still unknown. We assembled a comprehensive "line-up" of the 36 protein coding loci in the $1.5 \mathrm{Mb}$ minimal critical deleted region on hChr22q11.2, plus 20 protein coding loci in the distal $1.5 \mathrm{Mb}$ that defines the $3 \mathrm{Mb}$ typical 22q11DS deletion. We categorized candidates based upon apparent primary cell biological functions. We analyzed 41 of these genes that encode known proteins to determine whether haploinsufficiency of any single 22 11.2 gene-a one gene to one phenotype correspondence due to heterozygous deletion restricted to that locus - versus complex multigenic interactions can account for single or multiple 22q11DS phenotypes.

Conclusions: Our 22q11.2 functional genomic assessment does not support current theories of single gene haploinsufficiency for one or all 22q11DS phenotypes. Shared molecular functions, convergence on fundamental cell biological processes, and related consequences of individual 22 q11.2 genes point to a matrix of multigenic interactions due to diminished 22q11.2 gene dosage. These interactions target fundamental cellular mechanisms essential for development, maturation, or homeostasis at subsets of 22q11DS phenotypic sites.
\end{abstract}

Keywords: 22q11DS, Neural development, Cognition, Cardiovascular, Craniofacial, Copy number variants, Polygenic

\section{Background}

The frequency of 22q11.2 deletion-the chromosomal/copy number variant $(\mathrm{CNV})$ that results in most cases of DiGeorge/22q11DS [1, 2]-reflects the unusual genomic architecture of human chromosome 22 (hChr22), position q11.2. At least four repetitive DNA "cassettes" known as low copy-number repeats (LCRs): LCR A, B, C, and D;

\footnotetext{
* Correspondence: lamantia@gwu.edu

The Institute for Neuroscience, and Department of Anatomy and Cell

Biology, The George Washington University School of Medicine and Health

Sciences, Washington DC 20037, USA
}

define the region (Fig. 1a) [6]. These LCRs, due to substantial sequence similarity, facilitate non-allelic homologous meiotic recombination, or "deletion by crossing over of repetitive DNA" [7], resulting in unbalanced translocation, deletions, or duplication [8]. More than $85 \%$ of recombination occurs between LCR A and LCR D resulting in a $3 \mathrm{Mb}$ "typical" deletion. The smaller $1.5 \mathrm{Mb}$ "minimal critical" deletion, occurs between LCR A and LCR B in $\sim 10 \%$ of affected individuals $[6,8]$. Deleted individuals have complex and variable phenotypes including developmental delay, congenital heart defects, craniofacial 


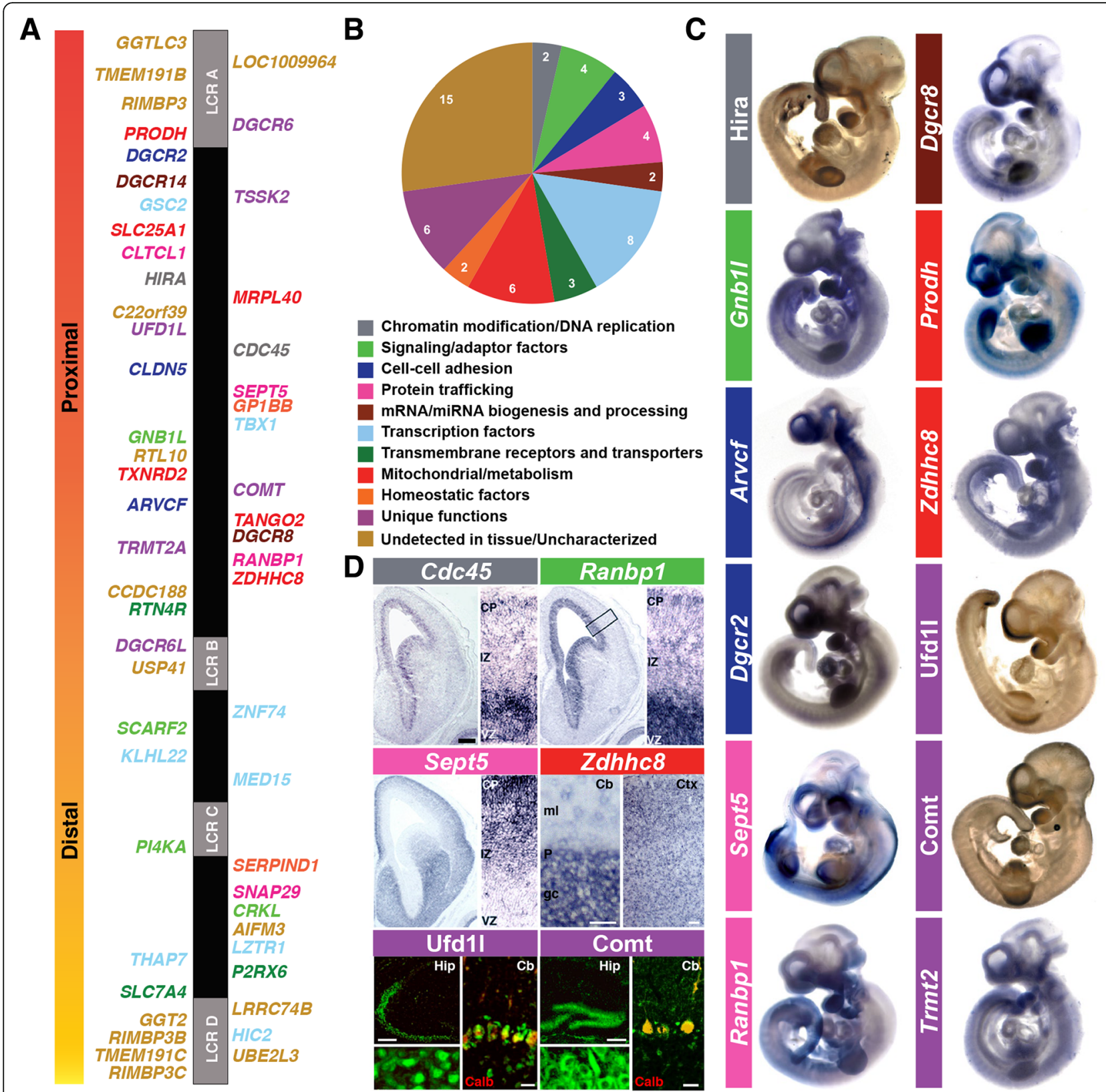

Fig. 1 Genes deleted in 22q11DS. a Schematic of the 22q11.2 region. Low copy repeats (LCRs) are shown as gray boxes: LCR A-D (not to scale). b Protein-coding genes $(n=56)$ are color-coded based on primary, putative, or family member functions as eleven groups. c mRNA (Prodh, Zdhhc8, Sept5, Gnb11, Ranbp1, Dgcr8, Arvcf, Dgcr2, and Trmt2a) or protein (Ufd11, Hira, Comt) expression of selected genes at mouse embryonic stage E10.5 [58, 73, 169]. d Expression localization of Cdc45, Ranbp 1, and Sept5 in the entire cortical hemisphere of E14.5 embryos (left) and in a higher magnification (right) [60]. Expression pattern of Zdhhc8 is shown in the adult cerebellum (left) and the cortex (right) [310]. Immunolocalization of Ufd 11 and Comt proteins in the hippocampus (left) and cerebellum (right) of the adult mouse brain are shown [58]. VZ ventricular zone, IZ intermediate zone, CP cortical plate, gc granular cell layer, $P$ purkinje cell layer, $\mathrm{ml}$ molecular layer, Cb cerebellum, Ctx cortex. Hip hippocampus, Calb calbindin. Scale bars: Cdc45, Ranbp1, Sept5 $=250 \mu \mathrm{m}$, insets $=6.6 \mathrm{x}, Z \mathrm{Zdhhc8}=50 \mu \mathrm{m}$ (left) and $100 \mu \mathrm{m}$ (right). Ufd/Comt: hippocampus (upper left) $=250 \mu \mathrm{m}$, insets (lower left) $=10 x$, cerebellum (right) $=25 \mu \mathrm{m}$

anomalies such as cleft palate and retrognathia, musculoskeletal anomalies, eye anomalies, hearing loss, absent or small thymus and parathyroid glands, hypocalcemia, compromised immune system, feeding difficulties, and seizures. In addition to these physical manifestations, 22q11.2 deletion syndrome (22q11DS) is associated with behavioral and psychiatric complications such as schizophrenia (SCZ) autistic spectrum disorders (ASD), attention deficit hyperactivity disorder (ADHD), anxiety disorder, as well as intellectual and learning disabilities 
[3-5]. Clearly, the range of genomic lesions, numbers of genes, and spectrum of phenotypes that define 22q11 CNV disorders defies straightforward explanations of genotype to phenotype correlations. The essential question remains: how CNVs of one, many, or all 22q11.2 genes disrupts developmental and homeostatic mechanisms and complicates the lives of children and adults with 22q11DS.

Individuals with the A to $\mathbf{B}$ deletion (we use this nomenclature to identify heterozygous elimination of 22q11.2 genes between LCRs A and B) have the full spectrum of phenotypes seen also with the typical A to D deletion (i.e., elimination of genes between LCRs A and D), suggesting that key 22q11DS phenotypes are largely due to diminished A to $\mathbf{B}$ gene dosage [9-11]. Microcephaly and ocular anomalies occur in about $50 \%$ of individuals with $\mathbf{A}$ to $\mathbf{B}$ or $\mathbf{A}$ to $\mathbf{D}$ deletions compared to $7 \%$ in $\mathbf{B}$ to $\mathbf{D}$ or $\mathbf{C}$ to $\mathbf{D}$ deleted individuals, and cardiovascular defects also appear to be $>3$ times more frequent in A to $\mathbf{B}$ or $\mathbf{A}$ to $\mathbf{D}$ deletions [12]. Nevertheless, deletions in distal regions, $\mathbf{B}$ to $\mathbf{D}$ or $\mathbf{C}$ to $\mathbf{D}$, have been associated with cardiac developmental anomalies similar to those associated with A to B or A to D deletions, albeit with lower frequency [13]. Furthermore, the presence and severity of phenotypes among individuals carrying the A to B deletion [14] varies significantly, even in siblings who inherit the same deletion from a 22q11.2-deleted parent [15]. In the context of these complex associations between penetrance and severity, it is unlikely that haploinsufficiency of TBX1 (a 22q11.2 A to $\mathbf{B}$ gene proposed to explain cardiovascular malformation) [16] or any other single 22q11.2 gene, accounts for the broad range of heart defects in 22q11.2-deleted individuals. This suggests that stochastic modifying interactions between genes in the A to $\mathbf{B}$ region, as well as unrecognized modifying functions of $\mathbf{B}$ to $\mathbf{D}$ genes, or convergence of subsets of 22q11.2 deleted genes on specific cellular mechanisms play a role in 22q11DS pathogenesis. We will evaluate this question based upon assessment of apparent obligate cellular function (that disrupted by full loss-of-function) of each of the 41 characterized proteins between LCRs A and D, based upon genetic as well as cell biological analyses in human and diverse model systems or organisms.

Phenotypic variability in 22q11DS extends to behavioral diagnoses associated with the syndrome. Several commonly diagnosed disorders, including ASD, are apparently more frequent in A to $\mathbf{B}$ deleted individuals $[12,17]$. Furthermore, several genes from $\mathbf{A}$ to $\mathbf{D}$ including COMT, PRODH, GNB1L, TBX1, SEPT5/GP1BB, ZDHHC8, PIAKA, and ARVCF have been individually associated with SCZ, ASD, ADHD, and other disorders frequently diagnosed in individuals with 22q11DS [18-20]. Recent population-based exome analysis, however, supports polygenic inheritance of broader, clinically defined behavioral disorders. In ASD, aside from 22q11.2, five additional CNV loci: 1q21.1, 3q29, 7q11.23, 16p11.2, and $15 \mathrm{q} 11.2-13$, as well as multiple de novo gene variants have been identified as risk factors [21]. Similarly, SCZ is associated with multiple, rare loss and gain of function mutations in genes that encode calcium channels, postsynaptic cytoskeleton-associated scaffold proteins, and cell adhesion/signaling molecules [22, 23]. Whole exome sequence analyses in individuals with non-syndromic congenital heart defects also fail to support robust individual gene/phenotype correlations [24]. It is thus unlikely that developmental phenotypes in individuals with 22q11.2 CNVs-including commonly diagnosed behavioral deficits associated with neurodevelopmental disorders-arise from the consequences of altered dosage of one single gene within the A to $\mathbf{D}$ region. Indeed, single gene explanation for individual phenotypes or complete phenotypic spectra are unlikely for most $\mathrm{CNV}$ syndromes, including fairly common deletions and duplications at 7q11.23 (Williams Syndrome), 15q11.2 (Prader-Willi Angelman Syndrome), 16p11.2 (Autism Susceptibility), and even whole or partial chromosomal anomalies like trisomy 21 (Down syndrome). Thus, a reassessment of the known protein coding genes at 22q11.2 between LCRs A and D, and their causal relationship to 22q11DS, based upon a thorough review of molecular and cellular mechanisms through which each gene influences development or ongoing physiological function, is necessary, timely, and may have broader resonance for understanding several dosage-related, $\mathrm{CNV}$-associated multigenic neurodevelopmental syndromes.

\section{Main text}

The 22Q11.2 gene "line-up": diverse genes on hChr 22q11.2 from $A$ to $D$

The genes deleted in 22q11DS are conserved across mammals with only modest rearrangements in the human versus mouse minimal deleted regions $[3,25,26]$. Thus, the mouse has emerged as the most common, accessible, genomically valid model for mammalian 22q11.2 gene function [26]. Drosophila and Caenorhabditis elegans as well as several non-mammalian vertebrates including zebrafish, frog, and chicken also have orthologues of most 22q11.2 genes [3, 25]. There are 154 GenBank entries in the $3 \mathrm{Mb}$ deleted region of hChr22 (LCR A to LCR D; annotation release 108), of which only 56 are predicted to encode proteins: 41 are characterized, while 15 have not been evaluated in any tissue (Additional file 1: Figure. S1). The A to $\mathbf{B}$ deletion includes 36 ( 28 characterized) of the 56 apparent protein-coding loci, and the additional 20 (13 characterized) are found in the $\mathbf{B}$ to $\mathbf{D}$ region. The $\mathbf{A}$ to $\mathbf{D}$ interval also contains seven microRNAs, 38 non-coding 
RNAs, and 53 pseudogenes (Additional file 1: Figure. S1). To better understand the functional and phenotypic consequences of 22q11.2 copy number variation, we divided the $41 \mathrm{~A}$ to $\mathbf{D}$ genes that encode known proteins into ten categories based upon established or inferred primary cellular functions or membership in larger gene families (Fig. 1b). Our criteria included shared functional domains or organelle localization sequences in each of the proteins, common subcellular localization in multiple cell types, and literature reports of apparent obligate functions of each gene. We then re-evaluated available data on specific functions of these protein-coding genes within these categories with a focus on potential contributions to four major 22q11DS phenotypes: heart, face, immune, and brain/behavioral anomalies based upon on the cellular mechanism-based categories.

\section{Chromatin modification/DNA replication genes}

HIRA Histone Cell Cycle Regulator (a.k.a. DGCR1 or TUPLE1; A to B) encodes a histone chaperone responsible for replication-independent chromatin incorporation of histone variant H3.3 [27]. HIRA, conserved across eukaryotes, is implicated in transcriptional silencing [28-33]. Its N-terminal domain also functions as a transcriptional activator marking active genes and enhancers [34-37], and potentially involved in transcriptional elongation and recovery after DNA damage [38, 39]. Post-translational modification of HIRA is crucial for $M y o D$ activation during muscle cell differentiation [40]. HIRA has two nuclear localization domains and seven WD40 repeats for protein-protein interactions [41, 42]. Among potential interactors, HIRA complexes with Pax3 [43], critical for neural, cardiac, craniofacial, thymic, thyroid, and parathyroid development [44]. In Xenopus, hira downregulation impairs gastrulation [45]. In mouse and chicken, Hira is detected in neural ectoderm, premigratory and migratory neural crest, limb buds, pharyngeal arches, and heart (Fig. 1c) [42, 46]. HIRA depletion in chicks increases persistent truncus arteriosus, a key 22q11DS phenotype [47]. Conditional Hira deletion in mouse cardiac myocytes alters gene expression, causes pathology and hypertrophy, but does not perturb cardiac morphogenesis [48]. $\mathrm{Hira}^{-/-}$mice, however, have severe phenotypes including gastrulation and neurulation defects, growth retardation, and aberrant cardiac development leading to embryonic lethality [41]. No phenotypes have been reported in heterozygous embryos, neonates, or adults.

CDC45 Cell Division Cycle 45 (A to B) is required for initiation, elongation, and coordination of eukaryotic chromosomal DNA replication [49-54]. Data from fission yeast, Xenopus egg extracts, and human cells indicate that $\mathrm{CDC} 45$ is a limiting factor for replication initiation [55-57]. Cdc45 is expressed in embryonic brain, pharyngeal arches, thymus and thyroid-where neural crest augments endodermal derivatives (Fig. 1d) [58-60]. Cdc45 $5^{-1-}$ mice have impaired inner cell mass proliferation and die shortly after implantation [61]. Heterozygotes, however, have no apparent phenotypes. Human CDC45 loss-of-function mutations are linked to craniosynostosis (premature cranial suture closure) and Meier-Gorlin Syndrome, a rare autosomal recessive disorder characterized by growth retardation, microcephaly, small ears and jaws, palatal anomalies, hearing, and vision loss [62], which are very similar to 22q11DS phenotypes [4].

\section{Perspective: chromatin modification/DNA replication genes}

Apparently, the chromatin remodeling/DNA replication genes $H I R A$ and $C D C 45$, in the $\mathbf{A}$ to $\mathbf{B}$ region, are necessary for embryonic survival and modulate neural, cardiovascular, and craniofacial development. Loss of function of either gene in mice results in embryonic lethality; however, heterozygotes have no reported anomalies. The appearance of this gene class, chromatin modifiers, in only the A to $\mathbf{B}$ region elevates their status as likely contributors to key 22q11DS phenotypes. Phenotypic severity, however, may depend upon diminished dosage of other A to $\mathbf{B}$ genes since neither Hira nor $\mathrm{Cdc} 45$ heterozygous deletion in mouse yields detectable phenotypes.

\section{Signaling/adaptor factors}

GNB1L G-Protein Subunit Beta (a.k.a. Wdvcf; A to B) encodes a G-protein/WD40 repeat protein of unknown function [63]. It is highly expressed in mouse forebrain, midbrain, and hindbrain (Fig. 1c) [64]. Homozygous mutation is embryonic lethal, and heterozygotes have pre-pulse inhibition (PPI) deficits, a potentially SCZ-related behavioral phenotype in animal models [64].

CRKL Chicken tumor virus number 10 regulator of kinase (B to $\mathbf{D}$ ) encodes an adapter protein with multiple $\mathrm{SH} 2$ and $\mathrm{SH} 3$ protein-protein interaction domains [65]. CRK proteins transmit extracellular signals by physically bridging tyrosine-phosphorylated proteins to mediators like Abl tyrosine kinase and guanine-nucleotide exchange factors (GEFs), to influence cell proliferation, differentiation, migration, adhesion, and immune responses [66]. Crkl binds to both phosphorylated Dab1, a mediator of Reelin signaling, and C3G, a Rap1 GEF, to coordinate neuronal migration by cytoskeletal regulation [67-69]. Crkl is expressed at high levels in pharyngeal arches, neural crest, and brain, and homozygous deletion compromises neural crest derivatives including cranial ganglia, aortic arch arteries, thymus, parathyroid glands, and craniofacial structures, leading to late-gestation lethality [70]. Homozygous loss-of-function in Snoopy, a point Crkl mutation [71], 
also results in craniofacial anomalies, pharyngeal occlusion, and holoprosencephaly. Snoopy or $\mathrm{Crkl}^{+/-}: \mathrm{Tb} \times 1^{+/-}$compound heterozygotes (Tbx1, an A to B gene, see below) have increased retinoic acid (RA) signaling, also seen in mouse embryos with an A to B deletion ( $L g D e l)$ [71-74]. Crkl may interact with other inductive signaling pathways; fibroblast growth factor (FGF) receptors directly bind to the $\mathrm{Ckrl} \mathrm{SH2}$ domain [75]. In 22q11DS, diminished CRKL dosage due to $\mathbf{B}$ to $\mathbf{D}$ deletion is associated with impaired $\mathrm{T}$ cell and natural killer cell function $[76,77]$, consistent with CRKL regulation of immune cells [78-80].

SCARF2 Scavenger Receptor Class F Member 2 (a.k.a. $S R E C-I I$; $\mathbf{B}$ to $\mathbf{D})$ encodes a $\mathrm{Ca}^{++}$binding protein that interacts with small molecule ligands such as acetylated low-density lipoprotein (Ac-LDL) [81]. The SCARF2 extracellular domain has multiple epidermal growth factor (EGF)-like repeats and several positively charged residues. Its intracellular domain contains 13 potential phosphorylation sites suggesting a role in cell signaling [81]. Scarf2 is expressed in neonatal and adult mouse skin, tongue, oral epithelia, and medullary thymus [82]. Its obligate functions in the developing or adult mouse remain unclear; there are no reports of Scarf2 mutations. SCARF2 mutations have been linked to Van Den Ende-Gupta syndrome, an extremely rare autosomal recessive disorder characterized by craniofacial anomalies: narrow eye openings, maxillary hypoplasia, flat/wide nasal bridge, everted lower lip, palatal disruptions, prominent ears, skeletal anomalies: scoliosis, long, slender foot and hand bones, mild bowing of long bones, respiratory difficulty due to laryngeal deficits, and cerebellar hyperplasia [83-85]. These overlap with phenotypes seen in 22q11DS [4].

PI4KA Phosphatidylinositol 4-Kinase Alpha (a.k.a. PI4KIII $\alpha$; B to D) catalyzes synthesis of phosphatidylinositol 4-phosphate (PtdIns4P), an essential precursor of PtdIns $(4,5) \quad P 2$ and PtdIns $(3,4,5) \quad P 3$ that mediate receptor-activated phospholipase $\mathrm{C}$ (PLC) and phosphoinositide 3-kinase (PI3) signaling [86]. The yeast PI4KA orthologue, STT4, is required for cell wall integrity and actin cytoskeleton organization [87]. PI4KA is found in endoplasmic reticulum (ER), nucleoli, and pericentriolar regions, coincident with the Golgi complex [88-90]. Membrane proteins TTC7 and EFR3 recruit PI4KA to the plasma membrane to help maintain protein and lipid composition [91, 92]. In zebrafish, pi4ka loss-of-function disrupts brain, heart, and trunk development perhaps due to impaired FGF signaling [93]. PI4KA is expressed in fetal and adult rodent and human brain [94, 95]. Conditional Pi4ka inactivation causes lethal gastrointestinal mucosal degeneration, but no obvious neural anomalies [96, 97]. Biallelic PI4KA mutation, however, is associated with cerebellar hypoplasia and polymicrogyria [98]. PI4KA is also recognized as a SCZ-susceptibility gene in adults with 22q11DS $[19,99]$.

\section{Perspective: signalling/adaptor genes}

The A to B signaling/adaptor gene, GNB1L, may contribute to 22q11DS phenotypes, especially in the brain based upon behavioral evidence; however, current data are inconclusive. The $\mathbf{B}$ to $\mathbf{D}$ signaling/adaptor genes, $C K R L, S C A R F 2$, and PI4KA, may modulate craniofacial, cardiac, or cerebral cortical differentiation. Thus, while heterozygous CRKL, SCARF2, or PIAKA deletion may not be necessary for core 22q11DS phenotypes, diminished dosage of one or more of these genes in individuals with the A to D deletion may enhance heart, face, or brain phenotypes, yielding more severe impairments or introducing greater phenotypic variation.

\section{Cell-cell adhesion genes}

ARVCF Armadillo Repeat Gene Deleted in Velo-cardio-facial syndrome (A to $\mathbf{B}$ ) is a member of the Catenin family, which includes $\alpha$ - and $\beta$-catenin, plakoglobin, and p120-related proteins $[100,101]$. Catenins are critical for adherens junction assembly to facilitate extracellular and intracellular communication. ARVCF protein contains an $\mathrm{N}$-terminus coiled-coil domain, 10 armadillo repeats, and a C-terminal PDZ motif that binds the scaffold protein ERBIN and tight junction proteins ZO-1 and ZO-2 [102-104]. When bound, ARVCF enhances the stability of classical cadherins by reducing their endocytosis $[105,106]$. When not bound to cadherin, ARVCF may regulate the cytoskeleton by interacting with small-GTPases such as Rho and Rac [107, 108]. Like most catenins, ARVCF also translocates to the nucleus where it may be involved in alternative mRNA splicing [109, 110]. ARVCF is expressed in the human forebrain ganglionic eminences; mouse Arvcf is expressed in the brainstem, hippocampus, cerebral cortex, and heart (Fig. 1c) [58, 111]. Arvcf depletion in Xenopus leads to defects in craniofacial skeleton and aortic arches (also observed in Tbx1-deficient tadpoles; see below) [112, 113]. The migration of cranial neural crest is not affected by knocking down of either arvcf or tbx1; however, their double depletion causes delayed migration suggesting these genes act cooperatively [113]. There are no reported loss-of-function Arvcf alleles; however, loss of function of p120 catenin results in substantially diminished embryonic Arvcf expression, in concert with disrupted renal differentiation [114]. ARVCF mutations and their related phenotypes do not include structural brain anomalies; however, they have been associated with increased susceptibility to $\operatorname{SCZ}[115,116]$.

CLDN5 Claudin5, (a.k.a. TMVCF; $\mathbf{A}$ to $\mathbf{B}$ ) is a member of the Claudin family, major structural components of tight junctions that are crucial for cell-cell contacts and 
paracellular permeability, and establishing apical to basolateral intra-membrane borders [117-119]. Cytokines, growth factors, and cadherins regulate claudins [120, 121]. All family members have similar predicted folding and high sequence homology in the first and fourth transmembrane domains and extracellular loops [118], and a C terminus PDZ motif that binds to PDZ peripheral membrane proteins, including ZO-1, -2 , and -3 , which in turn interact with the actin cytoskeleton to link tight junctions with signal transduction proteins [122, 123]. Cldn5 is expressed ubiquitously [124, 125]. In Xenopus, cldn5 is strongly expressed in cardiac primordia and its depletion leads to heart malformations [126] and in zebrafish, cldn5 is required for heart regeneration [127]. $\mathrm{Cldn} 5^{-/-}$mice, however, do not have cardiovascular malformations. Nevertheless, Cldn5 may modify cardiovascular development via interactions with additional myogenic genes $[128,129]$. In the Dystrophin ${ }^{-/-}$(Dmd1)/Utrophin ${ }^{-1-}$ (Utrn) cardiomyopathy model, Cldn 5 mRNA and protein levels decline [129]; in contrast, Cldn5 overexpression di-

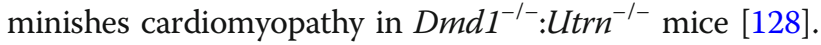
$\mathrm{Cldn} 5$ also is expressed in cerebral microvascular endothelial cells, perhaps regulating blood-brain barrier permeability $[124,130]$. Cldn $5^{-1-}$ mice develop normally but die shortly after birth [130]. There is no evidence for disrupted tight junction structure; however, small molecule paracellular permeability increases selectively in the mutant brain suggesting that lack of Cldn 5 alters junctional function [130]. CLDN5 is reduced in human end-stage cardiomyopathy $[131,132]$. In addition, CLDN5 is implicated in stem cell self-renewal. ZO-1, CLDN1, CLDN3, and CLDN5 are highly expressed in human neural stem cells, but significantly down-regulated during neuronal differentiation [133].

DGCR2 DiGeorge Syndrome Critical Region Gene 2 (a.k.a. SEZ12; A to B) encodes a novel putative transmembrane adhesion receptor [134] expressed in the developing and adult mouse brain (Fig. 1c) [58]. Recent studies support a role for Dgcr2 in cortical projection neuron migration and differentiation, apparently as part of a complex that regulates Reelin-dependent phosphorylation of Dab1, Akt, Erk1/2 and subsequent signaling targets [135]. Dgcr2 deficient mice have gait abnormalities, reduced movement, and impaired motor coordination possibly due to loss of cerebellar Purkinje cells [136]. Finally, a DGCR2 missense mutation has been associated with non-syndromic SCZ [137], reinforcing a potential contribution to neural development or function.

\section{Perspective: cell-cell adhesion genes}

The A to B cell-cell adhesion genes, $A R V C F$ and $C L D N 5$, belong to key junctional complex gene families: catenin/ cadherins and claudin/ZO-1, respectively. Based upon their A to B location and essential roles in adhesion, cell-cell interactions, morphogenesis, and maintenance of tissue integrity-all compromised in 22q11DS-they are likely, but as yet minimally investigated suspects for core phenotypes. Their fundamental functions assessed in vitro or by genetic manipulation in frog, zebrafish, and mouse are consistent with contributions to cardiac and neural anomalies. DGCR2, a proposed A to B SCZ vulnerability gene, is an apparent adhesion receptor involved in cortical neuronal migration. Diminished dosage of $\mathbf{A}$ to $\mathbf{B}$ adhesion genes may converge on broader signaling networks at 22q11DS phenotypic sites, or each gene may independently compromise development, differentiation, or adult function. Given the morphogenetic consequences of disrupted adhesion, the contributions of $\mathbf{A}$ to $\mathbf{B}$ cell adhesion gene dosage in 22q11DS pathogenesis merit additional genetic and functional analysis.

\section{Protein trafficking}

SEPT5 Septin 5 (a.k.a. CDCREL1 or PNUTL1; A to B) is a member of the highly conserved Septin family of GTP-binding proteins that act as dynamic, multifunctional protein scaffolds. First discovered as essential for cytokinesis in yeast, Septins are found in most eukaryotes except plants [138, 139]. They are found in protein complexes that regulate membrane dynamics, vesicle trafficking, cell cycle, cytokinesis, cytoskeletal reorganization, cell polarity, oncogenesis, and apoptosis [140]. SEPT5, expressed predominantly in neurons, was first isolated as a constituent of a synaptophysin-associated synaptic vesicle protein complex (Fig. 1c, d) [141, 142]. It localizes to presynaptic terminals, interacts with the SNARE protein Syntaxin, and negatively regulates exocytosis and neurotransmitter release [141, 143, 144]. Moreover, in mouse, Sept5 in the auditory calices of Held regulates the coupling of $\mathrm{Ca}^{++}$influx to presynaptic neurotransmitter release, and its overexpression inhibits dopamine release in transfected neurons in vitro $[145,146]$. Nevertheless, synaptic transmission is not disrupted in $\mathrm{Sept5}^{-/-}$or Sept $3^{-/-} /$Sept $5^{-1-}$ mice, suggesting compensation by other family members [147, 148]. In mouse and rat, altered Sept 5 levels are linked to defective social interactions and cognitive impairment [149-152]. In addition, homozygous deletion of SEPT5 and the adjacent GP1BB has been associated with cortical dysplasia with polymicrogyria, developmental delay, platelet secretion defects, social/emotional, and language/speech deficits [153].

CLTCL1 Clathrin Heavy Chain Like 1 (a.k.a. CHC22; A to $\mathbf{B}$ ) is a member of the CLATHRIN gene family crucial for intracellular endosome trafficking [154, 155]. Its potential function has been difficult to assess-it does not have a murine orthologue [156]. CLTCL1 is expressed in all cell types; however, levels differ between tissues and developmental stages $[157,158]$. It is expressed maximally 
during human prenatal brain development and declines significantly by early childhood-correlated with critical periods for neural circuit differentiation [159]. CLTCL1 homozygous missense mutations are associated with a recessive disorder characterized by touch and pain insensitivity and severe intellectual disability [159]. In a human neural crest-derived cell line-relevant because nociceptive (pain) neurons are derived from the neural crest [160]-CLTCL1 downregulation induces neuronal differentiation and facilitates RA-mediated neurite outgrowth [159]. CLTCL1 is highly expressed in skeletal muscle where it modulates glucose transporter 4 intracellular trafficking [157], myogenesis, and repair [161, 162]. Neuronal and myogenic activities implicate CLTCL1 as a candidate for $22 \mathrm{q} 11 \mathrm{DS}$ dosage-dependent phenotypes. The lack of an animal model to test hypotheses of organismal function complicates further assessment of CLTCL1's potential contributions to the 22q11DS phenotypic spectrum.

RANBP1 RAN Binding Protein 1 (A to $\mathbf{B}$ ) regulates the multi-protein "RAN complex" $[163,164]$. The Ran complex includes the small $G$ protein Ran, which when bound to GDP scaffolds other proteins including importins $(I \alpha / \beta)$ that bind nuclear transport cargos (Fig. 2a). In the nucleus, the guanine exchange factor RCC1 replaces GDP bound to RAN with GTP, establishing new exportin (Xpo1) complexes that scaffold outgoing cargo. RANBP1 binds to the RAN complex as cargos exit the nucleus, displacing and releasing them into the cytoplasm and facilitating RanGAP GTPase activity [165]. RANBP1 also modulates mitotic spindle formation [166], nuclear envelope disassembly/reassembly [167], and primary cilia protein trafficking [168]. Ranbp1 is expressed in neural crest and neocortical ventricular precursors at mid-gestation (Fig. 1c, d) $[169,170]$. Ranbp1 $1^{-/-}$mice are not viable [170]. Over $50 \%$ of these embryos are exencephalic. Non-exencephalic homozygotes are smaller than WT littermates (Fig. 2b) with craniofacial and ocular anomalies (Fig. 2c). Ranbp1 remains highly expressed in cerebral cortical ventricular and subventricular proliferative zones [58, 60, 170]. Non-exencephalic Ranbp1 ${ }^{-/-}$ fetuses are microcephalic (Fig. 2c) with diminished cortical thickness (Fig. 2d, e). RANBP1 haploinsufficiency has not been linked to single 22q11DS phenotypes; polymorphisms are associated with SCZ-related eye tracking anomalies [171] and reduced cortical expression is linked to disrupted metabotropic glutamate receptor signaling in ASD [172].

SNAP29 Synaptosome Associated Protein $29 k D a$ (B to D) belongs to the SNAP25 gene family encoding T-SNAREs that mediate vesicle/target membrane fusion [173]. SNAP29 co-localizes with endosomes, lysosomes, and Golgi in non-neuronal cells and influences protein trafficking, endocytosis, exocytosis, and phagocytosis
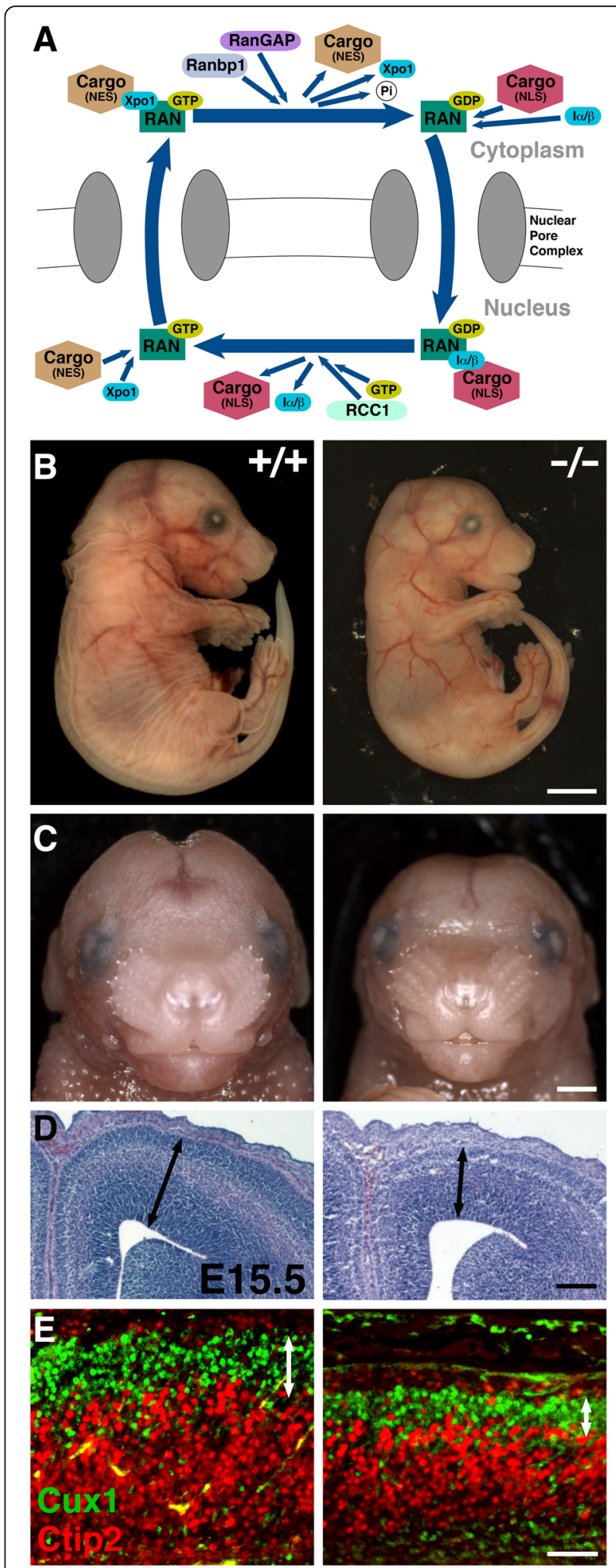
(See figure on previous page.)

Fig. 2 Ranbp1: function, craniofacial and neural phenotypes. a In the nucleus, the exportin (Xpo1) binds the cargo tagged with nuclear export signals (NES) and Ran-GTP and diffuses through the pore to the cytoplasm. Once in the cytoplasm, Ranbp1 along with RanGAPs that hydrolyze Ran-GTP into Ran-GDP dissociate the complex and release the transported macromolecule. In the cytoplasm, importin-a/ $\beta$ heterodimer forms a complex with cytoplasmic cargos tagged with a nuclear localization sequence (NLS) and Ran-GDP and transports them into the nucleus. Inside the nucleus, the high concentration of Ran-GTP rapidly binds to importin- $\beta$ to dissociate the complex, releasing the transported cargos, followed by recycling of the importins back to the cytoplasm. RCC (a guanine nucleotide exchange factor) stimulates Ran-GDP to release its GDP and pick up GTP [164]. b, c Examination of E17.5 embryos shows that Ranbp $1^{-/-}$embryos have visible abnormalities including a smaller and shorter head with a narrower face. $\mathbf{d}$ Coronal sections show a distinctive smaller, thinner cortex in E15.5 Ranbp 1/- $^{-/}$embryos. e Layer 2/3 projection

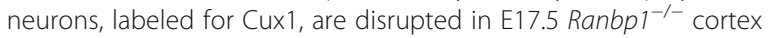
[170]. Cux1 and Ctip2 labels subsets of upper- and lower-layer projection neurons, respectively. Scale bars: $\mathbf{b}=250 \mu \mathrm{m}, \mathbf{c}=100 \mu \mathrm{m}$, $\mathbf{d}=25 \mu \mathrm{m}, \mathbf{e}=50 \mu \mathrm{m}$

[174-178]. Synaptic SNAP29 modulates neurotransmitter release by inhibiting SNARE complex disassembly $[179,180]$. Snap29 also interacts with GTPase Rab3A in myelinating glia and is implicated in surface-directed myelin proteolipid protein trafficking [181]. SNAP29 loss-of-function, independent of 22q11DS, is linked to CEDNIK: Cerebral Dysgenesis, Neuropathy, Ichthyosis, and Keratoderma [182, 183], characterized by psychomotor retardation, thick, scaly skin, facial anomalies, sensorineural deafness, microcephaly, corpus callosum dysgenesis, and cortical dysplasia. Parallel brain and epidermal phenotypes in constitutive and conditional Snap $2^{-/-}$mice [184] reinforces its potentially causal role in CEDNIK. Its contributions to 22q11DS phenotypes in typically deleted individuals (A to $\mathbf{D})$, however, remain unanalyzed.

\section{Perspective: protein trafficking genes}

Disrupted protein trafficking due to diminished 22q11.2 gene dosage could have significant effects on signaling during development, differentiation, or in the mature nervous system and other 22q11DS phenotypic sites. CLCTL1, RANBP1 (A to B), and SNAP29 (B to D) are required for early brain development; $\operatorname{SEPT5}$ (A to $\mathbf{B}$ ) is not. Instead, in mice, Sept 5 may modulate circuit development or neuronal signaling for cognitive and social behaviors. Evidence for Ranbp1-dependent regulation of neural and craniofacial differentiation is fairly strong. It is unclear, however, how diminished RANBP1 dosage interacts with other $\mathbf{A}$ to $\mathbf{B}$ or $\mathbf{B}$ to $\mathbf{D}$ genes to yield 22q11DS phenotypes. SNAP29 may modulate A to B dependent craniofacial development due to its activity in neural crest, or dosage sensitivity in non-neural crest cells that contribute to facial structures.
Accordingly, based upon obligate and disease-related functions, SNAP29 may act as a modifier for some 22q11DS phenotypes.

\section{mRNA/miRNA biogenesis and processing genes}

DGCR14 DiGeorge Critical Region Gene 14 (a.k.a. ESS2 or DGSI; A to B) encodes a nuclear protein with two N-terminal coiled-coil domains [185] and is conserved across eukaryotes from yeast to human [186-189]. In mice, $\operatorname{Dgcr} 14$ is expressed in the pharyngeal arches and neural tube [186]. Despite its expression at key sites, the consequences of loss-of-function mutations in this gene have not been reported in mice or any other model species. Dgcr14 expression has been assessed in the context of loss of function of another A to B gene, Gsc2 (see below), whose expression is limited to the interpeduncular nucleus (IPN) - a brain region that modulates dopaminergic neurotransmission, sleep, and eye movement. Dgcr14 expression, also enhanced in the IPN, is diminished following Gsc2 deletion [190]. The significance of this observation for Dgcr14 function or that of Gsc2 in the IPN, however, remains unexplored. A recent large-scale protein interactome study identified DGCR14 as a non-core component of the spliceosome C complex, suggesting a role in mRNA processing [191-193]. Indeed, Dgcr 14 apparently regulates $I L 17 a$ transcription during TH17 cell differentiation in vitro [194], perhaps relevant for immune dysfunction in 22q11DS. In human, DGCR14 is expressed in the heart, brain, and skeletal muscle [195]. The exact function of DGCR14 in human development or mature function, however, remains uncertain.

DGCR8 DiGeorge Critical Region Gene 8 (a.k.a. Pasha; A to B) encodes a heme-binding protein known as Pasha in flies and nematodes [196]. DGCR8 is localized to the nucleus as part of the Drosha/RNaseIII microprocessor complex that processes primary microRNAs (pri-miRNA) into precursor miRNA (pre-miRNA) in the first step of miRNA maturation [196, 197]. DGCR8 also has a microprocessor-independent role in small nucleolar RNAs (snoRNAs) and telomerase RNAs biogenesis [198]. DGCR8 is required for normal development of the nervous system [199, 200]. In Drosophila, pasha influences dendrite targeting and axon terminal arborization [201, 202]. In mice, Dgcr8 is highly expressed in the brain (Fig. 1c) and loss-of-function results in pre-implantation lethality [200]. Dgcr8 heterozygous deletion, however, results in working memory deficits and impaired short-term synaptic plasticity due to defective dendritic spines and complexity [200, 203]. Furthermore, $\operatorname{Dgcr} 8$ targeted deletion in pyramidal neurons alters synaptic transmission [204, 205]. Dgcr8 deficiency also has been suggested to underlie aberrant cortical interneuron migration caused by disrupted Cxcr4/Cxcl12 signaling [206, 207]. DGCR8 may modulate gene expression underlying establishment and maintenance of peripheral 
myelination [208]. Targeted Dgcr8 loss-of-function in cardiac neural crest leads to persistent truncus arteriosus, ventricular septal defects [209], cardiomyocyte-related cardiomyopathy, and premature lethality [210].

\section{Perspective: mRNA/miRNA biogenesis and processing genes}

The A to B location of miRNA biogenesis 22q11.2 genes DGCR14 and DGCR8, acknowledged functional importance of this miRNA regulation of development and homeostasis, and requirement for DGCR14 and DGCR8 for nervous system and heart development establishes these two genes as prime suspects for understanding 22q11DS phenotypes and their variability. A circumstantial case can be made for DGCR14 function in the nervous and immune systems; however, there is still surprisingly little known about indispensable functions of this gene. The contributions of DGCR8 to 22q11DS are beyond doubt. Nevertheless, Dgcr8 heterozygous phenotypes and those of mice with full deletion of the $\mathbf{A}$ to $\mathbf{B}$ orthologue are not identical [26]. Thus, key DGCR8 functions remain to be explored further in the context of diminished dosage of additional 22q11.2 A to B as well as $\mathbf{B}$ to $\mathbf{D}$ genes.

\section{Transcription factors}

$T B X 1$ (A to B) is a member of the "T-box" family of transcription factors. Although $T B X 1$ is neither a strong transcriptional activator nor a strong repressor, it regulates a large number of genes through epigenetic modifications [211]. Tbx1 is expressed in pharyngeal arch endoderm and mesoderm, an expression pattern conserved in mice, chickens, Xenopus, and zebrafish [212-214]. A great deal of insight-and speculation-has arisen from analyses of
Tbx1 loss-and gain-of-function mutants in a variety of model species. In zebrafish, the $t b x 1$ loss-of-function van gogh mutation results in ear, thymus, and pharyngeal arch defects [214]. In Xenopus, its loss-of-function disrupts head, pharyngeal apparatus, and heart development [212, 215]. Tbx1 heterozygous mutant mice have mild non-lethal phenotypes; homozygous null mutants, however, die at birth with cardiac outflow tract anomalies, craniofacial defects, cleft palate, and severe thymus and parathyroid abnormalities [216-218]. In mouse models, the narrowing (stenosis) of the fourth pharyngeal arch artery that develops into the central portion of the aortic arch is the most prominent cardiovascular phenotype (Fig. 3a-c) [74]. Complete $T b x 1$ inactivation in pharyngeal endoderm is sufficient to cause a phenotype identical to the Tbx1 null mutants [219]. Part of the cardiovascular defect in $T b x 1^{-/-}$mice reflects failed cardiac neural crest migration into the pharyngeal arches and heart where the crest produces signals such as RA that pattern heart structures [220]. $T b x 1$ in the otic vesicle is required for inner ear development, and also is essential for face and limb myoblast differentiation [213, 221-223]. FGF signaling apparently influences $T b x 1$ function for pharyngeal arch derivatives [224]. Tbx1 heterozygosity is partially responsible for cranial nerve dysmorphology in the $L g D e l$ model of 22q11DS (Fig. 3d-g) [74]. Tbx1 heterozygotes have a significantly higher frequency of fusions and anastomoses between the glossopharyngeal (IX) and vagus (X) cranial nerves than WT embryos (Fig. 3e, f) [74]. This frequency is equivalent to that in $L g D e l$ embryos (Fig. 3d); however, Tbx1 mutants do not display the RA-sensitive LgDel trigeminal nerve (V) phenotype [74]. TBX1 heterozygous mono-allelic mutations have been associated with

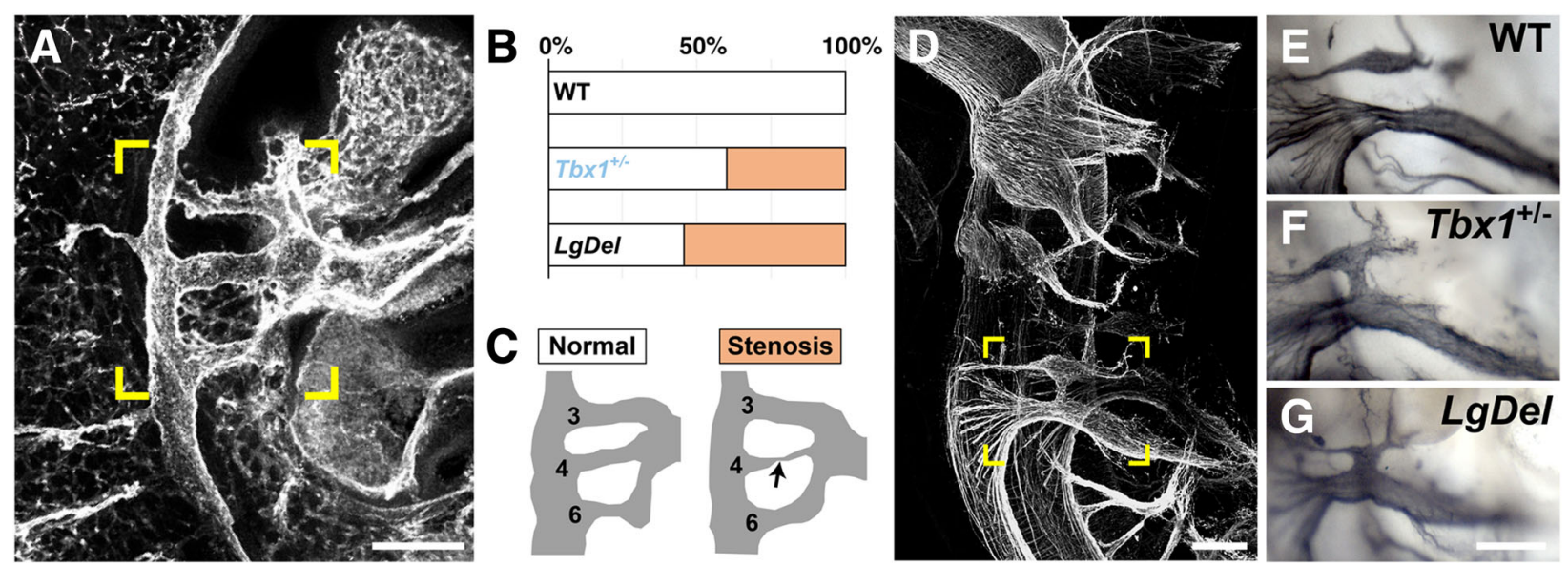

Fig. $3 \mathrm{~Tb} \times 1$ : heart and cranial nerve phenotypes. a The heart and pharyngeal arch arteries in an E10.5 WT embryo, stained for the cell-adhesion molecule PECAM/CD31 and imaged whole. b The graph indicates the \% stenosis in WT, Tbx ${ }^{+/-}$, and $\mathrm{LgDel}$ embryos [73]. c A schematic the arch vasculature is provided for clarity. $\mathbf{d}$ Lateral view of neurofilament labeled E10.5 cranial nerves in a Tbx $1^{+/-}$embryo (CNs). e, f The ganglia of CNIX and CNX are more frequently fused or connected by axon fascicles in Tbx $1^{+/-}$than WT littermates. $\mathbf{g}$ CNIX/X fusion is observed at similar frequency in LgDel embryos [74]. Scale bars: $200 \mu \mathrm{m}$ 
conotruncal anomaly face syndrome, thymic hypotrophy, parathyroid dysfunction, and deafness in a small sample of individuals without broader 22q11.2 deletion, providing a further suggestion of a key role in individuals with broader 22q11.2 deletion [225]. Finally, heterozygous Tbx1 mutation, like Gnb1l (an A to B protein trafficking gene; see above), reduces PPI in mice, indicating possible involvement in behavioral disorders [64]. This phenotypic equivalence, however, raises additional questions regarding the specificity of the PPI assay as well as a singular role for Tbx1 (or Gnb1l) in complex phenotypes, either in 22q11DS, or a wide range of animal models.

GSC2 Goosecoid Homeobox 2 (a.k.a. Goosecoid-like, GSCL; A to B) encodes a homeodomain-containing protein [226]. It is related to the homeobox gene, Goosecoid, which is required for craniofacial and rib development in mice [227]. Mouse Gsc2 is expressed in the neural tube and pharyngeal arches during neural crest migration and differentiation [228]. Nevertheless, homozygous Gsc2 mutant mice are viable with no obvious developmental anomalies [229]. As mentioned above, Gsc2 expression in the mature nervous system is restricted to the midbrain interpeduncular nucleus (IPN), implicated in dopaminergic modulation, sleep, and rapid eye movements. Despite this restricted expression, IPN-related phenotypes have not been reported in $G s c 2^{-/-}$mice, except for loss of expression of an additional 22q11.2 A to B gene, the miRNA biogenesis factor D $g \mathrm{cr} 14$ (see above) [190].

MED15 Mediator Complex Subunit 15 (a.k.a. ARC105; B to D) encodes a subunit of the mediator complex, a cofactor for RNA Polymerase II-dependent transcription. MED15 acts within the pre-initiation complex, which consists of MED15, POLII, TFIIA, TFIIB, TFIID, TFIIE, TFIIF, and TFIIH, and is considered a global regulator of gene expression [230, 231]. Mediator complex genes encode up to 30 subunits in some eukaryotes [231], and have limited homology between species. The MED15 subunit was initially identified based upon homology with Gal11, an essential transcriptional regulator of galactose metabolism in yeast [232], in which it may also function as a regulator of lipid homeostasis [233]. The C. elegans MED15 homo$\log , m d t-15$ is required for fatty acid metabolism via transcription of genes that modulate desaturation of stearic to oleic acid [234]. Mdt-15 deficient worms move abnormally, are sterile, are more sensitive to stress, have disrupted ER homeostasis, and shortened life spans [234-236]. In Drosophila, med15 is required for the transcription of decapentaplegic ( $d p p$, homolog of vertebrate bone morphogenetic proteins (BMPs)) target genes [237]. The Xenopus MED15 homolog, arc105, similarly regulates transforming growth factor beta (TGFß)/Activin/Nodal/Smad2/3 target gene expression [238]. MED15 function during mammalian development, however, remains elusive-there are no reported mouse mutants, nor are there any clinically described MED15 mutations, independent of heterozygous 22q11.2 A to D deletion, in humans.

KLHL22 Kelch Like Family Member 22 (B to D) encodes a member of the Bric-a-brac-Tramtrack-Broad complex (BTB)-Kelch transcription factor family that is conserved from Drosophila to humans [239, 240]. The BTB-Kelch proteins contain a BTB/POZ domain, a BACK domain, and five to seven Kelch motifs [239]. The BTB domains facilitate protein binding and have multiple cellular roles including recruitment of E3 ubiquitin ligase complex [241-243]. Kelch domains form a $\beta$-propeller structure that, at least in some cases, interacts with actin and intermediate filaments and is involved in cytoskeleton organization $[239,244]$. The BACK domain is a conserved motif found in the majority of proteins that contain both BTB and Kelch domains. Although no function has been reported for the BACK domain, it is likely to be of functional significance because mutations in this motif have been linked to human axonal neuropathy [245].

LZTR1 Leucine-Zipper-Like Transcription Regulator 1 (B to D) also encodes a member of the BTB-Kelch superfamily [244]. LZTR1 was initially described as a transcriptional regulator based on a weak homology to members of the basic leucine zipper-like family. However, further studies showed that LZTR1 localizes exclusively to the Golgi network where it helps stabilize the Golgi complex [246]. LZTR1 mutations are related to a rare genetic disorder called Schwannomatosis, characterized by multiple intracranial, spinal, and peripheral tumors (schwannomas) [247, 248]. Furthermore, biallelic pathogenic variants in LZTR1 have been linked to Noonan syndrome, a disorder characterized by unusual facial features, short stature, cardiovascular anomalies, bleeding, skeletal malformations, and developmental delays [249]. The parallels of Noonan/LZTR1 loss of function phenotypes with those in 22q11DS suggest it is a viable candidate for modulating core $22 \mathrm{q} 11.2$ anomalies in individuals with $3 \mathrm{Mb} \mathbf{A}$ to $\mathbf{D}$ deletions.

ZNF74 Zinc Finger Protein 74 (B to D) belongs to a large subfamily of $\mathrm{C}_{2}-\mathrm{H}_{2}\left(\mathrm{Cys}_{2}-\mathrm{His}_{2}\right)$ zinc finger proteins encoding Kruppel-associated box (KRAB) transcriptional repressor motifs [250]. In addition to DNA binding activity, a subset of the $\mathrm{C}_{2}-\mathrm{H}_{2}$ proteins bind RNAs and proteins [251, 252]. Family member TFIIIA binds to RNAs and proteins to regulate 5S rRNA transcription, storage, and transport from the nucleus to the cytoplasm [253, 254]. Similarly, ZNF74 encodes a nuclear matrixattached protein with RNA binding properties [255]. ZNF74 interacts with a hyper-phosphorylated form of the largest subunit of RNA polymerase II and may regulate its activity during pre-mRNA processing [256]. 
There are no mouse or human genetic or functional analyses of this gene.

HIC2 Hypermethylated in Cancer 2 (a.k.a. ZBTB3O and ZNF907; B to D) is a BTB-zinc finger transcription factor required for normal heart development [257]. Homozygous Hic2 loss-of-function is early embryonic lethal and heterozygous mutants have ventricular septal defects and die at birth [258]. These anomalies implicate HIC2 as a potential modulator of 22q11DS phenotypes, particularly those in the heart, in typically deleted (A to D) individuals.

THAP7 Thanatos-Associated Protein 7 (B to D) encodes a member of a large family of THAP, an $\mathrm{N}$-terminus 89 -amino acid motif/ $\mathrm{C}_{2}-\mathrm{CH}$ signature (Cys- $\mathrm{X}_{2-4}$-Cys- $\mathrm{X}_{35-53}$-Cys- $\mathrm{X}_{2}$-His) transcription factors [259]. THAP transcriptional regulators, found only in animal genomes $[259,260]$, are multifunctional transcriptional regulators. C. elegans THAP protein (HIM-17) is critical for chromosome segregation during meiosis [260]. The $\mathrm{C}_{2}-\mathrm{CH}$ signature zinc finger domain in THAP7 is similar to the site-specific DNA binding domain of Drosophila P-element transposase [259]. Human THAP7 functions as a transcriptional repressor by recruiting co-repressor $\mathrm{NcoR}$ and histone deacetylase HDAC3 to chromatin [261, 262]. Despite these intriguing functions, little is known about potential THAP7 contributions, based upon human mutations or animal models, to 22q11DS phenotypes.

\section{Perspective: transcription factors}

There are eight transcription factors located between LCRA and LCRD on hChr22q11.2: two in the A to B region, and six in the $\mathbf{B}$ to $\mathbf{D}$ region. Of these eight, TBX1 (A to B), HIC2 (B to D), and LZTR1 (B to D) when mutated in mice or humans influence heart and craniofacial phenotypes that have similarities to those in 22q11DS. Of all transcription factors, $T B X 1$ has received the most attention as a "candidate" or even a single explanatory gene for 22q11DS phenotypes. TBX1 makes an essential contribution to 22q11DS cardiac, craniofacial, and otic phenotypes. Whether these contributions distinguish it formally as haploinsufficient for subsets of 22q11DS heart and face phenotypes versus a modulator of additional $\mathbf{A}$ to $\mathbf{B}$ or $\mathbf{B}$ to $\mathbf{D}$ gene interactions remains unresolved [73, 74]. Evidence for TBX1 modulation of brain development, particularly phenotypes crucial for 22q11DS behavioral deficits [211, 263] also is unresolved, although it is likely more limited than its contributions to cardiac or craniofacial differentiation [26]. In mouse, Tbx 1 regulates distinct aspects of morphogenesis of cranial nerves IX and X (glossopharyngeal and vagal) that participate in respiratory control, feeding, and swallowing, suggesting that $T B X 1$ may contribute to abnormalities in swallowing behavior observed in many individuals with 22q11DS [74, 264]. GSC2 (A to B) is not a likely contributor to 22q11DS pathology based upon available evidence. The role for dosage-dependent modulation of "core" (A to B-related) 22q11DS phenotypes of the remaining five $\mathbf{B}$ to $\mathbf{D}$ transcription factors could be significant, based on their apparent far-reaching effects on development and function. Nevertheless, almost no data, as yet, address possible interactions between modifying $\mathbf{B}$ to $\mathbf{D}$ transcription factors critical $\mathbf{A}$ to $B$ genes.

\section{Transmembrane receptors/transporters}

RTN4R Reticulon 4 Receptor (a.k.a. Nogo receptor, Nogo-66 receptor, or NGR1; A to B). Of all the A to B genes, $R T N 4 R$ is an intriguing candidate for nervous system phenotypes, and perhaps the most controversial. RTN4R, a neuronal glycosylphosphatidylinositol (GPI)-linked receptor, is expressed mainly in cerebral cortical neurons, hippocampal neurons, cerebellar Purkinje cells, and pontine neurons [265]. RTN4R binds to myelin-derived inhibitory proteins, MAG, OMgp, and Nogo isoforms and may limit neurite growth and axon regeneration after CNS injury in adult mammals [266269]. Consistent with these observations, in vivo studies report improved axon growth and locomotor recovery in spinal cord injured $\mathrm{Rtn}_{4} \mathrm{r}^{-1-}$ mice or in injured rats treated with anti-Nogo-A antibodies [268, 270]. Adult rat motor cortical neurons can functionally reorganize after injury and treatment with anti-Nogo antibody, accompanied by increased movement of the lesion-impaired forelimb [271]. In the hippocampus, Rtnr4 restricts formation of both excitatory and inhibitory synapses, influences dendrite spine morphology and limits activity-dependent synaptic strength [272-275]. In the visual cortex, Rtnr4 consolidates neural circuitry established during the visual critical period, and in other forebrain regions, it is required for consolidation of long-term memory [276-278]. These results, however, have been challenged. Indeed, they have not been fully replicated and a great deal of evidence suggests that the Nogo/Rtn4r pathway alone makes at best a modest contribution to mammalian central nervous system regeneration and repair [279-281]. In addition to its adult CNS expression, $R t n 4 r$ is expressed during brain development [282]. Nogo-A signaling via Rtn4r is implicated in ES cell self-renewal and differentiation [283-285]. It may influence neural precursor migration in the developing and adult cerebral cortex $[282,286]$. RTN4R also has been implicated as a susceptibility gene in psychosis through disruption of the brain microstructure [287, 288]. Several recent in vitro studies detect $R \operatorname{tn} 4 r$ in immune cells, suggesting regulatory functions in immune cell adhesion and migration [289-291]. The lack of clear 
data defining the function of Nogo-A/Rtn4r signaling makes its contribution to 22q11DS phenotypes uncertain.

P2RX6 Purinergic 2X6 Receptor (B to D) encodes a member of the P2X purinergic receptor family, which are ligand-gated ion channels activated by extracellular ATP, a neurotransmitter that causes fast excitatory postsynaptic potentials in neurons and smooth muscles [292-295]. P2X receptors are trimers of P2X subunit proteins (P2X1-7) that associate as homomers or heteromers. The P2X6 subunit only assembles with P2X2 or P2X4 to form an active receptor complex [296, 297]. The P2rx6 gene was first isolated from a cDNA library from rat superior cervical ganglion cells [298], which are derived from the neural crest [299]. P2rx6 is expressed in the brain, localizes to glutamatergic synapses, increases during post-natal neurogenesis [300-302], and modulates neuronal differentiation from neural progenitors in vitro [303]. Despite cellular evidence for P2rx6 function throughout the murine nervous system, there is no evidence for the effect of P2RX6 deficiency or null mutation either on mouse or human brain development.

SLC7A4 Solute Carrier Family 7 Member 4 (a.k.a. CAT4; B to D) is related by sequence to the cationic amino acid transporters (CAT) family [304]. In spite of its localization in the plasma membrane, SLC7A4 does not have transport activity when overexpressed in human cells or in Xenopus oocytes [305].

\section{Perspective: transmembrane receptors/transporters}

The one transmembrane receptor in the A to $\mathbf{B}$ region, RTN4R or NogoR, has potential nervous system functions that may contribute to 22q11DS phenotypes. Nevertheless, mouse heterozygous or homozygous mutants do not have reported phenotypes that parallel any of those associated with individuals with 22q11DS or mice with the orthologous A to B deletion [268, 280, 306]. Despite the still uncertain function of RTNR4 in neuronal plasticity or regeneration, it may interact with other A to B or B to D genes to modify 22q11DS phenotypes, particularly in the nervous system. Of the two B to $\mathbf{D}$ receptors, the $P 2 R X 6$ is the most viable candidate for additional 22q11DS phenotypic variability.

\section{Mitochondrial genes}

PRODH Proline Dehydrogenase (a.k.a. Proline Oxidase; A to B) encodes a mitochondrial gene that catalyzes the first step of proline to glutamate conversion (Fig. 4a) [307, 308]. In the brain, Prodh is selectively expressed in the hypothalamus, amygdala, piriform cortex, hippocampus, and cerebral cortex (Figs. 1c and 4b, c) [58, 309-311]. PRODH may be key for synaptic transmission. Proline may act as a neurotransmitter; however, the lack of a specific receptor in the brain suggests it may function instead as a neuromodulator [312, 313]. Indeed, in the mouse

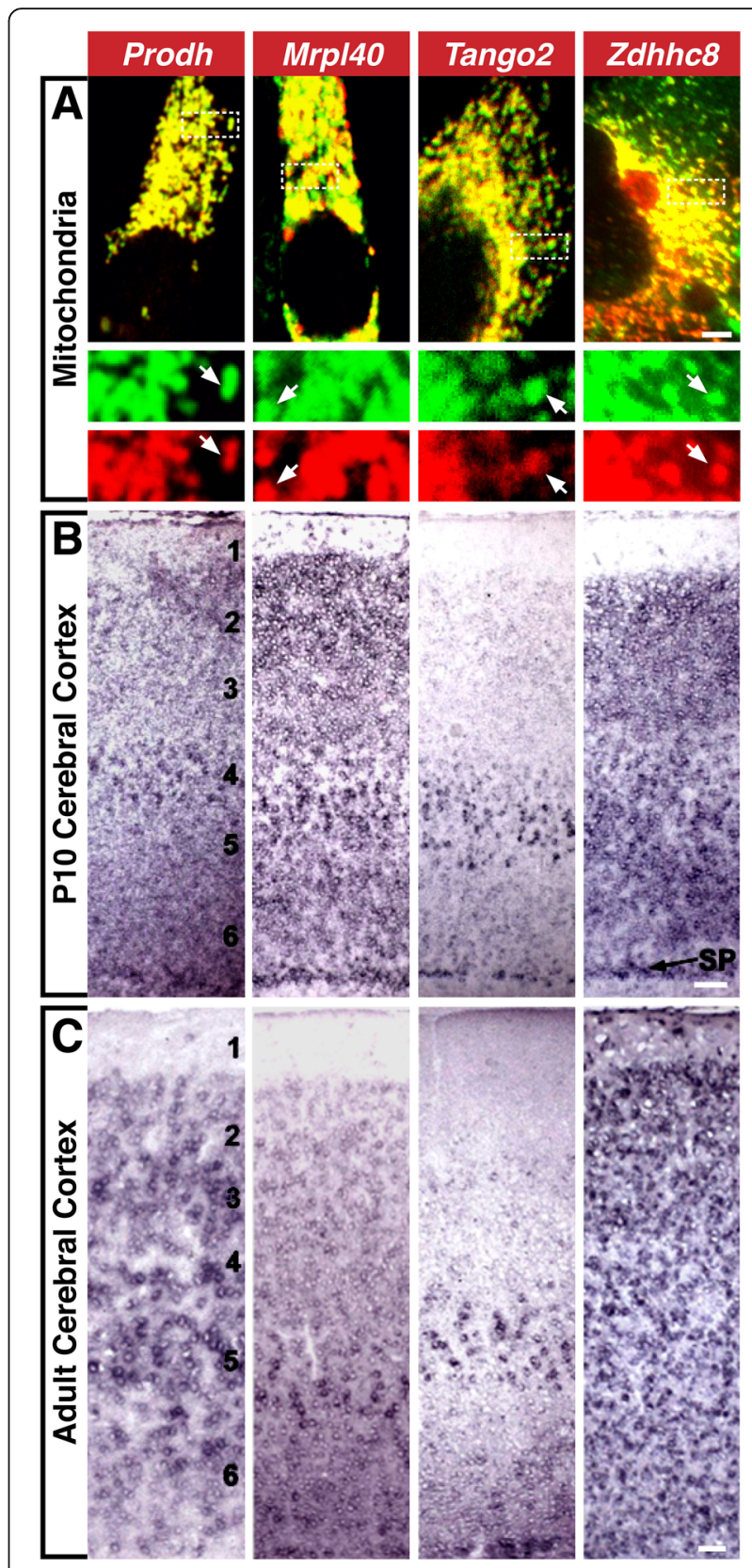

Fig. 4 Mitochondrial genes. a Co-localization of Prodh, Mrpl40, Tango, and Zdhhc8-GFP fusion proteins (green) and a mitochondria-targeted mCherry reporter (red). Inset: separated red and green channels. b and c Prodh, Mrpl40, Tango2, and Zdhhc8 expression patterns in P10 b and adult c cerebral cortex. 1-6 represent the six neocortical layers: 1, closest to the pia; 6 , closest to the subcortical white matter. SP subplate [310]. Scale bars: $\mathbf{a}=5 \mu \mathrm{m}$, inset $=2.66 x, \mathbf{b}, \mathbf{c}=50 \mu \mathrm{m}$

brain, proline may modulate glutamatergic synaptic transmission by directly activating glutamate receptors or potentiating transmission [314-318]. In hyperprolinemic mice, memory deficits accompany elevated proline levels [319-321]. Prodh ${ }^{-1-}$ mice have sensorimotor gating defects and decreased hypothalamic glutamate and GABA 
[322]. PRODH loss of function mutations results in hyperprolinemia type 1 , whose clinical symptoms largely depend on how severely proline function is reduced [307, 323]; while a minor increase in proline is mostly considered benign, high accumulation of proline is associated with severe phenotypes [323]. SCZ, intellectual disability, severe speech disorders, and seizures are associated with reduced PRODH activity due to polymorphisms or biallelic mutations independent of 22q11.2 deletion [323-326]. A genome-wide association study, however, has challenged PRODH's role as a risk factor for SCZ [327].

MRPL40 Mitochondrial Ribosomal Protein L40 (a.k.a. NLVCF; A to B) localizes to mitochondria and encodes the large subunit of the mitochondrial ribosome (Fig. 4a) [328]. Mrpl40 is expressed in the first and second pharyngeal arches in the mouse [329]. In the post-natal brain, Mrpl40 is enhanced in olfactory bulb mitral cells, cerebellar Purkinje cells, layer 5/6 cerebral cortex projection neurons, and the cortical subplate (Fig. 4b) [310], a transient early generated neuronal population between layer $5 / 6$ and the cerebral ventricle that is necessary for initial thalamo-cortical and cortico-thalamic circuit formation [330, 331]. In the adult, Mrpl40 is enhanced in the same projection neuron classes (Fig. 4c) [310]. Heterozygous Mrpl40 mutants have synaptic plasticity and working memory deficits, altered mitochondrial permeability, increased presynaptic cytosolic $\mathrm{Ca}^{++}$, and enhanced short-term potentiation [332].

TANGO2 Transport and Golgi Organization 2 Homo$\log$ (a.k.a. T10; A to B) encodes a member of the transport and Golgi organization family that plays roles in ER secretory protein loading [333]. In Drosophila, tango 2 loss-of-function leads to Golgi/ER fusion [333]. In contrast, mouse Tango2 has a mitochondrial localization motif and localizes to mitochondria, but not Golgi or peroxisomes (Fig. 4a) [310]. In the early postnatal mouse brain, Tango 2 is restricted to olfactory bulb mitral cells (OB projection neurons), layer $5 / 6$ cortical projection neurons, and the cortical subplate [310], and this restricted expression is maintained in the adult, except for the transient subplate (Fig. 4c). Mouse Tango 2 mutants have not been reported. However, TANGO2 biallelic truncation mutations have been linked to a metabolic disorder, infancy-onset episodic metabolic crisis [334, 335], characterized by muscle weakness, recurrent rhabdomyolysis, cardiac arrhythmia, encephalopathy, progressive neurodegeneration, and cognitive impairment. In fibroblasts from an individual with a TANGO2 mutation, ER stress increases, Golgi volume and density decline, and mitochondrial fatty acid $\beta$-oxidation is aberrant [335]. Apparently, TANGO2 merits further assessment in humans and model systems as a contributor to the 22q11DS phenotypic spectrum.
ZDHHC8 Zinc Finger DHHC-Type Containing 8 (A to B) encodes a putative member of a family of transmembrane palmitoyl-transferases that share a conserved cysteine-rich catalytic domain (DHHC) [336]. It may modify multiple substrates including cell adhesion molecules, ion channel components, signaling, scaffold, and membrane-associated proteins [336]. Zdhhc8 has a mitochondrial signal sequence and localizes to mitochondria (Fig. 4a) [310]. In developing and adult mouse brain, $Z d h h h c 8$ is enriched in the olfactory bulb, hippocampus, cerebellum, thalamic relay nuclei, and cerebral cortex (Figs. 1c, d and 4b, c) [58, 310, 311], and the protein is restricted to synapses in all of these regions. Zdhhc8 null mice are viable; however, hippocampal and cortical dendrite and axon growth as well as arborization, spine density, and glutamatergic synapse frequency declines [337, 338]. Some of these deficits can be rescued by enzymatically active ZDHHC8 [338]. Human ZDHHC8 palmitoylates PSD95, an adaptor involved in excitatory synapse development and plasticity [337, 339-342] and PICK1, whose palmitoylation is necessary for cerebellar long-term synaptic depression [343]. ZDHHC8-dependent palmitoylation also is required for trafficking and stability of the D2 dopamine receptor protein to the plasma membrane [344]. ZDHHC8 is suggested to increase the risk of SCZ [345], although this claim was challenged in a recent study [327].

SLC25A1 Solute Carrier Family 25 Member 1 (a.k.a. CTP; A to B) encodes a highly conserved inner mitochondrial membrane transporter that mediates the movement of citrate/isocitrate in exchange for cytosolic malate [346, 347]. It modulates mitochondrial homeostasis, fatty acid and sterol biosynthesis, glycolysis, chromosome maintenance, and cytokine-dependent inflammatory responses [346, 348-350]. In zebrafish, slc25a1 knockdown results in neuromuscular junction anomalies, axon outgrowth defects, and synaptic abnormality [351]. In humans, biallelic SLC25A1 mutations are associated with combined D-2- and L-2-hydroxyglutaric aciduria, a rare neurometabolic disorder characterized by hypotonia, epileptic encephalopathy, respiratory insufficiency, developmental arrest, severe neurodevelopmental dysfunction, lack of psychomotor development, and early death [352, 353]. Corpus callosum agenesis, optic nerve hypoplasia, and facial dysmorphism accompany these core clinical signs $[354,355]$. SLC25A1 hemizygous mutation in combination with 22q11.2 deletion has been reported in an individual with severe brain, heart, and face phenotypes along with combined D-2- and L-2-hydroxyglutaric aciduria [356].

TXNRD2 Thioredoxin Reductase 2 (a.k.a. TR3; A to B) encodes a pyridine nucleotide-disulfide oxidoreductase family seleno-cysteine enzyme [357]. Txnrd2 mainly localizes to mitochondria; however, various $\mathrm{N}$-terminal splicing variants may direct it to other cellular compartments 
[358]. Txnrd2 has two redox-active catalytic domains responsible for mitochondrial scavenging of reactive oxygen species essential for cell survival and mitochondria-mediated apoptosis [359-361]. During mouse development, Txnrd2 is expressed in the heart and its constitutive loss-of-function leads to anemia, heart ventricular thinning, and fetal death [362]. Heart-specific Txnrd2 inactivation also elicits heart chamber dilation, swollen, structurally altered mitochondria, and death shortly after birth [362], reminiscent of human dilated developmental cardiomyopathy [363]. Heart-specific Txnrd2 inactivation in adult mice increases vulnerability to myocardial ischemia/reperfusion injury due to mitochondrial degeneration and contractile dysfunction [364, 365]. Even though oxidative stress is linked with neurodegeneration, nervous system-specific ablation of Txnrd2 does not cause apparent gross abnormalities in any region of the mouse brain [366]. In contrast to other studies that support the critical role of selenium and selenoproteins in immune responses [367, 368], T cell- and B cell-specific Txnrd2 disruption failed to phenocopy key defects in fetal hematopoiesis [369]. Txnrd2 loss-of-function phenotypes are similar to clinical features of Keshan Disease, caused by severe selenium deficiency [370].

\section{Perspective: mitochondrial genes}

22q11.2 mitochondrial genes are found only in the $\mathbf{A}$ to B region. These six genes: PRODH, MRPL40, TANGO2, ZDHHC8, SLC25A1, and TXNRD2 are implicated in cardiac, facial, and neural development, as well as brain function, and cognitive skills. The absence of $\mathbf{B}$ to $\mathbf{D}$ mitochondrial genes suggests 22q11DS bioenergetic/ metabolic dysfunction may reflect primarily dosage change of the six A to $\mathbf{B}$ mitochondrial genes. Other $\mathbf{B}$ to $\mathbf{D}$ genes might modulate the functions of the six $\mathbf{A}$ to B mitochondrial genes, albeit indirectly. Nevertheless, single gene phenotypes in animal models and rare human homozygous loss-of-function mutations are all closely related to core 22q11DS phenotypes. Thus, a circumstantial case can be made for $\mathbf{A}$ to $\mathbf{B}$ mitochondrial gene contributions; however, this case needs to be strengthened by additional experimental and genetic evidence.

\section{Hemostatic factors}

GP1BB Glycoprotein Ib Platelet Beta Subunit (a.k.a. $C D 42 C$; A to B) encodes a subunit of the GP1b-V-IX complex, a hemostatic and thrombotic protein receptor primarily on platelet surfaces [371]. GP1BB mutations are associated with Bernard-Soulier syndrome [372], a rare disorder characterized by large platelets, low platelet count, and prolonged bleeding time [371]. Accordingly, there have been no assessments of $G p 1 b b$ mutant phenotypes in animal models.
SERPIND1 Serpin Family D Member 1 (a.k.a. Heparin Cofactor II; B to D), a serpin inflammation and coagulation superfamily modulator [373, 374], is a serine protease inhibitor that rapidly inactivates thrombin, a coagulation-related protease, and promotes angiogenesis and vascular remodeling after injury [375, 376]. Polymorphisms on the SERPIND1 promoter region may influence its expression [377]; however, no additional analyses confirm this finding.

\section{Perspective: hemostatic factors}

Hemostatic disruption has not been proposed as a frequent 22q11DS phenotype. Nevertheless, these anomalies are more common than previously thought [378-380]. The disruption is mostly linked to GP1BB; however, there is a recent report that challenges this correlation [381]. It also possible that SERPIND1 located in $\mathbf{B}$ to $\mathbf{D}$ region modifies the function of $G P 1 B B$ the in $\mathbf{A}$ to $\mathbf{D}$ deleted individuals, especially if regulatory polymorphisms further vary expression levels of this $\mathbf{B}$ to $\mathbf{D}$ gene.

\section{Additional genes with unique functions}

DGCR 6 DiGeorge Critical Region 6 (A to B) is encoded by two highly homologous ORFs (DGCR6 and DGCR6L) [382]. DGCR6 has homology to $G d l$, a gonadal development related protein in Drosophila, and the human laminin gamma-1 subunit, LAMC1, which is essential for basal lamina assembly [383]. Although distinct functions for the two ORFs encoding DGCR6 variants have not yet been fully defined, DGCR6 may influence neural crest migration and pharyngeal arch development [58, 384, 385]. In chick embryos, DGCR6 suppression results in cardiovascular anomalies [384]. In these embryos, attenuation of DGCR6 stimulates TBX1 and UFD1L but decreases heart and pharyngeal arch HIRA expression (all A to B genes), suggesting it is a modifier of critical region phenotypes [384]. DGCR6 also has been implicated in 22q11DS conotruncal heart defects, either directly or through $T B X 1$ activity [386]. Dysregulation of DGCR6 and DGCR6L is suggested to be associated with neuropsychological findings in 22q11DS children [387].

UFD1L Ubiquitin Fusion-Degradation Protein-1 Like (a.k.a. UFD1; A to B) is a component of the Ufd1L-Npl4-p97 multiprotein complex that recognizes and presents several polyubiquitin-tagged proteins to the proteasome for degradation [388, 389]. IP3 receptors, downstream components of PI4KA pathway (see above), are included among Ufd1L-Npl4-p97 targets [390]. The Ufd1-Npl4-p97 complex is required for clearance of damaged mitochondria [391, 392]. UFD1L also participates in ER-associated degradation, spindle disassembly, DNA-damage response, cell-cycle control, telomerase length regulation, and ribosome-associated degradation [393-397]. UFD1L functional attenuation in chick cardiac neural crest increases 
conotruncal septation defects [398]. Ufd1l is expressed in pharyngeal arches, palatal precursors, and developing ears, heart, and brain (Fig. 1c, d) [188, 399]. Ufd $1 l^{-1-}$ embryos die before organogenesis [398]. In human, UFD1L expression is reduced in bicuspid aortic valve, a common cardiac defect, further supporting a role in proper heart formation [400]. Drosophila ufd1 is implicated in neuronal function and maintenance [401]. Its role in mouse and human brain function is less clear. In the $L g D e l$ brain, $U f d 1 L$ transcripts decline by approximately $50 \%$, but Ufd $1 \mathrm{~L}$ protein is at WT levels [311]. UFD1L polymorphisms are associated with increased corpus callosum volumes and have been linked to cognitive deficits independent of 22q11.2 deletion [402, 403].

COMT Catechol-O-Methyltransferase (A to B) is one of several enzymes that degrade catecholamines, including dopamine, epinephrine, and norepinephrine [404]. COMT membrane-bound and soluble isoforms are predominately expressed in brain and peripheral tissues, respectively [404, 405]. Comt is expressed in several brain regions (Fig. 1c, d). Mutant mice lacking Comt show impaired emotional reactivity and cognition as well as increased aggressive behaviors [406, 407]. COMT polymorphisms are linked independently to SCZ, bipolar disorder, obsessive-compulsive disorder, anorexia, and ADHD [20, 408-410]-many are also 22q11DS behavioral phenotypes. This correlation suggests a potential role for COMT in regulating dopamine levels, which are disrupted in most of these disorders [411]. COMT association to SCZ, however, was challenged in a recent genome-wide association study [327].

TSSK2 Testis Specific Serine Kinase 2 (a.k.a. STK22b; A to B) encodes a serine/threonine kinase involved in spermatogenesis [412]. In mouse, the $S t k 22 b$ orthologue (STK22a is a pseudogene) is not expressed at 22q11.2 phenotypic sites (heart, face, limbs, thymus, brain), nor detected in the maturing or adult brain [58]. Recently, one patient with 22q11DS has been reported to have azoospermia, which could reflect TSSK2 deficiency [413].

TRMT2a tRNA Methyltransferase 2 Homolog A (a.k.a. HTF9C; A to B) is a tRNA methyltransferase with homology to a yeast $s c \operatorname{Trm} 2$ DNA repair enzyme [414]. TRMT2a is one of 34 human tRNA methyltransferases that target approximately 600 tRNA variants encoded by the human genome [415] to modulate tRNA stability, translational efficiency, and protein production. TRMT2A may contribute to 22q11DS phenotypes; however, genomic diversity of tRNA methyltransferases and their tRNA targets raises the possibility of functional redundancy and compensation. Trmt $2 a$ is expressed in the heart, pharyngeal arches, and brain (Fig. 1c) [58]. TRMT2 $a$ and its murine orthologue share a bidirectional promoter with Ranbp1, an established 22q11.2 contributor gene (see above); however, Trmt $2 a$ is expressed at
WT levels in Ranbp1 ${ }^{-1-}$ mice [170]. Promoter polymorphisms in the TRMT2A/RANBP1 locus, however, could yield additional dosage-dependent changes in 22q11DS.

\section{Perspective: additional genes with unique functions}

All "sui generis" 22q11.2 genes are in the A to B region, implicating each as a potential contributor to key phenotypes. Of the four, TSSK2 seems least likely to contribute to neural, cardiovascular, or craniofacial development. Similarly, UFD1L, if translationally dosage compensated in humans as in mice, is also less likely. DGCR6 merits further consideration following additional mechanistic studies. COMT remains a prime suspect based upon its contributions to aminergic neural signaling and potential association with behavioral disorders.

\section{Conclusion}

Single suspects and accomplices from the $22 q 11.2$ gene line-up

Over the last decade, data addressing developmental roles of several 22q11.2 genes have increased dramatically based on extrapolation of full loss-of-function phenotypes caused by deletion of single 22q11.2 orthologues in mouse and other model species. Nevertheless, the relationships between altered dosage of 22q11.2 genes-rather than homozygous loss of function-and the many and variable phenotypes in individuals with 22q11DS remain unclear. The spectrum of speculations regarding which gene "explains" 22q11.2 phenotypes is as broad as the 22q11DS phenotypic spectrum itself. Proposed explanations range from single gene haploinsufficiency accounting for all essential 22q11DS phenotypes, to more nuanced contiguous gene or gene-gene interactions that lead to subsets of clinically significant features. Several "genes of interest" have been identified; however, the potential contribution of several others-both confirmed coding loci as well as unannotated open reading frames with uncertain protein coding function as well as microRNAs-have not been thoroughly considered. We revisited the "line-up" of deleted 22q11.2 genes-focusing on those that encode identified proteins detected in at least one tissue in humans or model organisms-in the $3 \mathrm{Mb}$, typically deleted, $\mathbf{A}$ to $\mathbf{D}$ region. Our assessment of primary cellular functions and mutant dysfunction of all known protein coding 22q11.2 genes allows us to address two unsolved questions essential for understanding 22q11DS pathogenic mechanisms: (1) which phenotypes reflect true haploinsufficiency for A to B or A to D genes? (2) What causes phenotypic variability in individuals with distinct or even identical deletions? This 22q11.2 gene "line-up," reflecting insight from human and model system genetic analysis as well as parallel cell biological and molecular assessments establishes a genetic interaction matrix (Fig. 5) that generates multiple outcomes with differing severity 


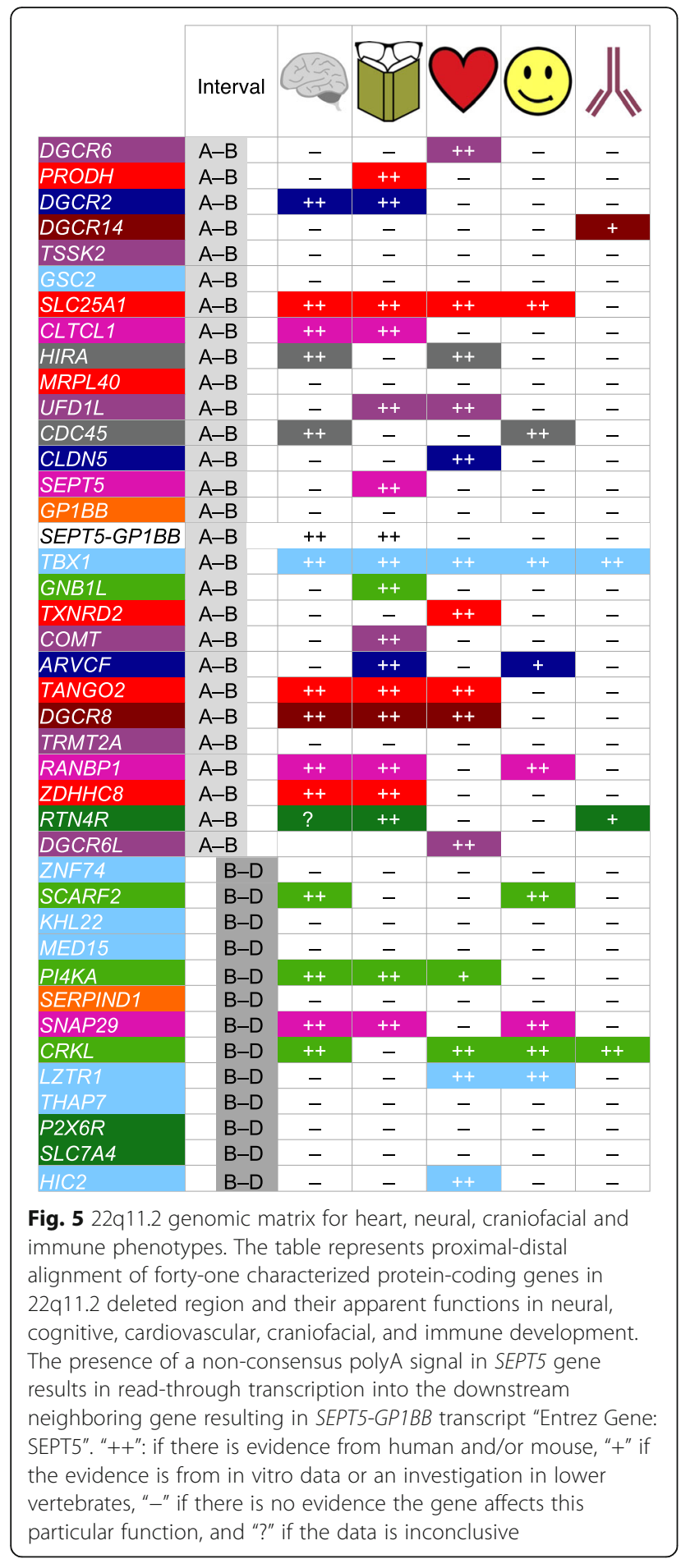

(Fig. 6). Understanding the detailed nature of this matrix, we suggest, will yield better therapeutic options for clinical challenges faced by individuals with 22q11DS. Additional investigation is necessary to complete the suspect list and decipher interactions that modify or diversify key 22q11DS features. Future studies targeting gene "cabals" in animal models should elucidate additional gene-gene interactions within the phenotypic matrix defined by A to $\mathbf{B}$ and $\mathbf{B}$ to $\mathbf{D}$ deletions (Figs. 5 and 6). Nevertheless, this matrix alone cannot reliably predict combinations of dosage-dependent phenotypes due to 22q11.2 deletions. Indeed, these predictions might be generated by combining the 22q11.2 interaction matrix with data on individual polymorphisms beyond 22q11.2 genes as well as fetal and post-natal environmental exposures [73, 264].

\section{Candidate genes}

"Which gene?" remains a central question for CNV-associated developmental disorders. If 22q11DS diagnostic assessment and therapies are to be targeted to pathogenic processes and delivered at appropriate times to maximize benefits in 22q11DS and other CNV-associated syndromes, it is imperative to identify culpable genes, characterize their obligate functions, and relate those data to disease-causing mechanisms and individual variability. Based upon evidence gathered by multiple investigators, it is unlikely that haploinsufficiency of a single 22q11.2 gene accounts for the full range of 22q11DS-related phenotypes. Nevertheless, our "line-up" indicates new promising leads on mechanistic interactions between suspects that disrupt development or homeostasis in 22q11DS. At least three possibilities-and one red herring-emerge from our functional genomic synthesis of minimally and typically deleted 22q11.2 genes.

\section{The red herring}

A single gene explains core 22q11DS phenotypes (Fig. 6a). Beyond doubt, several $\mathbf{A}$ to $\mathbf{B}$ as well as $\mathbf{B}$ to $\mathbf{D}$ genes, due to loss-of-function mutations or diminished dosage, contribute substantially, yet variably, to 22q11DS-related phenotypes. Nevertheless, the conclusion that any single gene "acts alone" to cause even one, let alone the full spectrum of 22q11DS phenotypes, without being influenced by diminished dosage of others, is no longer tenable based on judicious assessment of the evidence summarized here. What, then, more viable leads emerge from our thorough investigation of individual 22q11.2 genes and the primary cellular and developmental function of the proteins they encode?

\section{First}

22q11DS is a classic "contiguous gene syndrome" (Fig. 6b) in which diminished dosage of single $\mathbf{A}$ to $\mathbf{B}$ genes independently leads to each key 22q11.2 phenotype: one for the brain, one for the heart, one for the face, and one for the thymus. In this scenario, $\mathbf{B}$ to $\mathbf{D}$ genes may modulate each A to $\mathbf{B}$ gene's singular influence, but do not account for the core phenotypic change. Differing phenotypic frequencies in single gene heterozygous mutants versus broader 


\section{A Single causal gene}
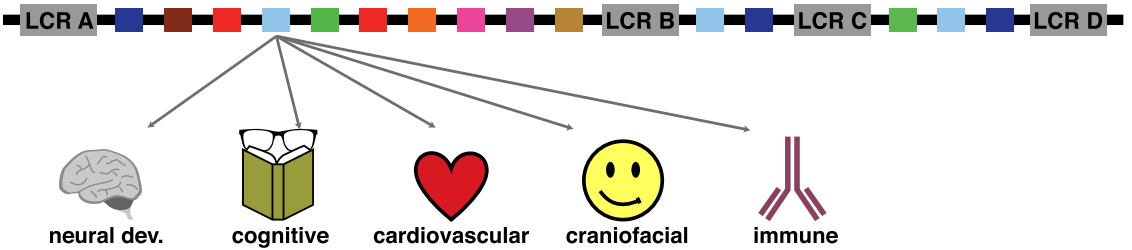

B Contiguous gene syndrome

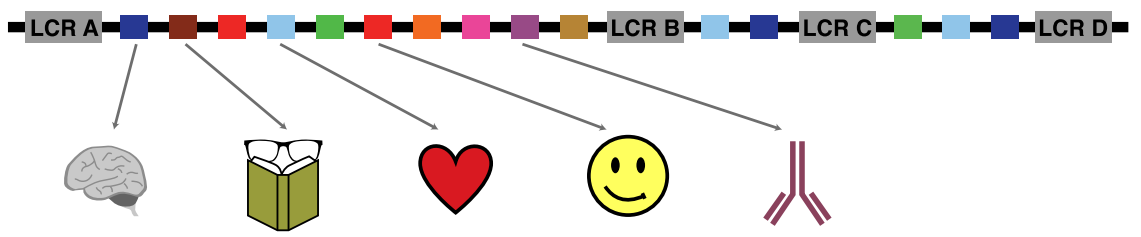

\section{Complex interaction}

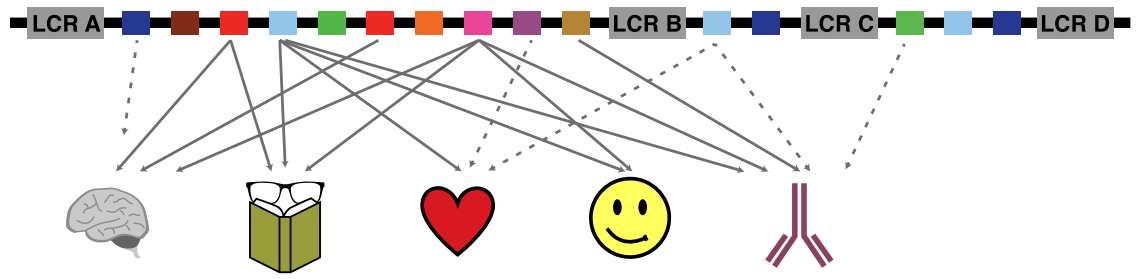

\section{Shared molecular/cellular targets}

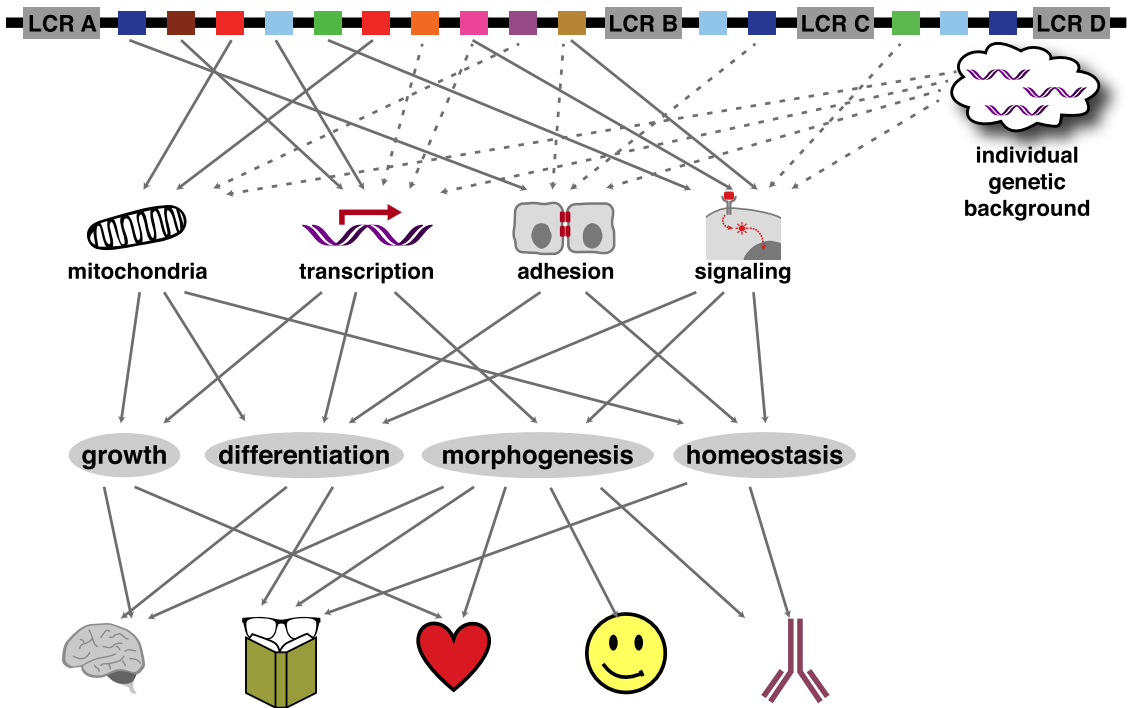

Fig. 6 Possible mechanism for 22q11.2 gene interaction. a Single causal gene; a single gene is responsible for all core 22q11DS phenotypes. b Contiguous genes; a single gene independently leads to each key 22q11DS phenotype. c Gene interactions; a combination of multiple genes are cooperatively responsible for each core 22q11DS phenotype. $\mathbf{d}$ Common functional targets; multiple genes conspire to disrupt key shared mechanisms, compromising key aspects of development or homeostasis at multiple 22q11DS phenotypic sites. "Individual genetic background" indicates contributions from allelic variants of genes outside the deletion region. The arrows are hypothetical illustrations of how multiple mechanisms could interact. Dotted arrows indicate weaker interactions

deletion (see Fig. 3), or stochastic interactions between A to $\mathbf{B}$ and $\mathbf{B}$ to $\mathbf{D}$ genes and signals like sonic hedgehog (Shh), RA, or FGF [73, 74, 217, 416] suggest this is unlikely.

\section{Second}

Gene subsets form multigenic "syndicates" to disrupt critical developmental mechanisms or homeostatic function at specific phenotypic sites (Fig. 6c). For example, 
diminished dosage of $\mathrm{Crkl}$ (B to D), combined with that of $T b x 1$ (A to $\mathbf{B}$ ) and a few other A to $\mathbf{B}$ genes may be responsible for many of the core cardiovascular anomalies as well as their variability [417]. Other distinct groups of 22q11 genes might similarly impact the brain, face, or thymus. There is considerable evidence for these sorts of selective, phenotype-specific interactions, at least in the heart, and most of this evidence has been reviewed here.

\section{Third}

A broader "interactome" is impacted by dosage-related changes in which proteins of similar cellular function encoded by multiple $\mathbf{A}$ to $\mathbf{B}$ genes, modulated by $\mathbf{B}$ to $\mathbf{D}$ genes, act in concert to disrupt essential cellular mechanisms at several phenotypic sites, rather than to elicit one single phenotype. These interactions may be due to sequential disruption of cell biological mechanisms leading to a threshold of developmental or homeostatic dysfunction at multiple phenotypic sites, or more direct, but locally distinct, interactions among functionally related 22q11.2 proteins in different organs and tissues. Such fundamental 22q11.2 dosage-dependent interactions may then be further modified by an individual's genomic background independent of 22q11.2 deletion (Fig. 6d). In this scenario, 22q11.2 genes with similar function, particularly mitochondrial, transcription factor, adhesion molecules, or signaling factors-some only in the A to B interval, others from $\mathbf{B}$ to $\mathbf{D}$-disrupt cellular mechanisms common to development and/or maintenance of heart, face, immune, skeletal, and brain integrity.

Additional evidence supports this "interactome" hypothesis as a viable solution to the yet unsolved mystery of 22q11.2 dosage-dependent phenotypic change and variability. Within the 22q11.2 deleted region, ARVCF and RANBP1 (A to B) as well as CRKL and SNAP29 (B to D) are predicted to interact with cadherin 1 (CDH1). Such interactions, influenced by stoichiometric change in proteins encoded by $22 \mathrm{q} 11.2$ genes, and modulated by polymorphisms in CDH1 in this example, or additional loci for other subsets of functionally related 22q11.2 proteins, could generally alter adhesion-dependent morphogenesis at all of 22q11DS phenotypic sites. CRKL (B to D), implicated in TBX1-dependent phenotypic changes, also interacts with phosphatase and tensin homolog (PTEN), a lipid phosphatase in the PI3K-AKT signaling pathway, involved in cell growth, proliferation, survival, and migration [418]. In addition, CRKL as well as DGCR8 interact with proteins involved in mRNA maturation and degradation, further supporting convergence on distinct cellular mechanisms that could compromise multiple phenotypic sites as more plausible mechanism for 22q11DS pathogenesis. The global instability of transcriptional regulation and its stochastic effects on 22q11 genes, perhaps effectively lowering their expression levels below a "loss of function" threshold on a cell-by-cell basis might broadly compromise multiple steps of development and maintenance of the heart, thymus, limbs, face, and brain. Analysis of genomic, transcriptomic, and proteomic databases can generate additional hypotheses of this sort of cellular mechanistic convergence. These hypotheses can then be tested genetically in the most appropriate model system among the several described here, or analyzed in cell lines, or in induced pluripotent stem cells (iPSCs) from several individuals with 22q11.2 deletions to further assess variability. Critically, one would predict that experiments in which key modulators of the cell biological mechanisms upon which subsets of 22q11.2 genes converge (see Fig. 6) were manipulated genetically or pharmacologically would provide further confirmation of the third scenario.

Our gene dosage-based/convergence-upon-cellular-mechanism hypothesis for 22q11DS is generally consistent with recent genomic analyses in non-syndromic individuals diagnosed with two behavioral disorders that are also significantly associated with 22q11DS: ASD and SCZ. There may be similar convergence on essential cellular mechanisms in ASD: 65 risk genes have been identified as chromatin regulators or establishment and maintenance of synaptic stability [21]. Multiple genes that encode cell adhesion molecules, tight junction proteins, and regulators of vesicle trafficking-all involved in critical processes for neural circuit development and neuronal signaling-have been implicated in SCZ susceptibility [22, 23]. Apparently, multigenic origins of complex brain disorders like ASD and SCZ may reflect a combination of single gene variants that independently are benign, but as a group, target common cellular mechanisms leading to dysfunction. Viewing these variants as independent actors, rather than interactors in a network, might result in incomplete explanations of pathology in clinically defined diseases like ASD, SCZ, or in multi-gene CNV syndromes like 22q11DS. New efforts to evaluate concerted actions of multiple genes on focal mechanisms for brain development and function are needed to advance our understanding of neurodevelopmental disorders generally. Our newly assembled gene 22q11.2 "line-up," from LCR A to LCR D, allows us to view "suspect" genes anew and formulate new investigative strategies for 22q11DS, perhaps providing a template for understanding a wider range of multigenic or CNV-associated syndromes.

\section{Additional file}

Additional file 1: Fig. S1. Human 22q11.2 region gene entries. There are 154 GenBank entries in the $3 \mathrm{Mb}$ deleted region of hChr22 between LCR A and LCR D at position q11.2. This includes 56 predicted proteincoding genes (white), 7 microRNAs (yellow), 38 non-coding RNAs (blue) 
and 53 pseudogenes (green). The gray areas represent predicted protein coding loci within the LCR regions. (PDF $66 \mathrm{~kb}$ )

\section{Abbreviations}

22q11DS: 22q11.2 deletion syndrome; Ac-LDL: Acetylated low-density lipoprotein; ADHD: Attention deficit hyperactivity disorder; ASD: Autistic spectrum disorders; BTB: Bric-a-brac-Tramtrack-Broad complex; CAT: Cationic amino acid transporters; CNs: Cranial nerves; CNV: Copy number variation: CP: Cortical plate; CTAF: Conotruncal anomaly face syndrome; Dmd1: Dystrophin; Dpp: Decapentaplegic; EGF: Epidermal growth factor; ER: Endoplasmic reticulum; FGF: Fibroblast growth factor; GEFs: Guaninenucleotide exchange factors; GPI: Glycosylphosphatidylinositol; $h$ Chr22: Human chromosome 22; IPN: Interpeduncular nucleus; iPSCs: Induced pluripotent stem cells; IZ: Intermediate zone; la/B: Importins; KRAB: Kruppel-associated box; LCR: Low copy number repeats; NES: Nuclear export signal; NLS: Nuclear localization signal; PI3: Phosphoinositide 3-kinase; PLC: Phospholipase C; PPI: Pre-pulse inhibition; Ptdlns4P: Phosphatidylinositol 4-phosphate; PTEN: Phosphatase and tensin homolog; RA: Retinoic acid; SCZ: Schizophrenia; snoRNA: Small nucleolar RNAs; SP: Subplate; Utrn: Utrophin; VCFS: Velo-cardiofacial syndrome; VZ: Ventricular zone; Xpo 1: Exportin

\section{Acknowledgements}

We thank members of the Moody and LaMantia laboratories for helpful discussions during the preparation of this manuscript.

\section{Funding}

Work in the authors' laboratories on 22q11DS has been supported by $\mathrm{NIH}$ HD042182 (ASL), HD083157 (A-S.L. and SAM), and Simons Foundation SFARI 306796 (ASL) and SFARI 342005(TM).

\section{Availability of data and materials}

There is no original data generated in the authors' laboratories presented in this review article. The supporting data is comprised entirely of references to published literature freely available in publicly accessible databases, particularly those maintained by the National Library of Medicine (PubMed, OMIM) as well as several genomic databases for which URLs are provided in the text of the manuscript.

\section{Authors' contributions}

ZM and TM conceived the scope of the review article and initiated its assembly. ZM wrote the original draft of the manuscript. TM generated the first drafts of the figures and assisted in drafting some sections describing specific 22q11 genes. ASL edited the initial and all subsequent drafts, conceived and wrote the Background and Conclusion sections with ZM, and revised figures and graphics with TM and ZM. SM edited the entire manuscript and monitored the scope of coverage and clarity of writing. All authors read and approved the final manuscript.

\section{Authors' information}

Zahra Motahari, Ph.D. Post-doctoral Associated, Department of Anatomy and Cell Biology, The George Washington University School of Medicine and Health Sciences, Washington DC, 20037 motahariz@gwu.edu

Sally A. Moody, Ph.D. Professor and Chair, Department of Anatomy and Cell Biology, The George Washington University School of Medicine and Health Sciences, Washington DC, 20037

samoody@gwu.edu

Thomas M. Maynard Ph.D., Associate Research Professor, Department of Anatomy and Cell Biology, The George Washington University School of Medicine and Health Sciences, Washington DC, 20037. maynard@gwu.edu

Anthony-Samuel LaMantia, Ph.D. Lieberman Professor of Neuroscience, Director, GW Institute for Neuroscience, Department of Anatomy and Cell Biology, The George Washington University School of Medicine and Health Sciences, Washington DC, 20037

lamantia@gwu.edu

\section{Ethics approval and consent to participate}

There are no data from human subject studies requiring IRB review or patient consent in this article. There are no original data collected for or presented in the paper.

\section{Consent for publication}

All four of the co-authors (Motahari, Moody, Maynard, LaMantia) read and approved the manuscript for submission for publication.

\section{Competing interests}

The authors declare that they have no competing interests.

\section{Publisher's Note}

Springer Nature remains neutral with regard to jurisdictional claims in published maps and institutional affiliations.

Received: 25 June 2018 Accepted: 21 April 2019

Published online: 07 June 2019

\section{References}

1. McDonald-McGinn DM, Sullivan KE. Chromosome 22q11.2 deletion syndrome (DiGeorge syndrome/ velocardiofacial syndrome). Medicine (Baltimore). 2011;90(1):1-18.

2. Burn J, Takao A, Wilson D, Cross I, Momma K, Wadey R, Scambler P, Goodship J. Conotruncal anomaly face syndrome is associated with a deletion within chromosome 22q11. J Med Genet. 1993;30(10):822-4.

3. Fernandez A, Meechan D, Baker JL, Karpinski BA, LaMantia AS, Maynard TM. $22 q 11$ deletion syndrome: copy number variations and development. In: Principles of Developmental Genetics. 2nd ed; 2015. p. 677-96.

4. Robin NH, Shprintzen RJ. Defining the clinical spectrum of deletion 22q11.2. J Pediatr. 2005:147(1):90-6.

5. Schneider M, Debbane M, Bassett AS, Chow EW, Fung WL, van den Bree M, et al. Psychiatric disorders from childhood to adulthood in 22q11.2 deletion syndrome: results from the international consortium on brain and behavior in 22q11.2 deletion syndrome. Am J Psychiatry. 2014;171(6):627-39.

6. Shaikh TH, Kurahashi H, Emanuel BS. Evolutionarily conserved low copy repeats (LCRS) in 22q11 mediate deletions, duplications, translocations, and genomic instability: an update and literature review. Genet Med. 2001;3(1):6-13.

7. Griffiths AJF. Modern genetic analysis : integrating genes and genomes, vol. xix. 2nd ed. New York: W.H. Freeman and Co; 2002. p. 736.

8. Emanuel BS. Molecular mechanisms and diagnosis of chromosome $22 \mathrm{q} 11.2$ rearrangements. Dev Disabil Res Rev. 2008;14(1):11-8.

9. Carlson C, Sirotkin H, Pandita R, Goldberg R, McKie J, Wadey R, et al. Molecular definition of 22q11 deletions in 151 velo-cardio-facial syndrome patients. Am J Hum Genet. 1997:61(3):620-9.

10. Michaelovsky E, Frisch A, Carmel M, Patya M, Zarchi O, Green G, et al. Genotype-phenotype correlation in 22q11.2 deletion syndrome. BMC Med Genet. 2012;13:122

11. Nogueira SI, Hacker AM, Bellucco FT, Christofolini DM, Kulikowski LD, Cernach MC, et al. Atypical 22q11.2 deletion in a patient with DGS/NCFS spectrum. Eur J Med Genet. 2008:51(3):226-30.

12. Burnside RD. 22q11.21 deletion syndromes: a review of proximal, central, and distal deletions and their associated features. Cytogenet Genome Res. 2015;146(2):89-99.

13. Racedo SE, McDonald-McGinn DM, Chung JH, Goldmuntz E, Zackai E, Emanuel BS, et al. Mouse and human CRKL is dosage sensitive for cardiac outflow tract formation. Am J Hum Genet. 2015;96(2):235-44.

14. Michaelovsky E, Frisch A, Carmel M, Patya M, Zarchi O, Green T, et al. Genotype-phenotype correlation in 22q11.2 deletion syndrome. BMC Med Genet. 2012;13:122.

15. Vergaelen E, Swillen A, Van Esch H, Claes S, Van Goethem G, Devriendt K. 3 generation pedigree with paternal transmission of the $22 q 11.2$ deletion syndrome: Intrafamilial phenotypic variability. Eur J Med Genet. 2015;58(4):244-8.

16. Guo T, McDonald-McGinn D, Blonska A, Shanske A, Bassett AS, Chow E, et al. Genotype and cardiovascular phenotype correlations with TBX1 in 1,022 velo-cardio-facial/DiGeorge/22q11.2 deletion syndrome patients. Hum Mutat. 2011;32(11):1278-89.

17. Clements CC, Wenger TL, Zoltowski AR, Bertollo JR, Miller JS, de Marchena $A B$, et al. Critical region within 22q11.2 linked to higher rate of autism spectrum disorder. Mol Autism. 2017;8:58.

18. Hiroi N, Takahashi T, Hishimoto A, Izumi T, Boku S, Hiramoto T. Copy number variation at 22q11.2: from rare variants to common mechanisms of developmental neuropsychiatric disorders. Mol Psychiatry. 2013;18(11):1153-65. 
19. Jungerius BJ, Hoogendoorn ML, Bakker SC, Van't Slot R, Bardoel AF, Ophoff RA, et al. An association screen of myelin-related genes implicates the chromosome 22q11 PIK4CA gene in schizophrenia. Mol Psychiatry. 2008; 13(11):1060-8

20. Prasad SE, Howley S, Murphy KC. Candidate genes and the behavioral phenotype in 22q11.2 deletion syndrome. Dev Disabil Res Rev. 2008; 14(1):26-34

21. Sanders SJ, He X, Willsey AJ, Ercan-Sencicek AG, Samocha KE, Cicek AE, et al. Insights into autism spectrum disorder genomic architecture and biology from 71 risk loci. Neuron. 2015;87(6):1215-33.

22. Purcell SM, Moran JL, Fromer M, Ruderfer D, Solovieff N, Roussos P, et al. A polygenic burden of rare disruptive mutations in schizophrenia. Nature. 2014;506(7487):185-90.

23. O'Dushlaine C, Kenny E, Heron E, Donohoe G, Gill M, Morris D, et al. Molecular pathways involved in neuronal cell adhesion and membrane scaffolding contribute to schizophrenia and bipolar disorder susceptibility. Mol Psychiatry. 2011;16(3):286-92.

24. Sifrim A, Hitz MP, Wilsdon A, Breckpot J, Turki SH, Thienpont B, et al. Distinct genetic architectures for syndromic and nonsyndromic congenital heart defects identified by exome sequencing. Nat Genet. 2016;48(9):1060-5.

25. Guna A, Butcher NJ, Bassett AS. Comparative mapping of the 22q11.2 deletion region and the potential of simple model organisms. J Neurodev Disord. 2015;7(1):18.

26. Meechan DW, Maynard TM, Tucker ES, Fernandez A, Karpinski BA, Rothblat LA, et al. Modeling a model: mouse genetics, 22q11.2 deletion syndrome, and disorders of cortical circuit development. Prog Neurobiol. 2015;130:1-28.

27. Ray-Gallet D, Quivy J, Scamps C, Martini EM, Lipinski M, Almouzni G. HIRA is critical for a nucleosome assembly pathway independent of DNA synthesis. Mol Cell. 2002;9(5):1091-100

28. Hall C, Nelson DM, Ye X, Baker K, DeCaprio JA, Seeholzer S, et al. HIRA, the human homologue of yeast Hir1p and Hir2p, is a novel cyclin-cdk2 substrate whose expression blocks S-phase progression. Mol Cell Biol. 2001; 21(5):1854-65.

29. Spector MS, Raff A, DeSilva H, Lee K, Osley MA. Hir1p and Hir2p function as transcriptional corepressors to regulate histone gene transcription in the Saccharomyces cerevisiae cell cycle. Mol Cell Biol. 1997;17(2):545-52.

30. Anderson HE, Wardle J, Korkut SV, Murton HE, Lopez-Maury L, Bahler J, et al. The fission yeast HIRA histone chaperone is required for promoter silencing and the suppression of cryptic antisense transcripts. Mol Cell Biol. 2009;29(18):5158-67.

31. Rai TS, Cole JJ, Nelson DM, Dikovskaya D, Faller WJ, Vizioli MG, et al. HIRA orchestrates a dynamic chromatin landscape in senescence and is required for suppression of neoplasia. Genes Dev. 2014;28(24):2712-25.

32. van der Heijden GW, Derijck AA, Posfai E, Giele M, Pelczar P, Ramos L, et al. Chromosome-wide nucleosome replacement and $\mathrm{H} 3.3$ incorporation during mammalian meiotic sex chromosome inactivation. Nat Genet. 2007;39(2):251-8

33. Zhang R, Poustovoitov MV, Ye X, Santos HA, Chen W, Daganzo SM, et al. Formation of MacroH2A-containing senescence-associated heterochromatin foci and senescence driven by ASF1a and HIRA. Dev Cell. 2005:8(1):19-30.

34. Ahmad A, Kikuchi H, Takami Y, Nakayama T. Different roles of N-terminal and C-terminal halves of HIRA in transcription regulation of cell cyclerelated genes that contribute to control of vertebrate cell growth. J Biol Chem. 2005;280(37):32090-100.

35. Ahmad K, Henikoff S. The histone variant H3.3 marks active chromatin by replication-independent nucleosome assembly. Mol Cell. 2002;9(6):1191-200.

36. Dutta D, Ray S, Home P, Saha B, Wang S, Sheibani N, et al. Regulation of angiogenesis by histone chaperone HIRA-mediated incorporation of lysine 56-acetylated histone $\mathrm{H} 3.3$ at chromatin domains of endothelial genes. J Biol Chem. 2010;285(53):41567-77.

37. Pchelintsev NA, McBryan T, Rai TS, van Tuyn J, Ray-Gallet D, Almouzni G, et al. Placing the HIRA histone chaperone complex in the chromatin landscape. Cell Rep. 2013;3(4):1012-9.

38. Adam S, Polo SE, Almouzni G. Transcription recovery after DNA damage requires chromatin priming by the $\mathrm{H} 3.3$ histone chaperone HIRA. Cell. 2013;155(1):94-106.

39. Mandemaker IK, Vermeulen W, Marteijn JA. Gearing up chromatin: a role for chromatin remodeling during the transcriptional restart upon DNA damage. Nucleus. 2014;5(3):203-10.
40. Yang JH, Song TY, Jo C, Park J, Lee HY, Song I, et al. Differential regulation of the histone chaperone HIRA during muscle cell differentiation by a phosphorylation switch. Exp Mol Med. 2016;48:e252.

41. Roberts C, Sutherland HF, Farmer H, Kimber W, Halford S, Carey A, et al. Targeted mutagenesis of the Hira gene results in gastrulation defects and patterning abnormalities of mesoendodermal derivatives prior to early embryonic lethality. Mol Cell Biol. 2002;22(7):2318-28.

42. Roberts C, Daw SC, Halford S, Scambler PJ. Cloning and developmental expression analysis of chick Hira (Chira), a candidate gene for DiGeorge syndrome. Hum Mol Genet. 1997;6(2):237-45.

43. Magnaghi P, Roberts C, Lorain S, Lipinski M, Scambler PJ. HIRA, a mammalian homologue of Saccharomyces cerevisiae transcriptional corepressors, interacts with Pax3. Nat Genet. 1998;20(1):74-7.

44. Conway SJ, Henderson DJ, Copp AJ. Pax3 is required for cardiac neural crest migration in the mouse: evidence from the splotch $(\mathrm{Sp} 2 \mathrm{H})$ mutant. Development. 1997;124(2):505-14.

45. Szenker E, Lacoste N, Almouzni G. A developmental requirement for HIRAdependent $\mathrm{H} 3.3$ deposition revealed at gastrulation in Xenopus. Cell Rep. 2012;1(6):730-40.

46. Wilming LG, Snoeren CA, van Rijswijk A, Grosveld F, Meijers C. The murine homologue of HIRA, a DiGeorge syndrome candidate gene, is expressed in embryonic structures affected in human $\mathrm{CATCH} 22$ patients. Hum Mol Genet. 1997;6(2):247-58

47. Farrell MJ, Stadt $H$, Wallis KT, Scambler P, Hixon RL, Wolfe R, Leatherbury L, Kirby ML. HIRA, a DiGeorge syndrome candidate gene, is required for cardiac outflow tract septation. Circ Res. 1999;84(2):127-35.

48. Valenzuela N, Fan Q, Fa'ak F, Soibam B, Nagandla H, Liu Y, et al. Cardiomyocyte-specific conditional knockout of the histone chaperone HIRA in mice results in hypertrophy, sarcolemmal damage and focal replacement fibrosis. Dis Model Mech. 2016;9(3):335-45.

49. Broderick R, Nasheuer HP. Regulation of Cdc45 in the cell cycle and after DNA damage. Biochem Soc Trans. 2009;37(Pt 4):926-30.

50. Machida YJ, Hamlin $J$, Dutta A. Right place, right time, and only once: replication initiation in metazoans. Cell. 2005;123(1):13-24.

51. Kang YH, Galal WC, Farina A, Tappin I, Hurwitz J. Properties of the human Cdc45/Mcm2-7/GINS helicase complex and its action with DNA polymerase epsilon in rolling circle DNA synthesis. Proc Natl Acad Sci U S A. 2012; 109(16):6042-7.

52. Makarova KS, Koonin EV, Kelman Z. The CMG (CDC45/RecJ, MCM, GINS) complex is a conserved component of the DNA replication system in all archaea and eukaryotes. Biol Direct. 2012;7(7). https://doi.org/10.1186/745-6150-7-7.

53. Pacek M, Tutter AV, Kubota Y, Takisawa H, Walter JC. Localization of MCM27, Cdc45, and GINS to the site of DNA unwinding during eukaryotic DNA replication. Mol Cell. 2006;21(4):581-7.

54. Zou L, Mitchell J, Stillman B. CDC45, a novel yeast gene that functions with the origin recognition complex and $\mathrm{mcm}$ proteins in initiation of DNA replication. Mol Cell Biol. 1997:17(2):553-63.

55. Kohler C, Koalick D, Fabricius A, Parplys AC, Borgmann K, Pospiech H, et al. Cdc45 is limiting for replication initiation in humans. Cell Cycle. 2016;15(7):974-85.

56. Edwards MC, Tutter AV, Cvetic C, Gilbert CH, Prokhorova TA, Walter JC. MCM2-7 complexes bind chromatin in a distributed pattern surrounding the origin recognition complex in Xenopus egg extracts. J Biol Chem. 2002;277(36):33049-57.

57. Wu PY, Nurse P. Establishing the program of origin firing during $S$ phase in fission yeast. Cell. 2009;136(5):852-64.

58. Maynard TM, Haskell GT, Peters AZ, Sikich L, Lieberman JA, LaMantia AS. A comprehensive analysis of 22q11 gene expression in the developing and adult brain. Proc Natl Acad Sci U S A. 2003;100(24):14433-8.

59. Shaikh TH, Gottlieb S, Sellinger B, Chen F, Roe BA, Oakey RJ, et al. Characterization of CDC45L: a gene inthe 22q11.2 deletion region expressed during murine and human development. Mamm Genome. 1999:10(3):322-6.

60. Meechan DW, Tucker ES, Maynard TM, LaMantia AS. Diminished dosage of $22 q 11$ genes disrupts neurogenesis and cortical development in a mouse model of 22q11 deletion/DiGeorge syndrome. Proc Natl Acad Sci U S A. 2009:106(38):16434-45.

61. Yoshida K, Kuo F, George EL, Sharpe AH, Dutta A. Requirement of CDC45 for postimplantation mouse development. Mol Cell Biol. 2001; 21(14):4598-603.

62. Fenwick AL, Kliszczak M, Cooper F, Murray J, Sanchez-Pulido L, Twigg SR, et al. Mutations in CDC45, encoding an essential component of the pre- 
initiation complex, cause Meier-Gorlin syndrome and craniosynostosis. Am J Hum Genet. 2016;99(1):125-38.

63. Gong L, Liu M, Jen J, Yeh ET. GNB1L, a gene deleted in the critical region for DiGeorge syndrome on 22q11 encodes a G-protein beta-subunit-like polypeptide. Biochim Biophys Acta. 2000;1494(1-2):185-8.

64. Paylor R, Glaser B, Mupo A, Ataliotis P. Spencer C, Sobotka A, et al. Tbx 1 haploinsufficiency is linked to behavioral disorders in mice and humans: implications for 22q11 deletion syndrome. Proc Natl Acad Sci U S A. 2006; 103(20):7729-34.

65. Feller S. Crk family adaptors -signalling complex formation and biological roles. Oncogene. 2001;20:6348-71.

66. Birge RB, Kalodimos C, Inagaki F, Tanaka S. Crk and CrkL adaptor proteins: networks for physiological and pathological signaling. Cell Commun Signal. 2009;7:13.

67. Ballif BA, Arnaud L, Arthur WT, Guris D, Imamoto A, Cooper JA. Activation of a Dab1/CrkL/C3G/Rap1 pathway in Reelin-stimulated neurons. Curr Biol. 2004;14(7):606-10

68. Feng $L$, Cooper JA. Dual functions of Dab1 during brain development. Mol Cell Biol. 2009;29(2):324-32.

69. Huang Y, Magdaleno S, Hopkins R, Slaughter C, Curran T, Keshvara L. Tyrosine phosphorylated disabled 1 recruits Crk family adapter proteins. Biochem Biophys Res Commun. 2004;318(1):204-12.

70. Guris DL, Fantes J, Tara D, Druker BJ, Imamoto A. Mice lacking the homologue of the human 22q11.2 geneCRKL phenocopy neurocristopathies of DiGeorge syndrome. Nat Genet. 2001;27(3):293-8.

71. Miller KA, Tan TY, Welfare MF, White SM, Stark Z, Savarirayan R, et al. A mouse splice-site mutant and individuals with atypical chromosome 22q11. 2 deletions demonstrate the crucial role for crkl in craniofacial and pharyngeal development. Mol Syndromol. 2014;5(6):276-86.

72. Guris DL, Duester G, Papaioannou VE, Imamoto A. Dose-dependent interaction of Tbx1 and Crkl and locally aberrant RA signaling in a model of del22q11 syndrome. Dev Cell. 2006;10(1):81-92.

73. Maynard TM, Gopalakrishna D, Meechan DW, Paronett EM, Newbern JM, LaMantia AS. 22q11 gene dosage establishes an adaptive range for sonic hedgehog and retinoic acid signaling during early development. Hum Mol Genet. 2013;22(2):300-12

74. Karpinski BA, Maynard TM, Fralish MS, Nuwayhid S, Zohn IE, Moody $\mathrm{SA}$, et al. Dysphagia and disrupted cranial nerve development in a mouse model of DiGeorge (22q11) deletion syndrome. Dis Model Mech. 2014;7(2):245-57.

75. Moon AM, Guris DL, Seo JH, Li L, Hammond J, Talbot A, et al. Crkl deficiency disrupts Fgf8 signaling in a mouse model of 22q11 deletion syndromes. Dev Cell. 2006;10(1):71-80.

76. Giacomelli M, Kumar R, Soresina A, Tamassia N, Lorenzini T, Moratto D, et al. Reduction of CRKL expression in patients with partial DiGeorge syndrome is associated with impairment of T-cell functions. J Allergy Clin Immunol. 2016;138(1):229-40 e3.

77. Zheng P, Noroski LM, Hanson IC, Chen Y, Lee ME, Huang Y, et al. Molecular mechanisms of functional natural killer deficiency in patients with partial DiGeorge syndrome. J Allergy Clin Immunol. 2015;135(5):1293-302.

78. Huang Y, Clarke F, Karimi M, Roy NH, Williamson EK, Okumura M, et al. CRK proteins selectively regulate T cell migration into inflamed tissues. J Clin Invest. 2015;125(3):1019-32.

79. Liu D. The adaptor protein Crk in immune response. Immunol Cell Biol. 2014:92(1):80-9.

80. Fish EN, Uddin S, Korkmaz M, Majchrzak B, Druker BJ, Platanias LC. Activation of a CrkL-stat5 signaling complex by type I interferons. J Biol Chem. 1999;274(2):571-3.

81. Ishii J, Adachi H, Aoki J, Koizumi H, Tomita S, Suzuki T, et al. SREC-II, a new member of the scavenger receptor type $F$ family, trans-interacts with SREC-I through its extracellular domain. J Biol Chem. 2002;277(42):39696-702.

82. Hwang M, Kalinin A, Morasso MI. The temporal and spatial expression of the novel $\mathrm{ca}^{++}$-binding proteins, scarf and Scarf2, during development and epidermal differentiation. Gene Expr Patterns. 2005;5(6):801-8.

83. Anastasio N, Ben-Omran T, Teebi A, Ha KC, Lalonde E, Ali R, et al. Mutations in SCARF2 are responsible for Van Den Ende-Gupta syndrome. Am J Hum Genet. 2010;87(4):553-9.

84. Migliavacca MP, Sobreira NL, Antonialli GP, Oliveira MM, Melaragno MI Casteels I, et al. Sclerocornea in a patient with van den Ende-Gupta syndrome homozygous for a SCARF2 microdeletion. Am J Med Genet A. 2014;164A(5):1170-4
85. Schweitzer DN, Lachman RS, Pressman BD, Graham JM Jr. Van den EndeGupta syndrome of blepharophimosis, arachnodactyly, and congenital contractures: clinical delineation and recurrence in brothers. Am J Med Genet A. 2003;118A(3):267-73.

86. Balla A, Balla T. Phosphatidylinositol 4-kinases: old enzymes with emerging functions. Trends Cell Biol. 2006;16(7):351-61.

87. Audhya A, Foti M, Emr SD. Distinct roles for the yeast phosphatidylinositol 4- kinases, Stt4p and Pik1p, in secretion, cell growth, and organelle membrane dynamics. Mol Biol Cell. 2000;11(8):2673-89.

88. Heilmeyer L, Vereb G, Vereb G, Kakuk A, Szivák I. Mammalian phosphatidylinositol 4-kinases. IUBMB Life. 2003;55(2):59-65.

89. Nakagawa T, Goto K, Kondo H. Cloning, expression, and localization of 230kDa phosphatidylinositol 4- kinase. J Biol Chem. 1996;271(20):12088-94.

90. Wong K. Meyers ddR, Cantley LC. Subcellular locations of phosphatidylinositol 4-kinase isoforms. J Biol Chem. 1997;272(20):13236-41.

91. Chung J, Nakatsu F, Baskin JM, De Camilli P. Plasticity of PI4KIllalpha interactions at the plasma membrane. EMBO Rep. 2015;16(3):312-20.

92. Nakatsu F, Baskin JM, Chung J, Tanner LB, Shui G, Lee SY, et al. Ptdlns4P synthesis by PI4KIIlalpha at the plasma membrane and its impact on plasma membrane identity. J Cell Biol. 2012;199(6):1003-16.

93. Ma H, Blake T, Chitnis A, Liu P, Balla T. Crucial role of phosphatidylinositol 4-kinase Illalpha in development of zebrafish pectoral fin is linked to phosphoinositide 3-kinase and FGF signaling. J Cell Sci. 2009;122(Pt 23):4303-10.

94. Wong K, Cantley LC. Cloning and characterization of a human phosphatidylinositol 4-kinase. J Biol Chem. 1994;269(46):28878-84.

95. Zólyomi A, Zhao X, Downing GJ, Balla T. Localization of two distinct type III phosphatidylinositol 4-kinase enzyme mRNAs in the rat. Am J Physiol Cell Physiol. 2000;278(5):C914-20.

96. Bojjireddy N, Botyanszki J, Hammond G, Creech D, Peterson R, Kemp DC, et al. Pharmacological and genetic targeting of the PI4KA enzyme reveals its important role in maintaining plasma membrane.phosphatidylinositol 4phosphate and phosphatidylinositol 4,5-bisphosphate levels. J Biol Chem. 2014;289(9):6120-32.

97. Vaillancourt FH, Brault M, Pilote L, Uyttersprot N, Gaillard ET, Stoltz JH, et al. Evaluation of phosphatidylinositol-4-kinase IIlalpha as a hepatitis $C$ virus drug target. J Virol. 2012;86(21):11595-607.

98. Pagnamenta AT, Howard MF, Wisniewski E, Popitsch N, Knight SJ, Keays DA, et al. Germline recessive mutations in PI4KA are associated with perisylvian polymicrogyria,cerebellar hypoplasia and arthrogryposis. Hum Mol Genet. 2015;24(13):3732-41.

99. Vorstman JA, Chow EW, Ophoff RA, van Engeland H, Beemer FA, Kahn RS, et al. Association of the PIK4CA schizophrenia-susceptibility gene in adults with the 22q11.2 deletion syndrome. Am J Med Genet B Neuropsychiatr Genet. 2009;150B(3):430-3.

100. Carnahan RH, Rokas A, Gaucher EA, Reynolds AB. The molecular evolution of the p120-catenin subfamily and its functional associations. PLoS One. 2010;5(12):e15747.

101. McCrea PD, Gu D. The catenin family at a glance. J Cell Sci. 2010;123(Pt 5):637-42.

102. Kausalya PJ, Phua DC, Hunziker W. Association of ARVCF with zonula occludens (ZO)-1 and ZO-2: binding to PDZ-domain proteins and cell-cell adhesion regulate plasma membrane and nuclear localization of ARVCF. Mol Biol Cell. 2004;15(12):5503-15.

103. Laura RP, Witt AS, Held HA, Gerstner R, Deshayes K, Koehler MF, et al. The Erbin PDZ domain binds with high affinity and specificity to the carboxyl termini of delta-catenin and ARVCF. J Biol Chem. 2002;277(15):12906-14.

104. Sirotkin H, O'Donnell H, DasGupta R, Halford S, St Jore B, Puech A, et al. Identification of a new human catenin gene family member (ARVCF) from the region deleted in velo-cardio-facial syndrome. Genomics. 1997;41(1):75-83.

105. Davis MA, Ireton RC, Reynolds AB. A core function for p120-catenin in cadherin turnover. J Cell Biol. 2003;163(3):525-34.

106. Kaufmann U, Zuppinger C, Waibler Z, Rudiger M, Urbich C, Martin B, et al. The armadillo repeat region targets ARVCF to cadherin-based cellular junctions. J Cell Sci. 2000;113:4121-35.

107. Cho K, Vaught TG, Ji H, Gu D, Papasakelariou-Yared C, Horstmann N, et al. Xenopus Kazrin interacts with ARVCF-catenin, spectrin and p190B RhoGAP, and modulates RhoA activity and epithelial integrity. J Cell Sci. 2010;123(Pt 23):4128-44.

108. Fang X, Ji H, Kim SW, Park JI, Vaught TG, Anastasiadis PZ, et al. Vertebrate development requires ARVCF and p120 catenins and their interplay with RhoA and Rac. J Cell Biol. 2004;165(1):87-98. 
109. Mariner DJ, Wang J, Reynolds AB. ARVCF localizes to the nucleus and adherens junction and is mutually exclusive with p120(ctn) in E-cadherin complexes. J Cell Sci. 2000;113(Pt8):1481-90.

110. Rappe U, Schlechter T, Aschoff M, Hotz-Wagenblatt A, Hofmann I. Nuclear ARVCF protein binds splicing factors and contributes to the regulation of alternative splicing. J Biol Chem. 2014;289(18):12421-34.

111. Ulfig N, Chan WY. Expression of ARVCF in the human ganglionic eminence during fetal development. Dev Neurosci. 2004;26(1):38-44.

112. Cho K, Lee M, Gu D, Munoz WA, Ji H, Kloc M, et al. Kazrin, and its binding partners ARVCF- and delta- catenin, are required for Xenopus laevis craniofacial development. Dev Dyn. 2011;240(12):2601-12.

113. Tran HT, Delvaeye M, Verschuere V, Descamps E, Crabbe E, Van Hoorebeke $L$, et al. ARVCF depletion cooperates with Tbx1 deficiency in the development of 22q11.2DS-like phenotypes in Xenopus. Dev Dyn. 2011; 240(12):2680-7.

114. Marciano DK, Brakeman PR, Lee CZ, Spivak N, Eastburn DJ, Bryant DM, et al. p120 catenin is required for normal renal tubulogenesis and glomerulogenesis. Development. 2011;138(10):2099-109.

115. Mas S, Bernardo M, Parellada E, Garcia-Rizo C, Gasso P, Alvarez S, et al. ARVCF single marker and haplotypic association with schizophrenia. Prog Neuro-Psychopharmacol Biol Psychiatry. 2009:33(6):1064-9.

116. Sanders AR, Rusu I, Duan J, Vander Molen JE, Hou C, Schwab SG, et al. Haplotypic association spanning the 22q11.21 genes COMT and ARVCF with schizophrenia. Mol Psychiatry. 2005;10(4):353-65.

117. Furuse M, Tsukita S. Claudins in occluding junctions of humans and flies. Trends Cell Biol. 2006;16(4):181-8.

118. Heiskala M, Peterson PA, Yang Y. The roles of claudin superfamily proteins in paracellular transport. Traffic. 2001;2(2):93-8.

119. Krause G, Winkler L, Mueller SL, Haseloff RF, Piontek J, Blasig IE. Structure and function of claudins. Biochim Biophys Acta. 2008;1778(3):631-45.

120. Capaldo $C T$, Nusrat $A$. Cytokine regulation of tight junctions. Biochim Biophys Acta. 2009;1788(4):864-71.

121. Taddei A, Giampietro C, Conti A, Orsenigo F, Breviario F, Pirazzoli V, et al. Endothelial adherens junctions control tight junctions by VE-cadherinmediated upregulation of claudin-5. Nat Cell Biol. 2008;10(8):923-34.

122. Guillemot L, Paschoud S, Pulimeno P, Foglia A, Citi S. The cytoplasmic plaque of tight junctions: a scaffolding and signalling center. Biochim Biophys Acta. 2008;1778(3):601-13.

123. Itoh M, Furuse M, Morita K, Kubota K, Saitou M, Tsukita S. Direct binding of three tight junction- associated MAGUKs, ZO-1, ZO-2, and ZO-3, with the $\mathrm{COOH}$ termini of claudins. J Cell Biol. 1999;147(6):1351-63.

124. Morita KSH, Furuse M, Tsukita S. Endothelial claudin: claudin-5/TMVCF constitutes tight junction strands in endothelial cells. J Cell Biol. 1999;147(1):185-94.

125. Morita K, Furuse M, Fujimoto K, Tsukita S. Claudin multigene family encoding four-transmembrane domain protein components of tight junction strands. Proc Natl Acad Sci U S A. 1999;96(2):511-6.

126. Yamagishi M, Ito $Y$, Ariizumi T, Komazaki S, Danno H, Michiue T, et al. Claudin5 genes encoding tight junction proteins are required for Xenopus heart formation. Develop Growth Differ. 2010;52(7):665-75.

127. Yin VP, Lepilina A, Smith A, Poss KD. Regulation of zebrafish heart regeneration by miR-133. Dev Biol. 2012;365(2):319-27.

128. Delfin DA, Xu Y, Schill KE, Mays TA, Canan BD, Zang KE, et al. Sustaining cardiac claudin-5 levels prevents functional hallmarks of cardiomyopathy in a muscular dystrophy mouse model. Mol Ther. 2012;20(7):1378-83.

129. Sanford JL, Edwards JD, Mays TA, Gong B, Merriam AP, Rafael-Fortney JA Claudin-5 localizes to the lateral membranes of cardiomyocytes and is altered in utrophin/dystrophin-deficient cardiomyopathic mice. J Mol Cell Cardiol. 2005;38(2):323-32.

130. Nitta T, Hata M, Gotoh S, Seo Y, Sasaki H, Hashimoto N, et al. Size-selective loosening of the blood-brain barrier in claudin-5-deficient mice. J Cell Biol. 2003;161(3):653-60.

131. Mays TA, Binkley PF, Lesinski A, Doshi AA, Quaile MP, Margulies KB, et al. Claudin-5 levels are reduced in human end-stage cardiomyopathy. J Mol Cell Cardiol. 2008:45(1):81-7.

132. Swager SA, Delfin DA, Rastogi N, Wang H, Canan BD, Fedorov W, et al. Claudin-5 levels are reduced from multiple cell types in human failing hearts and are associated with mislocalization of ephrin-B1. Cardiovasc Pathol. 2015;24(3):160-7.

133. Watters AK, Rom S, Hill JD, Dematatis MK, Zhou Y, Merkel SF, et al. Identification and dynamic regulation of tight junction protein expression in human neural stem cells. Stem Cells Dev. 2015;24(12):1377-89.
134. Kajiwara K, Nagasawa H, Shimizu-Nishikawa K, Ookura T, Kimura M, Sugaya E. Cloning of SEZ-12 encoding seizure-related and membrane-bound adhesion protein. Biochem Biophys Res Commun. 1996;222(1):144-8.

135. Molinard-Chenu A, Dayer A. The candidate schizophrenia risk gene DGCR2 regulates early steps of corticogenesis. Biol Psychiatry. 2018;83(8):692-706.

136. Mugikura SI, Katoh A, Watanabe S, Kimura M, Kajiwara K. Abnormal gait, reduced locomotor activity and impaired motor coordination in Dgcr2deficient mice. Biochem Biophys Rep. 2016;5:120-6.

137. Xu B, Roos JL, Dexheimer P, Boone B, Plummer B, Levy S, et al. Exome sequencing supports a de novo mutational paradigm for schizophrenia. Nat Genet. 2011:43(9):864-8.

138. Hartwell LH, Mortimer R, Culotti J, Culotti M. Genetic control of the cell division cycle in yeast: V. Genetic analysis of cdc mutants. Genetics. 1973;74(2):267-86

139. Martinez C, Ware J. Mammalian septin function in hemostasis and beyond. Exp Biol Med. 2004;229:1111-9.

140. Hall PA, Jung K, Hillan KJ, Russell SE. Expression profiling the human septin gene family. J Pathol. 2005;206(3):269-78.

141. Beites $\mathrm{CL}$, Xie H, Bowser R, Trimble WS. The septin CDCrel-1 binds syntaxin and inhibits exocytosis. Nat Neurosci. 1999;2(5):434-9.

142. Kinoshita A, Noda M, Kinoshita M. Differential localization of septins in the mouse brain. J Comp Neurol. 2000;428(2):223-39.

143. Amin ND, Zheng YL, Kesavapany S, Kanungo J, Guszczynski T, Sihag RK, et al. Cyclin-dependent kinase 5 phosphorylation of human septin SEPT5 (hCDCrel-1) modulates exocytosis. J Neurosci. 2008;28(14): 3631-43.

144. Beites CL, Campbell KA, Trimble WS. The septin Sept5/CDCrel-1 competes with a-SNAP for binding to the SNARE complex. Biochem J. 2005;385(Pt2):347-53.

145. Dong Z, Ferger B, Paterna JC, Vogel D, Furler S, Osinde M, et al. Dopaminedependent neurodegeneration in rats induced by viral vector-mediated overexpression of the parkin target protein, CDCrel-1. Proc Natl Acad Sci U S A. 2003;100(21):12438-43.

146. Yang YM, Fedchyshyn MJ, Grande G, Aitoubah J, Tsang CW, Xie H, et al. Septins regulate developmental switching from microdomain to nanodomain coupling of $\mathrm{ca}^{(2+)}$ influx to neurotransmitter release at a central synapse. Neuron. 2010;67(1):100-15.

147. Peng XR, Jia Z, Zhang Y, Ware J, Trimble WS. The Septin CDCrel-1 is dispensable for normal development and neurotransmitter release. Mol Cell Biol. 2002;22(1):378-87.

148. Tsang CW, Fedchyshyn M, Harrison J, Xie H, Xue J, Robinson PJ, et al. Superfluous role of mammalian septins 3 and 5 in neuronal development and synaptic transmission. Mol Cell Biol. 2008;28(23):7012-29.

149. Barr AM, Young CE, Sawada K, Trimble WS, Phillips AG, Honer WG Abnormalities of presynaptic protein CDCrel-1 in striatum of rats reared in social isolation: relevance to neural connectivity in schizophrenia. Eur J Neurosci. 2004:20(1):303-7.

150. Harper KM, Hiramoto T, Tanigaki K, Kang G, Suzuki G, Trimble W, et al. Alterations of social interaction through genetic and environmental manipulation of the 22q11.2 gene Sept5 in the mouse brain. Hum Mol Genet. 2012;21(15):3489-99.

151. Son JH, Kawamata H, Yoo MS, Kim DJ, Lee YK, Kim S, et al. Neurotoxicity and behavioral deficits associated with Septin 5 accumulation in dopaminergic neurons. J Neurochem. 2005;94(4):1040-53.

152. Suzuki G, Harper KM, Hiramoto T, Sawamura T, Lee M, Kang G, et al. Sept5 deficiency exerts pleiotropic influence on affective behaviors and cognitive functions in mice. Hum Mol Genet. 2009;18(9):1652-60.

153. Bartsch I, Sandrock K, Lanza F, Nurden P, Hainmann I, Pavlova A, et al. Deletion of human GP1BB and SEPT5 is associated with Bernard-Soulier syndrome, platelet secretion defect, polymicrogyria, and developmental delay. Thromb Haemost. 2011;106(3):475-83.

154. Esk C, Chen CY, Johannes L, Brodsky FM. The clathrin heavy chain isoform CHC22 functions in a novel endosomal sorting step. J Cell Biol. 2010;188(1):131-44

155. Hood FE, Royle SJ. Functional equivalence of the clathrin heavy chains $\mathrm{CHC} 17$ and $\mathrm{CHC} 22$ in endocytosis and mitosis. J Cell Sci. 2009; 122(Pt 13):2185-90.

156. Wakeham DE, Abi-Rached L, Towler MC, Wilbur JD, Parham P, Brodsky FM Clathrin heavy and light chain isoforms originated by independent mechanisms of gene duplication during chordate evolution. Proc Natl Acad Sci U S A. 2005;102(20):7209-14. 
157. Vassilopoulos S, Esk C, Hoshino S, Funke BH, Chen CY, Plocik AM, et al. A role for the $\mathrm{CHC} 22$ Clathrin heavy-chain isoform in human glucose metabolism. Science. 2009;324(5931):1192-6.

158. Kedra D, Peyrard M, Fransson I, Collins JE, Dunham I, Roe BA, et al. Characterization of a second human clathrin heavy chain polypeptide gene (CLH-22) from chromosome 22q11. Hum Mol Genet. 1996:5(5):625-31.

159. Nahorski MS, Al-Gazali L, Hertecant J, Owen DJ, Borner GH, Chen YC, et al. A novel disorder reveals clathrin heavy chain-22 is essential for human pain and touch development. Brain. 2015:138(Pt 8):2147-60.

160. Woolf CJ, Ma Q. Nociceptors--noxious stimulus detectors. Neuron. 2007:55(3):353-64.

161. Hoshino S, Sakamoto K, Vassilopoulos S, Camus SM, Griffin CA, Esk C, et al. The CHC22 clathrin-GLUT4 transport pathway contributes to skeletal muscle regeneration. PLoS One. 2013;8(10):e77787.

162. Towler MC, Gleeso P, Hoshino S, Rahkila P, Manalo V, Ohkoshi N, et al. Clathrin isoform CHC22, a component of neuromuscular and myotendinous junctions, binds sorting nexin 5 and has increased expression during myogenesis and muscle regeneration. Mol Biol Cell. 2004;15(7):3181-95.

163. Kehlenbach RH, Assheuer R, Kehlenbach A, Becker J, Gerace L. Stimulation of nuclear export and inhibition of nuclear import by a ran mutant deficient in binding to ran-binding protein 1. J Biol Chem. 2001;276(17):14524-31.

164. Freitas N, Cunha C. Mechanisms and signals for the nuclear import of proteins. Curr Genomics. 2009;10(8):550-7.

165. Koyama M, Matsuura Y. An allosteric mechanism to displace nuclear export cargo from CRM1 and Ran GTP by RanBP1. EMBO J. 2010;29(12):2002-13.

166. Zhang MS, Arnaoutov A, Dasso M. RanBP1 governs spindle assembly by defining mitotic ran-GTP production. Dev Cell. 2014;31(4):393-404.

167. Ciciarello M, Roscioli E, Di Fiore B, Di Francesco L, Sobrero F, Bernard $D$, et al. Nuclear reformation after mitosis requires downregulation of the Ran GTPase effector RanBP1 in mammalian cells. Chromosoma. 2010;119(6):651-68

168. Fan S, Whiteman EL, Hurd TW, McIntyre JC, Dishinger JF, Liu CJ, et al. Induction of Ran GTP drives ciliogenesis. Mol Biol Cell. 2011;22(23):4539-48.

169. Maynard TM, Haskell GT, Bhasin N, Lee JM, Gassman AA, Lieberman JA, et al. RanBP1, a velocardiofacial/DiGeorge syndrome candidate gene, is expressed at sites of mesenchymal/epithelial induction. Mech Dev. 2002:111(1-2):177-80.

170. Paronett EM, Meechan DW, Karpinski BA, LaMantia AS, Maynard TM. Ranbp1, deleted in DiGeorge/ 22q11.2 deletion syndrome, is a microcephaly gene that selectively disrupts layer 2/3 cortical projection neuron generation. Cereb Cortex. 2015;25(10):3977-93.

171. Cheong HS, Park BL, Kim EM, Park CS, Sohn JW, Kim BJ, et al. Association of RANBP1 haplotype with smooth pursuit eye movement abnormality. Am J Med Genet B Neuropsychiatr Genet. 2011;156B(1):67-71.

172. Wenger TL, Kao C, McDonald-McGinn DM, Zackai EH, Bailey A, Schultz RT, et al. The role of mGluR copy number variation in genetic and environmental forms of syndromic autism spectrum disorder. Sci Rep. 2016;6:19372.

173. Steegmaier M, Yang B, Yoo JS, Huang B, Shen M, Yu S, Luo Y, Scheller RH. Three novel proteins of the syntaxin/SNAP-25 family. J Biol Chem. 1998; 273(51):34171-9.

174. Hohenstein AC, Roche PA. SNAP-29 is a promiscuous syntaxin-binding SNARE. Biochem Biophys Res Commun. 2001;285(2):167-71.

175. Kang J, Bai Z, Zegarek MH, Grant BD, Lee J. Essential roles of snap-29 in C. elegans. Dev Biol. 2011;355(1):77-88.

176. Morelli E, Ginefra P, Mastrodonato V, Beznoussenko GV, Rusten TE, Bilder D, et al. Multiple functions of the SNARE protein Snap29 in autophagy, endocytic, and exocytic trafficking during epithelial formation in Drosophila. Autophagy. 2014;10(12):2251-68.

177. Rapaport DLY, Sprecher E, Horowitz M. Loss of SNAP29 impairs endocytic recycling and cell motility. PLoS One. 2010;5(3):e9759.

178. Wesolowski J, Caldwell V, Paumet F. A novel function for SNAP29 (synaptosomal-associated protein of $29 \mathrm{kDa}$ ) in mast cell phagocytosis. PLoS One. 2012;7(11):e49886

179. Su Q, Mochida S, Tian JH, Mehta R, Sheng ZH. SNAP-29: a general SNARE protein that inhibits SNARE disassembly and is implicated in synaptic transmission. Proc Natl Acad Sci U S A. 2001:98(24):14038-43.

180. Pan PY, Cai Q, Lin L, Lu PH, Duan S, Sheng ZH. SNAP-29-mediated modulation of synaptic transmission in cultured hippocampal neurons. Biol Chem. 2005;280(27):25769-79.
181. Schardt A, Brinkmann BG, Mitkovski M, Sereda MW, Werner HB, Nave KA. The SNARE protein SNAP- 29 interacts with the GTPase Rab3A: implications for membrane trafficking in myelinating glia. J Neurosci Res. 2009;87(15):3465-79.

182. Fuchs-Telem D, Stewart H, Rapaport D, Nousbeck J, Gat A, Gini M, et al. CEDNIK syndrome results from loss-of-function mutations in SNAP29. Br J Dermatol. 2011;164(3):610-6.

183. Sprecher E, Ishida-Yamamoto A, Mizrahi-Koren M, Rapaport D, Goldsher D, Indelman M, et al. A mutation in SNAP29, coding for a SNARE protein involved in intracellular trafficking, causes a novel neurocutaneous syndrome characterized by cerebral dysgenesis, neuropathy, ichthyosis, and palmoplantar keratoderma. Am J Hum Genet. 2005;77(2):242-51.

184. Schiller SA, Seebode C, Wieser GL, Goebbels S, Mobius W, Horowitz M, et al. Establishment of two mouse models for CEDNIK syndrome reveals the pivotal role of SNAP29 in epidermal differentiation. J Invest Dermatol. 2016;136(3):672-9

185. Delorenzi M, Speed T. An HMM model for coiled-coil domains and a comparison with PSSM-based predictions. Bioinformatics. 2002;18(4):617-25.

186. Lindsay EA, Harvey EL, Scambler PJ, Baldini A. ES2, a gene deleted in DiGeorge syndrome, encodes a nuclear protein and is expressed during early mouse development, where it shares an expression domain with a Goosecoid-like gene. Hum Mol Genet. 1998;7(4):629-35.

187. Noma K, Goncharov A, Jin Y. Systematic analyses of rpm-1 suppressors reveal roles for ESS-2 in mRNA splicing in Caenorhabditis elegans. Genetics. 2014;198(3):1101-15.

188. Rizzu P, Lindsay EA, Taylor C, O'Donnell H, Levy A, Scambler P, et al. Cloning and comparative mapping of a gene from the commonly deleted region of DiGeorge and Velocardiofacial syndromes conserved in C. elegans. Mamm Genome. 1996;7(9):639-43.

189. Taricani L, Tejada ML, Young PG. The fission yeast ES2 homologue, Bis1, interacts with the Ish1 stress- responsive nuclear envelope protein. J Biol Chem. 2002;277(12):10562-72.

190. Funato H, Sato M, Sinton CM, Gautron L, Williams SC, Skach A, et al. Loss of Goosecoid-like and DiGeorge syndrome critical region 14 in interpeduncular nucleus results in altered regulation of rapid eye movement sleep. Proc Nat Acad Sci U S A. 2010:107(42):18155-60.

191. Hegele A, Kamburov A, Grossmann A, Sourlis C, Wowro S, Weimann M, et al. Dynamic protein-protein interaction wiring of the human spliceosome. Mol Cell. 2012:45(4):567-80.

192. Bessonov S, Anokhina M, Will CL, Urlaub H, Lührmann R. Isolation of an active step I spliceosome and composition of its RNP core. Nature. 2008; 452(7189):846-50

193. Takada I, Tsuchiya M, Yanaka K, Hidano S, Takahashi S, Kobayashi T, et al. Ess2 bridges transcriptional regulators and spliceosomal complexes via distinct interacting domains. Biochem Biophys Res Commun. 2018; 497(2):597-604.

194. Takada I. DGCR14 induces II17a gene expression through the RORgamma/ BAZ1B/RSKS2 complex. Mol Cell Biol. 2015;35(2):344-55.

195. Gong W, Emaneul B, Galili N, Kim DH, Roe B, Driscoll DA, et al. Structura and mutational analysis of a conserved gene (DGSI) from the minimal DiGeorge syndrome critical region. Hum Mol Genet. 1997;6(2):267-76.

196. Denli AM, Tops BB, Plasterk RH, Ketting RF, Hannon GJ. Processing of primary microRNAs by the microprocessor complex. Nature. 2004;432(7014):231-5.

197. Gregory RI, Yan KP, Amuthan G, Chendrimada T, Doratotaj B, Cooch N, et al. The microprocessor complex mediates the genesis of microRNAs. Nature. 2004;432(7014):235-40.

198. Macias S, Cordiner RA, Gautier P, Plass M, Caceres JF. DGCR8 acts as an adaptor for the exosome complex to degrade double-stranded structured RNAs. Mol Cell. 2015;60(6):873-85.

199. Babiarz JE, Hsu R, Melton C, Thomas M, Ullian EM, Blelloch R. A role for noncanonical microRNAs in the mammalian brain revealed by phenotypic differences in Dgcr8 versus Dicer1 knockouts and small RNA sequencing. RNA. 2011;17(8):1489-501.

200. Stark KL, Xu B, Bagchi A, Lai WS, Liu H, Hsu R, et al. Altered brain microRNA biogenesis contributes to phenotypic deficits in a 22q11-deletion mouse model. Nat Genet. 2008;40(6):751-60.

201. Berdnik D, Fan AP, Potter CJ, Luo L. MicroRNA processing pathway regulates olfactory neuron morphogenesis. Curr Biol. 2008;18(22):1754-9.

202. Luhur A, Chawla G, Wu YC, Li J, Sokol NS. Drosha-independent DGCR8/ pasha pathway regulates neuronal morphogenesis. Proc Natl Acad Sci U S A. $2014 ; 111(4): 1421-6$. 
203. Fénelon K, Mukai J, Xu B, Hsu PK, Drew L, Karayiorgou M, et al. Deficiency of Dgcr8, a gene disrupted by the 22q11.2 microdeletion, results in altered short-term plasticity in the prefrontal cortex. Proc Natl Acad Sci U S A. 2011; 108(11):4447-52.

204. Hsu R, Schofield CM, Dela Cruz CG, Jones-Davis DM, Blelloch R, Ullian EM. Loss of microRNAs in pyramidal neurons leads to specific changes in inhibitory synaptic transmission in the prefrontal cortex. Mol Cell Neurosci. 2012;50(3-4):283-92

205. Schofield CM, Hsu R, Barker AJ, Gertz CC, Blelloch R, Ullian EM. Monoallelic deletion of the microRNA biogenesis gene Dgcr8 produces deficits in the development of excitatory synaptic transmission in the prefrontal cortex. Neural Dev. 2011;6:11. https://doi.org/10.1186/1749-8104-6-11.

206. Meechan DW, Tucker ES, Maynard TM, LaMantia AS. Cxcr4 regulation of interneuron migration is disrupted in 22q11.2 deletion syndrome. Proc Natl Acad Sci U S A. 2012;109(45):18601-6.

207. Toritsuka M, Kimoto S, Muraki K, Landek-Salgado MA, Yoshida A, Yamamoto $\mathrm{N}$, et al. Deficits in microRNA-mediated $\mathrm{Cxcr4/Cxcl} 12$ signaling in neurodevelopmental deficits in a 22q11 deletion syndrome mouse model. Proc Natl Acad Sci U S A. 2013;110(43):17552-7.

208. Lin HP, Oksuz I, Hurley E, Wrabetz L, Awatramani R. Microprocessor complex subunit DiGeorge syndrome critical region gene 8 (Dgcr8) is required for schwann cell myelination and myelin maintenance. J Biol Chem. 2015;290(40):24294-307.

209. Chapnik E, Sasson V, Blelloch R, Hornstein E. Dgcr8 controls neural crest cells survival in cardiovascular development. Dev Biol. 2012;362(1):50-6.

210. Rao PK, Toyama Y, Chiang HR, Gupta S, Bauer M, Medvid R, et al. Loss of cardiac microRNA-mediated regulation leads to dilated cardiomyopathy and heart failure. Circ Res. 2009;105(6):585-94.

211. Baldini A, Fulcoli FG, Illingworth E. Tbx1: transcriptional and developmental functions. Curr Top Dev Biol. 2017;122:223-43.

212. Ataliotis $P$, Ivins $S$, Mohun TJ, Scambler PJ. XTbx1 is a transcriptional activator involved in head and pharyngeal arch development in Xenopus laevis. Dev Dyn. 2005;232(4):979-91

213. Garg V, Yamagishi C, Hu T, Kathiriya IS, Yamagishi H, Srivastava D. Tbx1, a DiGeorge syndrome candidate gene, is regulated by sonic hedgehog during pharyngeal arch development. Dev Biol. 2001;235(1):62-73.

214. Piotrowski T, Ahn DG, Schilling TF, Nair S, Ruvinsky I, Geisler R, et al. The zebrafish van gogh mutation disrupts tbx1, which is involved in the DiGeorge deletion syndrome in humans. Development. 2003; 130(20):5043-52.

215. Smith SJ, Ataliotis P, Kotecha S, Towers N, Sparrow DB, Mohun TJ. The MLC1v gene provides a transgenic marker of myocardium formation within developing chambers of the Xenopus heart. Dev Dyn. 2005;232(4):1003-12.

216. Merscher S, Funke B, Epstein JA, Heyer J, Puech A, Lu MM, et al. TBX1 is responsible for cardiovascular defects in velo-cardio-facial/DiGeorge syndrome. Cell. 2001;104(4):619-29.

217. Lindsay EA, Vitelli F, Su H, Morishima M, Huynh T, Pramparo T, et al. Tbx haploinsufficieny in the DiGeorge syndrome region causes aortic arch defects in mice. Nature. 2001;410(6824):97-101.

218. Jerome LA, Papaioannou VE. DiGeorge syndrome phenotype in mice mutant for the T-box gene, Tbx1. Nat Genet. 2001;27(3):286-91.

219. Arnold JS, Werling U, Braunstein EM, Liao J, Nowotschin S, Edelmann W, et al. Inactivation of Tbx1 in the pharyngeal endoderm results in 22q11DS malformations. Development. 2006;133(5):977-87.

220. Vitelli F, Morishima M, Taddei I, Lindsay EA, Baldini A. Tbx1 mutation causes multiple cardiovascular defects and disrupts neural crest and cranial nerve migratory pathways. Hum Mol Genet. 2002;11(8):915-22.

221. Dastjerdi A, Robson L, Walker R, Hadley J, Zhang Z, Rodriguez-Niedenführ M, et al. Tbx1 regulation of myogenic differentiation in the limb and cranial mesoderm. Dev Dyn. 2007;236(2):353-63.

222. Vitelli F. TBX1 is required for inner ear morphogenesis. Human molecular genetics. 2003;12(16):2041-8.

223. Zoupa M, Seppala M, Mitsiadis T, Cobourne MT. Tbx1 is expressed at multiple sites of epithelial- mesenchymal interaction during early development of the facial complex. Int J Dev Biol. 2006;50(5):504-10.

224. Vitelli F, Taddei I, Morishima M, Meyers EN, Lindsay EA, Baldini A. A genetic link between $\mathrm{Tbx} 1$ and fibroblast growth factor signaling. Development. 2002;129(19):4605-11.

225. Yagi H, Furutani Y, Hamada H, Sasaki T, Asakawa S, Minoshima S, et al. Role of TBX1 in human del22q11.2 syndrome. Lancet. 2003;362(9393):1366-73.
226. Funke B, Saint-Jore B, Puech A, Sirotkin H, Edelmann L, Carlson C, et al. Characterization and mutation analysis of goosecoid-like (GSCL), a homeodomain-containing gene that maps to the critical region for VCFS/ DGS on 22q11. Genomics. 1997;46(3):364-72.

227. Rivera-Pérez JA, Mallo M, Gendron-Maguire M, Gridley T, Behringer RR. Goosecoid is not an essential component of the mouse gastrula organizer but is required for craniofacial and rib development. Development. 1995;121(9):3005-12.

228. Gottlieb S, Hanes DS, Golden JA, Oakey RJ, Budarf ML. Goosecoid-like, a gene deleted in DiGeorge and velocardiofacial syndromes, recognizes DNA with a bicoid-like specificity and is expressed in the developing mouse brain. Hum Mol Genet. 1998;7(9):1497-505.

229. Saint-Jore B, Puech A, Heyer J, Lin Q, Raine C, Kucherlapati R, Skoultchi Al. Goosecoid-like (Gscl), a candidate gene for velocardiofacial syndrome, is not essential for normal mouse development. Hum Mol Genet. 1998;7(12):1841-9.

230. Malik S, Roeder RG. The metazoan mediator co-activator complex as an integrative hub for transcriptional regulation. Nat Rev Genet. 2010; 11(11):761-72.

231. Poss ZC, Ebmeier CC, Taatjes DJ. The mediator complex and transcription regulation. Crit Rev Biochem Mol Biol. 2013;48(6):575-608.

232. Suzuki Y, Nogi Y, Abe A, Fukasawa T. GAL11 protein, an auxiliary transcription activator for genes encoding galactose-metabolizing enzymes in Saccharomyces cerevisiae. Mol Cell Biol. 1992;12(10):4806.

233. Thakur JK, Arthanari H, Yang F, Chau KH, Wagner G, Naar AM. Mediator subunit Gal11p/MED15 is required for fatty acid-dependent gene activation by yeast transcription factor Oaf1p. J Biol Chem. 2009;284(7): 4422-8.

234. Yang F, Vought BW, Satterlee JS, Walker AK, Jim Sun ZY, Watts JL, et al. An ARC/mediator subunit required for SREBP control of cholesterol and lipid homeostasis. Nature. 2006;442(7103):700-4.

235. Hou NS, Gutschmidt A, Choi DY, Pather K, Shi X, Watts JL, et al. Activation of the endoplasmic reticulum unfolded protein response by lipid disequilibrium without disturbed proteostasis in vivo. Proc Natl Acad Sci U S A. 2014;111(22):E2271-80.

236. Taubert S, Hansen M, Van Gilst MR, Cooper SB, Yamamoto KR. The mediator subunit MDT-15 confers metabolic adaptation to ingested material. PLoS Genet. 2008;4(2):e1000021.

237. Terriente-Felix A, Lopez-Varea A, de Celis JF. Identification of genes affecting wing patterning through a loss-of-function mutagenesis screen and characterization of med15 function during wing development. Genetics. 2010;185(2):671-84.

238. Kato $Y$, Habas R, Katsuyama $Y$, Näär AM, He X. A component of the $\mathrm{ARC} /$ mediator complex required for TGF beta/nodal signalling. Nature. 2002:418(6898):641-6.

239. Dhanoa BS, Cogliati T, Satish AG, Bruford EA, Friedman JS. Update on the Kelch-like (KLHL) gene family. Hum Genomics. 2013;7(13). https://doi.org/10. 1186/479-7364-7-13

240. Albagli O, Dhordain P, Deweindt C, Lecocq G, Leprince D. The BTB/POZ domain: a new protein-protein interaction motif common to DNA- and actin-binding proteins. Cell Growth Differ. 1995:6(9):1193-8.

241. Beck J, Maerki S, Posch M, Metzger T, Persaud A, Scheel H, et al. Ubiquitylation-dependent localization of PLK1 in mitosis. Nat Cell Biol. 2013; 15(4):430-9.

242. Metzger T, Kleiss C, Sumara I. CUL3 and protein kinases: insights from PLK1/ KLHL22 interaction. Cell Cycle. 2013;12(14):2291-6.

243. Furukawa M, He YJ, Borchers C, Xiong Y. Targeting of protein ubiquitination by BTB-Cullin 3-Roc1 ubiquitin ligases. Nat Cell Biol. 2003;5(11):1001-7.

244. Adams J, Kelso R, Cooley L. The kelch repeat superfamily of proteins: propellers of cell function. Trends Cell Biol. 2000;10(1):17-24.

245. Yang Y, Allen E, Ding J, Wang W. Giant axonal neuropathy. Cell Mol Life Sci. 2007;64(5):601-9.

246. Nacak TG, Leptien K, Fellner D, Augustin HG, Kroll J. The BTB-kelch protein LZTR-1 is a novel Golgi protein that is degraded upon induction of apoptosis. J Biol Chem. 2006;281(8):5065-71.

247. Paganini I, Chang VY, Capone GL, Vitte J, Benelli M, Barbetti L, et al. Expanding the mutational spectrum of LZTR1 in schwannomatosis. Eur J Hum Genet. 2015;23(7):963-8.

248. Piotrowski A, Xie J, Liu YF, Poplawski AB, Gomes AR, Madanecki P, et al. Germline loss-of-function mutations in LZTR1 predispose to an inherited disorder of multiple schwannomas. Nat Genet. 2014;46(2):182-7. 
249. Johnston JJ, van der Smagt JJ, Rosenfeld JA, Pagnamenta AT, Alswaid A Baker $\mathrm{EH}$, et al. Autosomal recessive Noonan syndrome associated with biallelic LZTR1 variants. Genet Med. 2018; 20(10):1175-85.

250. Matthews JM, Sunde M. Zinc fingers-folds for many occasions. IUBMB Life. 2002;54(6):35.

251. Brayer KJ, Segal DJ. Keep your fingers off my DNA: protein-protein interactions mediated by $\mathrm{C} 2 \mathrm{H} 2$ zinc finger domains. Cell Biochem Biophys. 2008;50(3):111-31.

252. Hall TM. Multiple modes of RNA recognition by zinc finger proteins. Curr Opin Struct Biol. 2005;15(3):367-73.

253. Guddat U, Bakken AH, Pieler T. Protein-mediated nuclear export of RNA: $5 S$ rRNA containing small RNPs in xenopus oocytes. Cell. 1990;60(4):619-28.

254. Theunissen O, Rudt F, Guddat U, Mentzel H, Pieler T. RNA and DNA binding zinc fingers in Xenopus TFIIIA. Cell. 1992;71(4):679-90.

255. Grondin BBM, Aubry M. The KRAB zinc finger gene ZNF74 encodes an RNAbinding protein tightly associated with the nuclear matrix. J Biol Chem. 1996;271(26):15458-67.

256. Grondin BCF, Bazinet M, Vincent M, Aubry M. Direct interaction of the KRAB/Cys2-His2 zinc finger protein ZNF74 with a hyperphosphorylated form of the RNA polymerase II largest subunit. J Biol Chem. 1997;272(44):27877-85.

257. Dykes IM, van Bueren KL, Scambler PJ. HIC2 regulates isoform switching during maturation of the cardiovascular system. J Mol Cell Cardiol. 2018;114:29-37.

258. Dykes IM, van Bueren KL, Ashmore RJ, Floss T, Wurst W, Szumska D, et al. HIC2 is a novel dosage- dependent regulator of cardiac development located within the distal 22q11 deletion syndrome region. Circ Res. 2014;115(1):23-31.

259. Roussigne M, Kossida S, Lavigne AC, Clouaire T, Ecochard V, Glories A, et al. The THAP domain: a novel protein motif with similarity to the DNA-binding domain of P element transposase. Trends Biochem Sci. 2003;28(2):66-9.

260. Reddy KC, Villeneuve AM. C. elegans HIM-17 links chromatin modification and competence for initiation of meiotic recombination. Cell. 2004;118(4):439-52.

261. Macfarlan T, Kutney S, Altman B, Montross R, Yu J, Chakravarti D. Human THAP7 is a chromatin- associated, histone tail-binding protein that represses transcription via recruitment of HDAC3 and nuclear hormone receptor corepressor. J Biol Chem. 2005;280(8):7346-58.

262. Macfarlan T, Parker JB, Nagata K, Chakravarti D. Thanatos-associated protein 7 associates with template activating factor-lbeta and inhibits histone acetylation to repress transcription. Mol Endocrinol. 2006;20(2): 335-47.

263. Hiramoto T, Kang G, Suzuki G, Satoh Y, Kucherlapati R, Watanabe $Y$, et al. Tbx1: identification of a 22q11.2 gene as a risk factor for autism spectrum disorder in a mouse model. Hum Mol Genet. 2011;20(24):4775-85.

264. LaMantia AS, Moody SA, Maynard TM, Karpinski BA, Zohn IE, Mendelowitz D, et al. Hard to swallow: developmental biological insights into pediatric dysphagia. Dev Biol. 2016;409(2):329-42.

265. Schwab ME. Functions of Nogo proteins and their receptors in the nervous system. Nat Rev Neurosci. 2010;11(12):799-811.

266. Fournier AEGT, Strittmatter SM. Identification of a receptor mediating Nogo66 inhibition of axonal regeneration. Nature. 2001;409(6818):341-6.

267. Huebner EA, Kim BG, Duffy PJ, Brown RH, Strittmatter SM. A multi-domain fragment of Nogo-A protein is a potent inhibitor of cortical axon regeneration via Nogo receptor 1. J Biol Chem. 2011;286(20):18026-36.

268. Kim JE, Liu BP, Park JH, Strittmatter SM. Nogo-66 receptor prevents raphespinal and rubrospinal axon regeneration and limits functional recovery from spinal cord injury. Neuron. 2004;44(3):439-51.

269. Wang KC, Koprivica V, Kim JA, Sivasankaran R, Guo Y, Neve RL, et al. Oligodendrocyte-myelin glycoprotein is a Nogo receptor ligand that inhibits neurite outgrowth. Nature. 2002;417(6892):941-4.

270. Merkler D, Metz G, Raineteau O, Dietz V, Schwab ME, Fouad K. Locomotor recovery in spinal cord-injured rats treated with an antibody neutralizing the myelin-associated neurite growth inhibitor Nogo-A. J Neurosci. 2001:21(10):3665-73

271. Emerick AJ, Neafsey E, Schwab ME, Kartje GL. Functional reorganization of the motor cortex in adult rats after cortical lesion and treatment with monoclonal antibody IN-1. J Neurosci. 2003;23(12):4826-30.

272. Lee H, Raiker SJ, Venkatesh K, Geary R, Robak LA, Zhang Y, et al. Synaptic function for the Nogo-66 receptor NgR1: regulation of dendritic spine morphology and activity-dependent synaptic strength. J Neurosci. 2008; 28(11):2753-65.
273. Peng X, Kim J, Zhou Z, Fink DJ, Mata M. Neuronal Nogo-A regulates glutamate receptor subunit expression in hippocampal neurons. J Neurochem. 2011;119(6):1183-93.

274. Wills ZP, Mandel-Brehm C, Mardinly AR, McCord AE, Giger RJ, Greenberg ME. The Nogo receptor family restricts synapse number in the developing hippocampus. Neuron. 2012;73(3):466-81.

275. Murthy R, Kim J, Sun X, Giger RJ, Fink DJ, Mata M. Post-transcriptional regulation of GABAB receptor and GIRK1 channels by Nogo receptor 1 . Mol Brain. 2013;6(30). https://doi.org/10.1186/756-6606-6-30.

276. Karlén A, Karlsson T, Mattsson A, Lundströmer K, Codeluppi S, Pham TM. Nogo receptor 1 regulates formation of lasting memories. Proc Natl Acad Sci U S A. 2009;106(48):20476-81.

277. McGee AW, Yang Y, Fischer QS, Daw NW, Strittmatter SM. Experience-driven plasticity of visual cortex limited by myelin and Nogo receptor. Science. 2005:309(5744):2222-6.

278. Stephany CE, Chan LL, Parivash SN, Dorton HM, Piechowicz M, Qiu S, et al. Plasticity of binocularity and visual acuity are differentially limited by nogo receptor. J Neurosci. 2014;34(35):11631-40.

279. Lee JK, Chan AF, Luu SM, Zhu Y, Ho C, Tessier-Lavigne M, et al. Reassessment of corticospinal tract regeneration in Nogo-deficient mice. J Neurosci. 2009;29(27):8649-54.

280. Zheng B, Atwal J, Ho C, Case L, He XL, Garcia KC, et al. Genetic deletion of the Nogo receptor does not reduce neurite inhibition in vitro or promote corticospinal tract regeneration in vivo. Proc Natl Acad Sci U S A. 2005; 102(4):1205-10

281. Zheng B, Ho C, Li S, Keirstead H, Steward O, Tessier-Lavigne M. Lack of enhanced spinal regeneration in Nogo-deficient mice. Neuron. 2003:38:213-24.

282. Mathis C, Schroter A, Thallmair M, Schwab ME. Nogo-a regulates neural precursor migration in the embryonic mouse cortex. Cereb Cortex. 2010; 20(10):2380-90.

283. Ramasamy S, Yu F, Hong Yu Y, Srivats H, Dawe GS, Ahmed S. NogoR1 and PirB signaling stimulates neural stem cell survival and proliferation. Stem Cells. 2014:32(6):1636-48.

284. Wang B, Xiao Z, Chen B, Han J, Gao Y, Zhang J, et al. Nogo-66 promotes the differentiation of neural progenitors into astroglial lineage cells through mTOR-STAT3 pathway. PLoS One. 2008;3(3):e1856.

285. Gao Y, Wang B, Xiao Z, Chen B, Han J, Wang X, et al. Nogo-66 regulates nanog expression through stat3 pathway in murine embryonic stem cells. Stem Cells Dev. 2010;19(1):53-60.

286. Rolando C, Parolisi R, Boda E, Schwab ME, Rossi F, Buffo A. Distinct roles of Nogo-a and Nogo receptor 1 in the homeostatic regulation of adult neural stem cell function and neuroblast migration. J Neurosci. 2012;32(49):17788-99.

287. Perlstein MD, Chohan MR, Coman IL, Antshel KM, Fremont WP, Gnirke MH, et al. White matter abnormalities in 22q11.2 deletion syndrome: preliminary associations with the Nogo-66 receptor gene and symptoms of psychosis. Schizophr Res. 2014;152(1):117-23.

288. Thompson CA, Karelis J, Middleton FA, Gentile K, Coman IL, Radoeva PD, et al. Associations between neurodevelopmental genes, neuroanatomy, and ultra high risk symptoms of psychosis in 22q11.2 deletion syndrome. Am J Med Genet B Neuropsychiatr Genet. 2017;174(3):295-314

289. Fang Y, Yan J, Li C, Zhou X, Yao L, Pang T, et al. The Nogo/Nogo receptor $(\mathrm{NgR})$ signal is involved in neuroinflammation through the regulation of microglial inflammatory activation. J Biol Chem. 2015; 290(48):28901-14

290. Pool M, Niino M, Rambaldi I, Robson K, Bar-Or A, Fournier AE. Myelin regulates immune cell adhesion and motility. Exp Neurol. 2009;217(2):371-7.

291. Yan J, Zhou X, Guo JJ, Mao L, Wang YJ, Sun J, et al. Nogo-66 inhibits adhesion and migration of microglia via GTPase rho pathway in vitro. J Neurochem. 2012;120(5):721-31.

292. Evans RJ, Surprenant A. Vasoconstriction of Guinea-pig submucosal arterioles following sympathetic nerve stimulation is mediated by the release of ATP. Br J Pharmacol. 1992;106(2):242-9.

293. Nieber K, Poelchen W, Illes P. Role of ATP in fast excitatory synaptic potentials in locus coeruleus neurones of the rat. Br J Pharmacol. 1997;122(3):423-30.

294. Pankratov Y, Castro E, Miras-Portugal MT, Krishtal O. A purinergic component of the excitatory post- synaptic current mediated by P2X receptors in the CA1 neurons of the rat hippocampus. Eur J Neurosci. 1998; 10(12):3898-902. 
295. Ryten M, Hoebertz A, Burnstock G. Sequential expression of three receptor subtypes for extracellular ATP in developing rat skeletal muscle. Dev Dyn. 2001;22(3):331-41.

296. King BF, Towsend-Nicholson A, Wildman SS, Thomas T, Spyer KM, Burnstock G. Coexpression of rat P2X2 and P2X6 subunits in Xenopus oocytes. J Neurosci. 2000;20(13):4871-7.

297. Lê KT, Babinski K, Séguéla P. Central P2X4 and P2X6 channel subunits coassemble into a novel heteromeric ATP receptor. J Neurosci. 1998; 18(18):7152-9.

298. Collo G, North RA, Kawashima E, Merlo-Pich E, Neidhart S, Surprenant A, et al. Cloning of $P 2 X$, and $P 2 X$, receptors and the distribution and properties of an extended family of ATP-gated ion channels. J Neurosci. 1996:16(8):2495-507.

299. Kameda Y, Saitoh T, Nemoto N, Katoh T, Iseki S. Hes1 is required for the development of the superior cervical ganglion of sympathetic trunk and the carotid body. Dev Dyn. 2012;241(8):1289-300.

300. Cheung KK, Chan WY, Burnstock G. Expression of P2X purinoceptors during rat brain development and their inhibitory role on motor axon outgrowth in neural tube explant cultures. Neuroscience. 2005;133(4):937-45.

301. da Silva RL, Resende RR, Ulrich H. Alternative splicing of P2X6 receptors in developing mouse brain and during in vitro neuronal differentiation. Exp Physiol. 2007;92(1):139-45.

302. Rubio ME, Soto F. Distinct localization of $P 2 X$ receptors at excitatory postsynaptic specializations. J Neurosci. 2001;21(2):641-53.

303. Schwindt TT, Trujillo CA, Negraes PD, Lameu C, Ulrich H. Directed differentiation of neural progenitors into neurons is accompanied by altered expression of P2X purinergic receptors. J Mol Neurosci. 2011;44(3):141-6.

304. Closs El, Boissel JP, Habermeier A, Rotmann A. Structure and function of cationic amino acid transporters (CATs). J Membr Biol. 2006;213(2):67-77.

305. Wolf SJA, Vékony N, Martiné U, Strand D, Closs El. Expression of solute carrier 7A4 (SLC7A4) in the plasma membrane is not sufficient to mediate amino acid transport activity. Biochem J. 2002;364(Pt3):767-75.

306. Zheng B, Ho C, Li S, Keirstead H, Steward O, Tessier-Lavigne M. Lack of enhanced spinal regeneration in Nogo-deficient mice. Neuron. 2003;38(2):213-24.

307. Mitsubuchi H, Nakamura K, Matsumoto S, Endo F. Biochemical and clinical features of hereditary hyperprolinemia. Pediatr Int. 2014;56(4):492-6.

308. Wang SS, Brandriss MC. Proline utilization in Saccharomyces cerevisiae: sequence, regulation, and mitochondrial localization of the PUT1 gene product. Mol Cell Biol. 1987;7(12):4431-40.

309. Takemoto Y, Semba R. Immunohistochemical evidence for the localization of neurons containing the putative transmitter L-proline in rat brain. Brain Res. 2006;1073-1074:311-5.

310. Maynard TM, Meechan DW, Dudevoir ML, Gopalakrishna D, Peters AZ, Heindel CC, et al. Mitochondrial localization and function of a subset of 22 q11 deletion syndrome candidate genes. Mol Cell Neurosci. 2008;39(3):439-51.

311. Meechan DW, Maynard TM, Wu Y, Gopalakrishna D, Lieberman JA, LaMantia AS. Gene dosage in the developing and adult brain in a mouse model of 22q11 deletion syndrome. Mol cell Neurosci. 2006;33(4):412-28. 312. Nadler JV, Wang A, Hakim A. toxicity of L-proline toward rat hippocampal neurons. Brain Res. 1988:456(1):168-72

312. Nadler JV, Wang A, Hakim A. Toxicity of L-proline toward rat hippocampal neurons. Brain Res. 1988;456(1):168-72.

313. Nickolson VJ. "On" and "off" responses of $\mathrm{K}^{+}$-induced synaptosomal proline release: involvement of the sodium pump. J Neurochem. 1982; 38(1):289-92.

314. Ault B, Wang CM, Yawn BC. L-proline depolarizes rat spinal motoneurones by an excitatory amino acid antagonist-sensitive mechanism. $\mathrm{Br}$ J Pharmacol. 1987;92(2):319-26.

315. Cohen SM, Nadler JV. Proline-induced potentiation of glutamate transmission. Brain Res. 1997;761(2):271-82.

316. Henzi V, Reichling DB, Helm SW, MacDermott AB. L-proline activates glutamate and glycine receptors in cultured rat dorsal horn neurons. Mol Pharmacol. 1992;4(14):793-801.

317. Martin D, Ault B, Nadler JV. NMDA receptor-mediated depolarizing action of proline on CA1 pyramidal cells. Eur J Pharmacol. 1992;219(1):59-66.

318. Cohen SM, Nadler JV. Proline-induced inhibition of glutamate release in hippocampal area CA1. Brain Res. 1997;769(2):333-9.

319. Bavaresco CS, Luíz Streck E, Netto CA, de Wyse ATS. Chronic hyperprolinemia provokes a memory deficit in the Morris water aaze task. Metab Brain Dis. 2005;20(1):73-80.
320. Baxter CF, Baldwin RA, Davis JL, Flood JF. High proline levels in the brains of mice as related to specific learning deficits. Pharmacol Biochem Behav. 1985;22(6):1053-9.

321. Davis JL, Pico RM, Flood JF. Differences in learning between hyperprolinemic mice and their congenic controls. Behav Neural Biol. 1987:48(1):128-37.

322. Gogos JA, Santha M, Takacs Z, Beck KD, Luine V, Lucas LR, et al. The gene encoding proline dehydro- genase modulates sensorimotor gating in mice. Nat Genet. 1999;21(4):434-9.

323. Bender HU, Almashanu S, Steel G, Hu CA, Lin WW, Willis A, et al. Functional consequences of PRODH missense mutations. Am J Hum Genet. 2005;76(3):409-20.

324. Afenjar A, Moutard ML, Doummar D, Guet A, Rabier D, Vermersch Al, et al. Early neurological phenotype in 4 children with biallelic PRODH mutations. Brain and Development. 2007:29(9):547-52.

325. Jacquet H, Berthelot J, Bonnemains C, Simard G, Saugier-Veber P, Raux G, et al. The severe form of type I hyperprolinaemia results from homozygous inactivation of the PRODH gene. J Med Genet. 2003;40(1):e7.

326. Jacquet H, Raux G, Thibaut F, Hecketsweiler B, Houy E, Demilly C, et al. $\mathrm{PRODH}$ mutations and hyper- prolinemia in a subset of schizophrenic patients. Hum Mol Genet. 2002;11(19):2243-9.

327. Johnson EC, Border R, Melroy-Greif WE, de Leeuw CA, Ehringer MA, Keller MC. No evidence that schizophrenia candidate genes are more associated with schizophrenia than noncandidate genes. Biol Psychiatry. 2017;82(10):702-8

328. Jia L, Kaur J, Stuart RA. Mapping of the Saccharomyces cerevisiae Oxa1mitochondrial ribosome interface and identification of MrpL40, a ribosomal protein in close proximity to Oxa1 and critical for oxidative phosphorylation complex assembly. Eukaryot Cell. 2009;8(11):1792-802.

329. Funke BPA, Saint-Jore B, Pandita R, Skoultchi A, Morrow B. Isolation and characterization of a human gene containing a nuclear localization signal from the critical region for Velo-cardio-facial syndrome on 22q11. Genomics. 1998;53(2):146-54.

330. Allendoerfer $\mathrm{KL}$, Shatz CJ. The subplate, a transient neocortical structure: its role in the development of connections between thalamus and cortex. Annu Rev Neurosci. 1994;17:185-218.

331. Hoerder-Suabedissen A, Molnar Z. Development, evolution and pathology of neocortical subplate neurons. Nat Rev Neurosci. 2015;16(3):133-46.

332. Devaraju P, Yu J, Eddins D, Mellado-Lagarde MM, Earls LR, Westmoreland JJ, et al. Haploinsufficiency of the 22q11.2 microdeletion gene Mrpl40 disrupts short-term synaptic plasticity and working memory through dysregulation of mitochondrial calcium. Mol Psychiatry. 2016;22(9):1313-26.

333. Bard F, Casano L, Mallabiabarrena A, Wallace E, Saito K, Kitayama H, et al. Functional genomics reveals genes involved in protein secretion and Golgi organization. Nature. 2006;439(7076):604-7.

334. Kremer LS, Distelmaier F, Alhaddad B, Hempel M, luso A, Kupper C, et al. Bi-allelic truncating mutations in TANGO2 cause infancy-onset recurrent metabolic crises with encephalocardiomyopathy. Am J Hum Genet. 2016;98(2):358-62.

335. Lalani SR, Liu P, Rosenfeld JA, Watkin LB, Chiang T, Leduc MS, et al. Recurrent muscle weakness with rhabdomyolysis, metabolic crises, and cardiac arrhythmia due to bi-allelic TANGO2 mutations. Am J Hum Genet. 2016;98(2):347-57

336. Fukata Y, Fukata M. Protein palmitoylation in neuronal development and synaptic plasticity. Nat Rev Neurosci. 2010;11(3):161-75.

337. Mukai J, Dhilla A, Drew LJ, Stark KL, Cao L, MacDermott AB, et al. Palmitoylation-dependent neuro- developmental deficits in a mouse model of 22q11 microdeletion. Nat Neurosci. 2008;11(11):1302-10.

338. Mukai J, Tamura M, Fenelon K, Rosen AM, Spellman TJ, Kang R, et al. Molecular substrates of altered axonal growth and brain connectivity in a mouse model of schizophrenia. Neuron. 2015;86(3):680-95.

339. Charych El, Akum BF, Goldberg JS, Jornsten RJ, Rongo C, Zheng JQ, et al. Activity-independent regulation of dendrite patterning by postsynaptic density protein PSD-95. J Neurosci. 2006;26(40):10164-76.

340. Ehrlich I, Malinow R. Postsynaptic density 95 controls AMPA receptor incorporation during long-term potentiation and experience-driven synaptic plasticity. J Neurosci. 2004;24(4):916-27.

341. El-Husseini AE, Schnell E, Chetkovich DM, Nicoll RA, Bredt DS. PSD-95 involvement in maturation of excitatory synapses. Science. 2000; 290(5495):1364-8. 
342. Ho GP, Selvakumar B, Mukai J, Hester LD, Wang Y, Gogos JA, et al. Snitrosylation and S-palmitoylation reciprocally regulate synaptic targeting of PSD-95. Neuron. 2011;71(1):131-41.

343. Thomas GM, Hayashi T, Huganir RL, Linden DJ. DHHC8-dependent PICK1 palmitoylation is required for induction of cerebellar long-term synaptic depression. J Neurosci. 2013;33(39):15401-7.

344. Ebersole B, Petko J, Woll M, Murakami S, Sokolina K, Wong V, et al. Effect of C-terminal S-palmitoylation on D2 dopamine receptor trafficking and stability. PLoS One. 2015;10(11):e0140661.

345. Mukai J, Liu H, Burt RA, Swor DE, Lai WS, Karayiorgou M, et al. Evidence that the gene encoding $\mathrm{ZDHHC} 8$ contributes to the risk of schizophrenia. Nat Genet. 2004;36(7):725-31.

346. Giudetti AM, Stanca E, Siculella L, Gnoni GV, Damiano F. Nutritional and hormonal regulation of citrate and carnitine/acylcarnitine transporters: two mitochondrial carriers involved in fatty acid metabolism. Int J Mol Sci. 2016; 17(6):817.

347. Morciano P, Carrisi C, Capobianco L, Mannini L, Burgio G, Cestra G, et al. A conserved role for the mitochondrial citrate transporter sea/SLC25A1 in the maintenance of chromosome integrity. Hum Mol Genet. 2009;18(21):4180-8.

348. Catalina-Rodriguez O, Kolukula VK, Tomita Y, Preet A, Palmieri F, Wellstein A, et al. The mitochondrial citrate transporter, $\mathrm{CIC}$, is essential for mitochondrial homeostasis. Oncotarget. 2012;3(10):1220-35.

349. Infantino $V$, lacobazzi $V$, Menga A, Avantaggiati ML, Palmieri F. A key role of the mitochondrial citrate carrier (SLC25A1) in TNFalpha- and IFNgammatriggered inflammation. Biochim Biophys Acta. 2014;1839(11):1217-25.

350. Majd H, King MS, Smith AC, Kunji ERS. Pathogenic mutations of the human mitochondrial citrate carrier SLC25A1 lead to impaired citrate export required for lipid, dolichol, ubiquinone and sterol synthesis. Biochim Biophys Acta Bioenerg. 2018;1859(1):1-7.

351. Chaouch A, Porcelli V, Cox D, Edvardson S, Scarcia P, De Grassi A, et al Mutations in the mitochondrial citrate carrier SLC25A1 are associated with impaired neuromuscular transmission. J Neuromuscul Dis. 2014;1(1):75-90.

352. Nota B, Struys EA, Pop A, Jansen EE, Fernandez Ojeda MR, Kanhai WA, et al. Deficiency in SLC25A1, encoding the mitochondrial citrate carrier, causes combined D-2- and L-2-hydroxyglutaric aciduria. Am J Hum Genet. 2013:92(4):627-31.

353. Smith A, McBride S, Marcadier JL, Michaud J, Al-Dirbashi OY, Schwartzentruber J, et al. Severe neonatal presentation of mitochondrial citrateccarrier (SLC25A1) deficiency. In: JIMD Rep 2016 Jun 16; 2016.

354. Edvardson S, Porcelli V, Jalas C, Soiferman D, Kellner Y, Shaag A, et al. Agenesis of corpus callosum and optic nerve hypoplasia due to mutations in SLC25A1 encoding the mitochondrial citrate transporter. J Med Genet. 2013;50(4):240-5

355. Prasun P, Young S, Salomons G, Werneke A, Jiang YH, Struys E, et al. Expanding the clinical spectrum of mitochondrial citrate carrier (SLC25A1) deficiency: facial dysmorphism in siblings with epileptic encephalopathy and combined D,L-2-hydroxyglutaric aciduria. JIMD Rep. 2015;19:111-5.

356. Eguchi M, Ozaki E, Yamauchi T, Ohta M, Higaki T, Masuda K, et al. Manifestation of recessive combined D-2-, L-2-hydroxyglutaric aciduria in combination with 22q11.2 deletion syndrome. Am J Med Genet A. 2018;176(2):351-8.

357. Damdimopoulos AE, Miranda-Vizuete A, Pelto-Huikko M, Gustafsson JA, Spyrou G. Human mitochondrial thioredoxin. Involvement in mitochondrial membrane potential and cell death. J Biol Chem. 2002;277(36):33249-57.

358. Turanov AA, Su D, Gladyshev VN. Characterization of alternative cytosolic forms and cellular targets of mouse mitochondrial thioredoxin reductase. J Biol Chem. 2006;281(32):22953-63.

359. Conrad M. Transgenic mouse models for the vital selenoenzymes cytosolic thioredoxin reductase, mitochondrial thioredoxin reductase and glutathione peroxidase 4. Biochim Biophys Acta. 2009;1790(11):1575-85

360. Kim MR, Chang HS, Kim BH, Kim S, Baek SH, Kim JH, et al. Involvements of mitochondrial thioredoxin reductase (TrxR2) in cell proliferation. Biochem Biophys Res Commun. 2003;304(1):119-24.

361. Tanaka T, Hosoi F, Yamaguchi-Iwai Y, Nakamura H, Masutani H, Ueda S, et al. Thioredoxin-2 (TRX-2) is an essential gene regulating mitochondriadependent apoptosis. EMBO J. 2002;21(7):1695-703.

362. Conrad M, Jakupoglu C, Moreno SG, Lippl S, Banjac A, Schneider M, et al. Essential role for mitochondrial thioredoxin reductase in hematopoiesis, heart development, and heart function. Mol Cell Biol. 2004;24(21):9414-23.
363. Sibbing D, Pfeufer A, Perisic T, Mannes AM, Fritz-Wolf K, Unwin S, et al. Mutations in the mitochondrial thioredoxin reductase gene TXNRD2 cause dilated cardiomyopathy. Eur Heart J. 2011;32(9):1121-33.

364. Horstkotte J, Perisic T, Schneider M, Lange P, Schroeder M, Kiermayer C, et al. Mitochondrial thioredoxin reductase is essential for early postischemic myocardial protection. Circulation. 2011;124(25):2892-902.

365. Kiermayer C, Northrup E, Schrewe A, Walch A, de Angelis MH, Schoensiegel $F$, et al. Heart-specific knockout of the mitochondrial thioredoxin reductase (Txnrd2) induces metabolic and contractile dysfunction in the aging myocardium. J Am Heart Assoc. 2015;4(7):e002153.

366. Soerensen J, Jakupoglu C, Beck H, Forster H, Schmidt J, Schmahl W, et al. The role of thioredoxin reductases in brain development. PLoS One. 2008;3(3):e1813.

367. Beck MA, Levander OA, Handy J. Selenium deficiency and viral infection. J Nutr. 2003;133(5 Suppl 1):1463S-7S

368. Khoso PA, Yang Z, Liu C, Li S. Selenium deficiency downregulates selenoproteins and suppresses immune function in chicken thymus. Biol Trace Elem Res. 2015;167(1):48-55.

369. Geisberger R, Kiermayer C, Homig C, Conrad M, Schmidt J, ZimberStrobl U, et al. B- and T-cell-specific inactivation of thioredoxin reductase 2 does not impair lymphocyte development and maintenance. Biol Chem. 2007;388(10):1083-90.

370. Ge KY, Xue A, Bai J, Wang SQ. Keshan disease - an endemic cardiomyopathy in China. Virchows Arch A Pathol Anat Histol. 1983;401(1):1-15.

371. Andrews RK, Berndt MC. Bernard-Soulier syndrome: an update. Semin Thromb Hemost. 2013;39(6):656-62

372. Sumitha E, Jayandharan GR, David S, Jacob RR, Sankari Devi G, Bargavi B, et al. Molecular basis of Bernard-Soulier syndrome in 27 patients from India. J Thromb Haemost. 2011;9(8):1590-8.

373. Gooptu B, Lomas DA. Polymers and inflammation: disease mechanisms of the serpinopathies. J Exp Med. 2008;205(7):1529-34.

374. Rein CM, Desai UR, Church FC. Serpin-glycosaminoglycan interactions. Methods Enzymol. 2011;501:105-37.

375. Aihara K, Azuma H, Akaike M, Ikeda Y, Sata M, Takamori N, et al. Straindependent embryonic lethality and exaggerated vascular remodeling in heparin cofactor II-deficient mice. J Clin Invest. 2007;117(6):1514-26.

376. Ikeda Y, Aihara K, Yoshida S, Iwase T, Tajima S, Izawa-Ishizawa Y, et al. Heparin cofactor II, a serine protease inhibitor, promotes angiogenesis via activation of the AMP-activated protein kinase-endothelial nitric-oxide synthase signaling pathway. J Biol Chem. 2012;287(41):34256-63.

377. Hoogendoorn B, Coleman SL, Guy CA, Smith SK, O'Donovan MC, Buckland PR. Functional analysis of polymorphisms in the promoter regions of genes on 22q11. Hum Mutat. 2004;24(1):35-42.

378. Akar NA, Adekile AD. Chromosome 22q11.2 deletion presenting with immune-mediated cytopenias, macrothrombocytopenia and platelet dysfunction. Med Princ Pract. 2007;16(4):318-20.

379. Rosa RF, Rosa RC, Dos Santos PP, Zen PR, Paskulin GA. Hematological abnormalities and 22q11.2 deletion syndrome. Rev Bras Hematol Hemoter. 2011;33(2):151-4.

380. Brenner MK, Clarke S, Mahnke DK, Simpson P, Bercovitz RS, Tomita-Mitchell A, et al. Effect of 22q11.2 deletion on bleeding and transfusion utilization in children with congenital heart disease undergoing cardiac surgery. Pediatr Res. 2016;79(2):318-24.

381. Zwifelhofer NMJ, Bercovitz RS, Weik LA, Moroi A, LaRose S, Newman PJ, et al. Hemizygosity for the gene encoding glycoprotein lb beta (GPlbbeta) is not responsible for macrothrombocytopenia and bleeding in patients with 22q11 deletion syndrome. J Thromb Haemost. 2019;17(2):295-305.

382. Edelmann L, Stankiewicz P, Spiteri E, Pandita RK, Shaffer L, Lupski JR, et al. Two functional copies of the DGCR6 gene are present on human chromosome 22q11 due to a duplication of an ancestral locus. Genome Res. 2001;11(2):208-17.

383. Demczuk S, Thomas G, Aurias A. Isolation of a novel gene from the DiGeorge syndrome critical region with homology to Drosophila gdl and to human LAMC1 genes. Hum Mol Genet. 1996;5(5):633-8.

384. Hierck BP, Molin DG, Boot MJ, Poelmann RE, Gittenberger-de Groot AC. A chicken model for DGCR6 as a modifier gene in the DiGeorge critical region. Pediatr Res. 2004;56(3):440-8.

385. Lindsay EA, Baldini A. A mouse gene (Dgcr6) related to the Drosophila gonadal gene is expressed in early embryogenesis and is the homolog of a human gene deleted in DiGeorge syndrome. Cytogenet Cell Genet. 1997;79(3-4):243-7. 
386. Gao W, Higaki T, Eguchi-Ishimae M, Iwabuki H, Wu Z, Yamamoto E, et al. DGCR6 at the proximal part of the DiGeorge critical region is involved in conotruncal heart defects. Hum Genome Var. 2015;2:15004.

387. Das Chakraborty R, Bernal AJ, Schoch K, Howard TD, Ip EH, Hooper SR, et al. Dysregulation of DGCR6 and DGCR6L: psychopathological outcomes in chromosome 22q11.2 deletion syndrome. Transl. Psychiatry. 2012;2:e105.

388. Bruderer RM, Brasseur C, Meyer HH. The AAA ATPase p97NCP interacts with its alternative co-factors, Ufd1-Npl4 and p47, through a common bipartite binding mechanism. J Biol Chem. 2004;279(48):49609-16.

389. Bays NW, Hampton RY. Cdc48-Ufd1-Np|4: stuck in the middle with Ub. Curr biol. 2002;12(10):R366-71.

390. Alzayady KJ, panning MM, Kelley GG, Wojcikiewicz RJ. Involvement of the p97-Ufd1-Npl4 complex in the regulated endoplasmic reticulumassociated degradation of inositol 1,4,5-trisphosphate receptors. J Biol Chem. 2005;280(41):34530-7.

391. Kim NC, Tresse E, Kolaitis RM, Molliex A, Thomas RE, Alami NH, et al. VCP is essential for mitochondrial quality control by PINK1/Parkin and this function is impaired by VCP mutations. Neuron. 2013;78(1):65-80.

392. Kimura Y, Fukushi J, Hori S, Matsuda N, Okatsu K, Kakiyama Y, et al. Different dynamic movements of wild-type and pathogenic VCPs and their cofactors to damaged mitochondria in a Parkin-mediated mitochondrial quality control system. Genes Cells. 2013;18(12):1131-43.

393. Cao K, Nakajima R, Meyer HH, Zheng Y. The AAA-ATPase Cdc48/p97 regulates spindle disassembly at the end of mitosis. Cell. 2003;115(3):355-67.

394. Lee JJ, Park JK, Jeong J, Jeon H, Yoon JB, Kim EE, et al. Complex of Fasassociated factor 1 (FAF1) with valosin-containing protein (VCP)-Npl4-Ufd1 and polyubiquitinated proteins promotes endoplasmic reticulum-associated degradation (ERAD). J Biol Chem. 2013;288(10):6998-7011.

395. Lin KW, McDonald KR, Guise AJ, Chan A, Cristea IM, Zakian VA. Proteomics of yeast telomerase identified Cdc48-Npl4-Ufd1 and Ufd4 as regulators of Est1 and telomere length. Nat Commun. 2015;6:8290.

396. Riemer A, Dobrynin G, Dressler A, Bremer S, Soni A, Iliakis G, et al. The p97Ufd1-Npl4 ATPase complex ensures robustness of the G2/M checkpoint by facilitating CDC25A degradation. Cell Cycle. 2014;13(6):919-27.

397. Verma R, Oania RS, Kolawa NJ, Deshaies RJ. Cdc48/p97 promotes degradation of aberrant nascent polypeptides bound to the ribosome. Elife. 2013;2:e00308

398. Yamagishi C, Hierck BP, Gittenberger-De Groot AC, Yamagishi H, Srivastava D. Functional attenuation of UFD1l, a 22q11.2 deletion syndrome candidate gene, leads to cardiac outflow septation defects in chicken embryos. Pediatr Res. 2003;53(4):546-53.

399. Yamagishi H, Garg V, Matsuoka R, Thomas T, Srivastava D. A molecular pathway revealing a genetic basis for human cardiac and craniofacial defects. Science. 1999;283(5405):1158-61.

400. Mohamed SA, Hanke T, Schlueter C, Bullerdiek J, Sievers HH. Ubiquitin fusion degradation 1-like gene dysregulation in bicuspid aortic valve. J Thorac Cardiovasc Surg. 2005;130(6):1531-6.

401. Byrne DJ, Harmon MJ, Simpson JC, Blackstone C, O'Sullivan NC. Roles for the VCP co-factors Npl4 and Ufd1 in neuronal function in Drosophila melanogaster. J Genet Genomics. 2017:44(10):493-501.

402. De Luca A, Pasini A, Amati F, Botta A, Spalletta G, Alimenti S, et al. Association study of a promoter polymorphism of UFD1L gene with schizophrenia. Am J Med Genet. 2001;105(6):529-33.

403. Shashi V, Francis A, Hooper SR, Kranz PG, Zapadka M, Schoch K, et al. Increased corpus callosum volume in children with chromosome 22q11.2 deletion syndrome is associated with neurocognitive deficits and genetic polymorphisms. Eur J Hum Genet. 2012;20(10):1051-7.

404. Männistö PT, Kaakkola S. Catechol-O-methyltransferase (COMT): biochemistry, molecular biology, pharmacology, and clinical efficacy of the new selective COMT inhibitors. Pharmacol Rev. 1999;5(14):593-628.

405. Lundström K, Salminen M, Jalanko A, Savolainen R, Ulmanen I. Cloning and characterization of human placental catechol-O-methyltransferase cDNA. DNA Cell Biol. 1991;10(3):181-9.

406. Babovic D, O'Tuathaigh CM, O'Connor AM, O'Sullivan GJ, Tighe O, Croke DT, et al. Phenotypic characterization of cognition and social behavior in mice with heterozygous versus homozygous deletion of catechol-Omethyltransferase. Neuroscience. 2008;155(4):1021-9.

407. Gogos JA, Morgan M, Luine V, Santha M, Ogawa S, Pfaff D, et al. Catechol-O-methyltransferase-deficient mice exhibit sexually dimorphic changes in catecholamine levels and behavior. Proc Natl Acad Sci U S A. 1998;95(17):9991-6.
408. Godar SC, Bortolato M. Gene-sex interactions in schizophrenia: focus on dopamine neurotransmission. Front Behav Neurosci. 2014:8:71.

409. Hosak L. Role of the COMT gene Val158Met polymorphism in mental disorders: a review. Eur Psychiatry. 2007;22(5):276-81.

410. Wahlstrom D, White T, Hooper CJ, Vrshek-Schallhorn S, Oetting WS, Brott MJ, et al. Variations in the catechol O-methyltransferase polymorphism and prefrontally guided behaviors in adolescents. Biol Psychiatry. 2007;61(5):626-32.

411. Money KM, Stanwood GD. Developmental origins of brain disorders: roles for dopamine. Front Cell Neurosci. 2013;7:260.

412. Hao Z, Jha KN, Kim YH, Vemuganti S, Westbrook VA, Chertihin O, et al. Expression analysis of the human testis-specific serine/threonine kinase (TSSK) homologues. A TSSK member is present in the equatorial segment of human sperm. Mol Hum Reprod. 2004;10(6):433-44.

413. Ozcan A, Sahin Y. DiGeorge syndrome associated with azoospermia: first case in the literature. Turk J Urol. 2017;43(3):390-2.

414. Towns WL, Begley TJ. Transfer RNA methytransferases and their corresponding modifications in budding yeast and humans: activities, predications, and potential roles in human health. DNA Cell Biol. 2012;31(4):434-54

415. Parisien M, Wang X, Pan T. Diversity of human tRNA genes from the 1000 genomes project. RNA Biol. 2013;10(12):1853-67.

416. Hu T, Yamagishi H, Maeda J, McAnally J, Yamagishi C, Srivastava D. Tbxi regulates fibroblast growth factors in the anterior heart field through a reinforcing autoregulatory loop involving forkhead transcription $f$ actors. Development. 2004:131(21):5491-502.

417. Yutzey KE. DiGeorge syndrome, Tbx1, and retinoic acid signaling come full circle. Circ Res. 2010;106(4):630-2.

418. Maehama T, Taylor GS, Dixon JE. PTEN and myotubularin: novel phosphoinositide phosphatases. Annu Rev Biochem. 2001;70:247-79.

\section{Ready to submit your research? Choose BMC and benefit from:}

- fast, convenient online submission

- thorough peer review by experienced researchers in your field

- rapid publication on acceptance

- support for research data, including large and complex data types

- gold Open Access which fosters wider collaboration and increased citations

- maximum visibility for your research: over $100 \mathrm{M}$ website views per year

At $\mathrm{BMC}$, research is always in progress.

Learn more biomedcentral.com/submissions 